\title{
Photoinduced skeletal rearrangement of $N$-substituted colchicine derivatives
}

\section{Dominika Czerwonka $^{1}$, Szymon Sobczak ${ }^{1}$, Tomasz Pędziński ${ }^{1,2}$, Ewa Maj ${ }^{3}$, Joanna

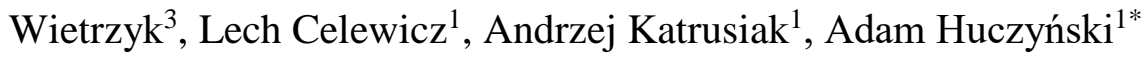

\author{
${ }^{1}$ Faculty of Chemistry, Adam Mickiewicz University, Uniwersytetu Poznańskiego 8, 61-614 Poznan, Poland; \\ ${ }^{2}$ Center for Advanced Technology, Adam Mickiewicz University, Uniwersytetu Poznańskiego 10, 61-614 \\ Poznań, Poland \\ ${ }^{3}$ Hirszfeld Institute of Immunology and Experimental Therapy, Polish Academy of Sciences, Rudolfa Weigla 12, \\ 53-114 Wroctaw, Poland; \\ * Correspondence: adhucz@amu.edu.pl; Tel.: +48618291673
}

\section{Supplementary Information}

\section{INDEX}

The antiproliferative activity S4

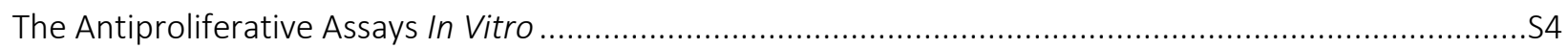

$\mathrm{SRB}$...........

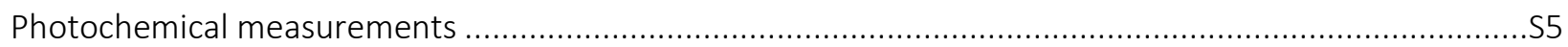

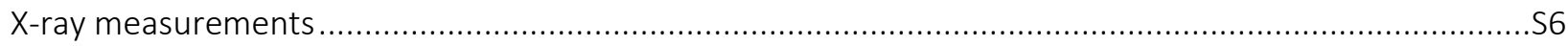

Figure S1. Crystallographically determined X-ray structure representations of $\beta$-lumicolchicine. .............S7

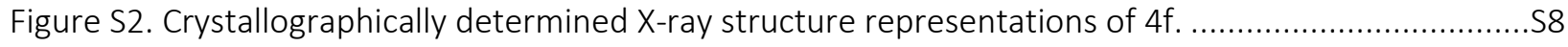

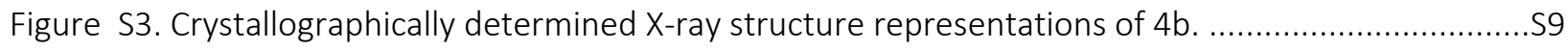

Figure S4. Crystallographically determined X-ray structure representations of 3.0.5 Ac.......................S10

Figure S5. Crystallographically determined X-ray structure representations of 2.Ac............................S11

Table S1. Detailed crystallographic data compounds $\beta$-lumicolchicine, 2, 3 and 4b-UV and 4f-UV..........S12

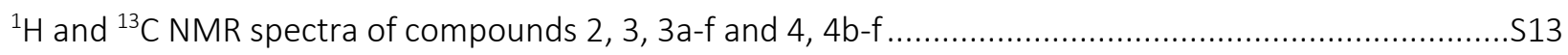

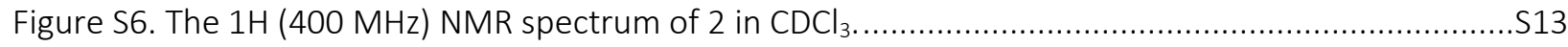

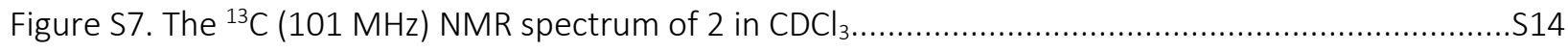

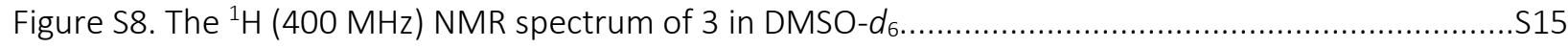

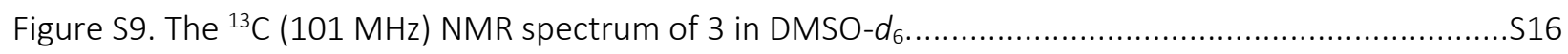

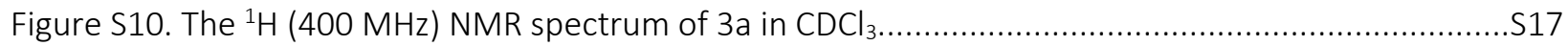

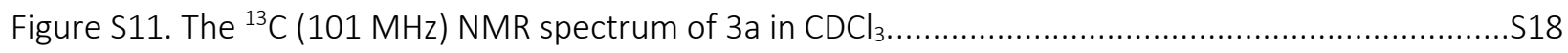


Figure $\mathrm{S} 12$. The ${ }^{1} \mathrm{H}(400 \mathrm{MHz}) \mathrm{NMR}$ spectrum of $3 \mathrm{~b}$ in $\mathrm{CDCl}_{3}$. S19

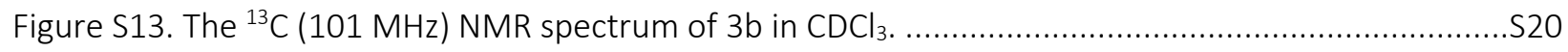

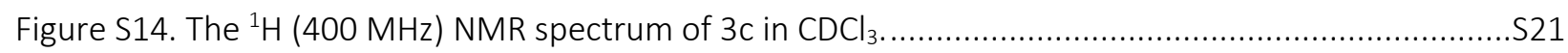

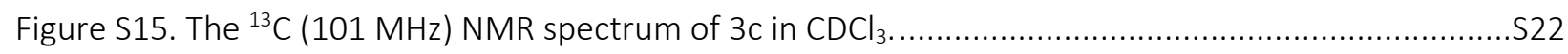

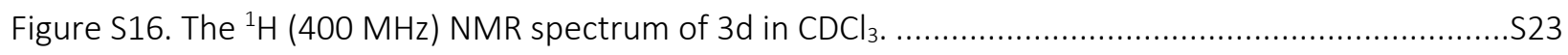

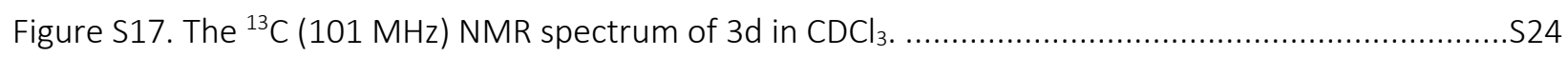

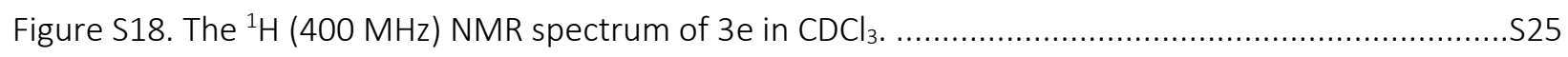

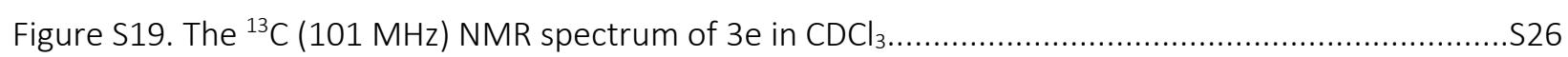

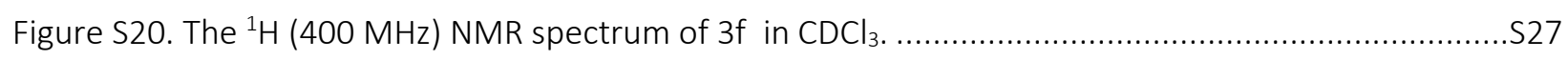

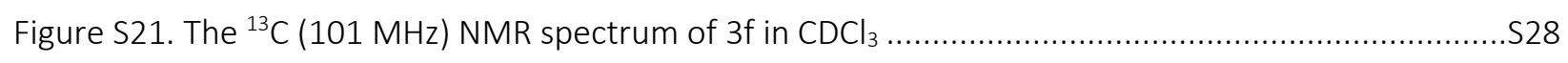

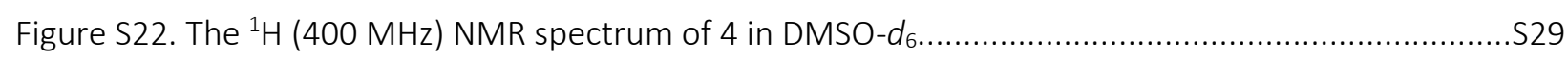

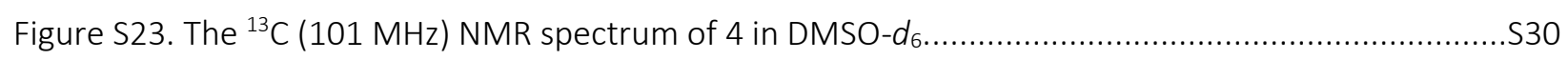

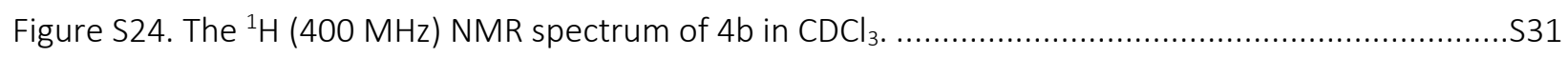

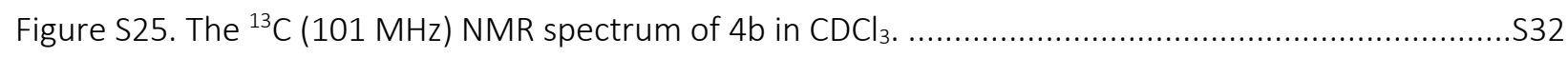

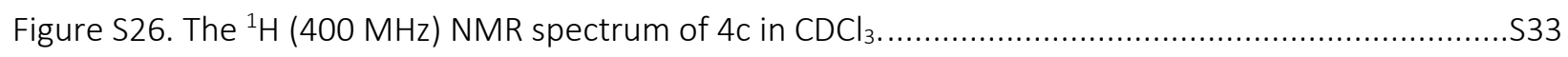

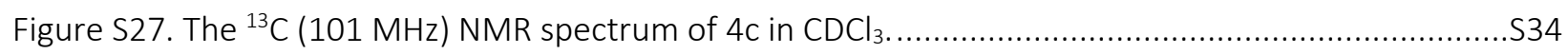

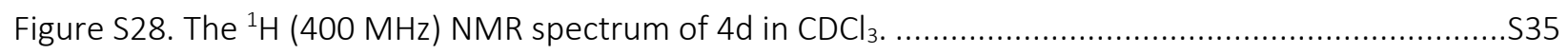

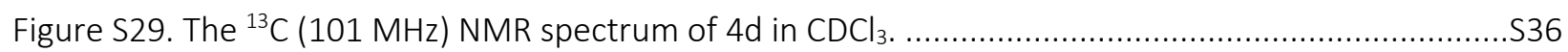

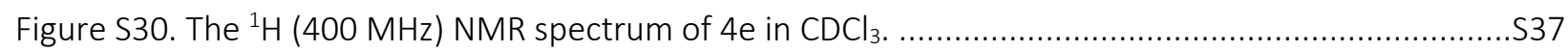

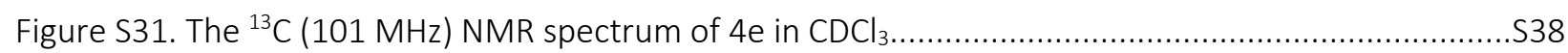

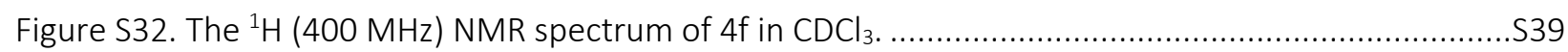

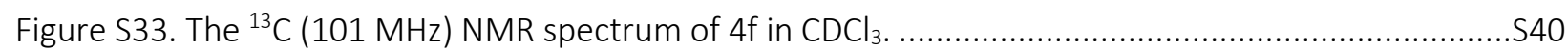

${ }^{1} \mathrm{H}$ and ${ }^{13} \mathrm{C}$ NMR spectra of $\beta$-lumiderivatives: $\beta$-lumicolchicine, 2-UV, 3-UV, 3b-UV, 3f-UV, 4b-UV, 4f-UV)

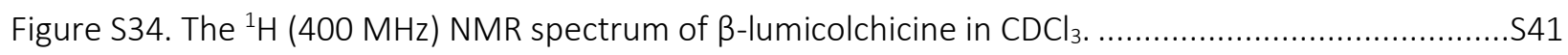

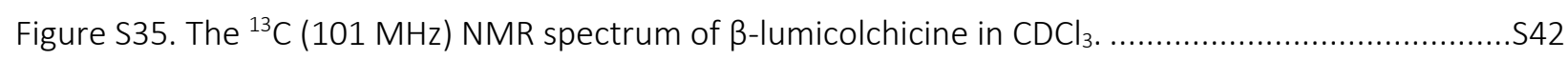

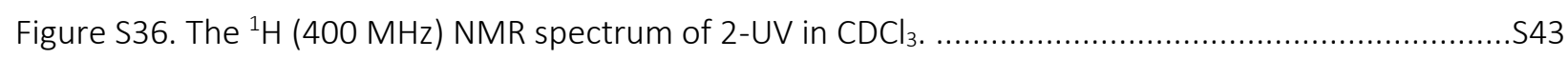

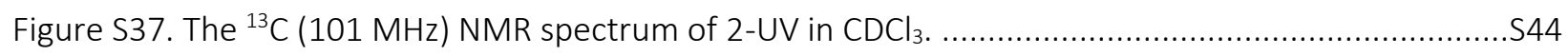

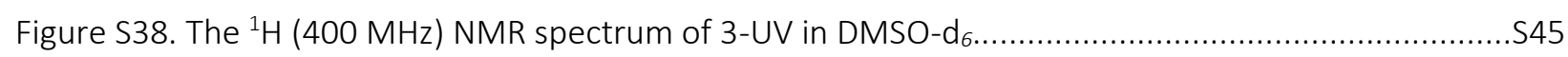

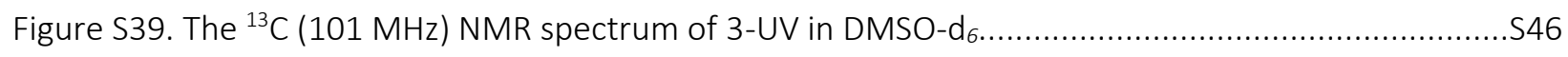

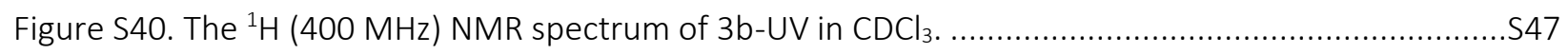

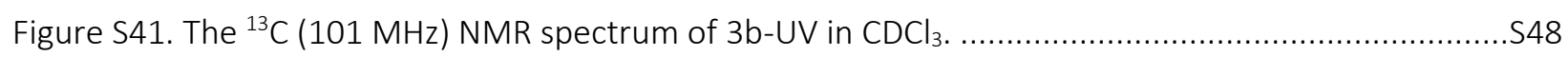

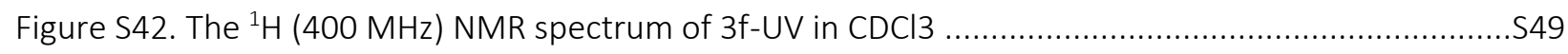

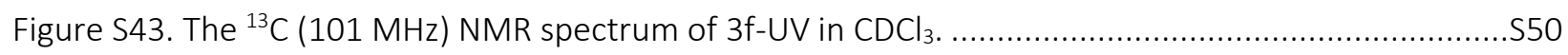

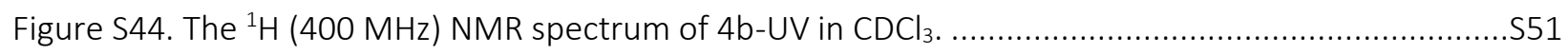

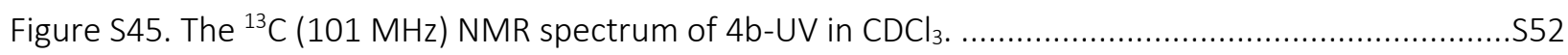


Figure S46. The ${ }^{1} \mathrm{H}(400 \mathrm{MHz}) \mathrm{NMR}$ spectrum of $4 \mathrm{f}-\mathrm{UV}$ in $\mathrm{CDCl}_{3}$.

Figure S47. The ${ }^{13} \mathrm{C}(101 \mathrm{MHz})$ NMR spectrum of $4 \mathrm{f}-\mathrm{UV}$ in $\mathrm{CDCl}_{3}$

Table S2. The ${ }^{1} \mathrm{H}$ and ${ }^{13} \mathrm{C}$ NMR chemical shifts $\delta$ (ppm) of 2 and 2-UV in chloroform-d, assigned based on 2D NMR.

Figure S48. The stacked FT-IR spectra of colchicine (blue solid line) and $\beta$-lumicolchicine (red dashed line) in $\mathrm{KBr}$ : (a) $4000-500 \mathrm{~cm}^{-1}$, (b) $1800-1000 \mathrm{~cm}^{-1}$.

Figure S49. The stacked FT-IR spectra of 2 (blue solid line) and 2-UV (red d.....

Figure S50. The stacked FT-IR spectra of 3 (blue solid line) and 3-UV (red dashed line) in KBr: (a) 4000$500 \mathrm{~cm}^{-1}$, (b) $1800-1000 \mathrm{~cm}^{-1}$.

Figure S51. The stacked FT-IR spectra of 3b (blue solid line) and 3b-UV (red dashed line) in $\mathrm{KBr}$ : (a) 4000$500 \mathrm{~cm}^{-1}$, (b) $1800-1000 \mathrm{~cm}^{-1}$.

Figure S52. The stacked FT-IR spectra of $3 f$ (blue solid line) and 3f-UV (red dashed line) in KBr: (a) 4000$500 \mathrm{~cm}^{-1}$, (b) $1800-1000 \mathrm{~cm}^{-1}$.

Figure S53. The stacked FT-IR spectra of 4b (blue solid line) and 4b-UV (red dashed line) in KBr: (a) 4000$500 \mathrm{~cm}^{-1}$, (b) $1800-1000 \mathrm{~cm}^{-1}$.

Figure S54. The stacked FT-IR spectra of $4 \mathrm{f}$ (blue solid line) and 4f-UV (red dashed line) in $\mathrm{KBr}$ : (a) 4000$500 \mathrm{~cm}^{-1}$, (b) $1800-1000 \mathrm{~cm}^{-1}$.

UV-VIS spectra

Figure S55. The stacked UV-VIS spectra of colchicine (blue solid line) and $\beta$-lumicolchicine (red dashed line) in methanol.

Figure S56. The stacked UV-VIS spectra of 2 (blue solid line) and 2-UV (red dashed line) in methanol. ...S63 Figure S57. The stacked UV-VIS spectra of 3 (blue solid line) and 3-UV (red dashed line) in methanol. ...S64 Figure S58. The stacked UV-VIS spectra of 3b (blue solid line) and 3b-UV (red dashed line) in methanol.

Figure S59. The stacked UV-VIS spectra of $3 f$ (blue solid line) and 3f-UV (red dashed line) in methanol. .S65 Figure S60. The stacked UV-VIS spectra of 4b (blue solid line) and 4b-UV (red dashed line) in methanol.

Figure S61. The stacked UV-VIS spectra of $4 \mathrm{f}$ (blue solid line) and 4f-UV (red dashed line) in methanol. .S66 Photoreaction Setup

Figure S62. Photograph of a photoreaction setup.

Figure S63. Emission spectrum of the Hanau TQ $150 \mathrm{~W}$ lamp after passing through the standard Pyrex filter. 


\section{The antiproliferative activity}

Three human cancer cell lines and one murine normal cell line were used to evaluate antiproliferative activity of colchicine and its derivatives: human lung adenocarcinoma (A549), human breast adenocarcinoma (MCF-7), human colon adenocarcinoma cell line (LoVo), and normal murine embryonic fibroblast cell line (BALB/3T3). The BALB/3T3 cell line was purchased from the American Type Culture Collection (ATCC, Manassas, VA, USA), A549 and MCF-7 cell lines_-from European Collection of Authenticated Cell Cultures (Salisbury, UK), LoVo cell line was purchased from the ATCC (ATCC, Manassas, VA, USA). All the cell lines are maintained in the Institute of Immunology and Experimental Therapy (IIET), Wroclaw, Poland. Human lung adenocarcinoma cell line was cultured in mixture of OptiMEM and RPMI 1640 (1:1) medium (IIET, Wroclaw, Poland), supplemented with 5\% fetal bovine serum (GE Healthcare, Logan, UT, USA) and $2 \mathrm{mM}$ L-glutamine (Sigma-Aldrich, Merck KGaA, Saint Louis, MO, USA). Human breast adenocarcinoma cell line was cultured in mixture of Eagle medium (IIET, Wroclaw, Poland), supplemented with $10 \%$ fetal bovine serum, $2 \mathrm{mM}$ L-glutamine, $8 \mu \mathrm{g} / \mathrm{mL}$ insulin and $1 \%$ amino-acids (SigmaAldrich, Merck KGaA, Saint Louis, MO, USA). Human colon adenocarcinoma cell line was cultured in mixture of OptiMEM and RPMI 1640 (1:1) medium (IIET, Wroclaw, Poland), supplemented with 5\% fetal bovine serum (GE Healthcare, Logan UT, USA), 2 mM Lglutamine, $1 \mathrm{mM}$ sodium pyruvate (Sigma-Aldrich, Merck KGaA, Saint Louis, MO, USA). Murine embryonic fibroblast cells were cultured in Dulbecco medium (Life Technologies Limited, Paisley, UK), supplemented with 10\% fetal bovine serum (GE Healthcare, Logan, UT, USA) and $2 \mathrm{mM}$ glutamine (Sigma-Aldrich, Merck KGaA, Saint Louis, MO, USA). All culture media contained antibiotics: $100 \mathrm{U} / \mathrm{mL}$ penicillin and $100 \mu \mathrm{g} / \mathrm{mL}$ streptomycin (PolfaTarchomin, Warsaw, Poland). All cell lines were cultured during entire experiment in humid atmosphere at $37{ }^{\circ} \mathrm{C}$ and $5 \% \mathrm{CO}_{2}$. Cells were tested for mycoplasma contamination by mycoplasma detection kit for conventional PCR: Venor GeM Classic (Minerva Biolabs $\mathrm{GmbH}$, Berlin, Germany) and negative results was obtained. The procedure is repeated every year or in the case of less frequently used lines: after thawing.

\section{The Antiproliferative Assays In Vitro}

Twenty-four hours before adding the tested compounds, all cell lines were seeded in 384-well plates (Sarstedt, Nümbrecht, Germany) in appropriate media with $1 \times 10^{3}$ or $1,5 \times 10^{3}$ 
or $3 \times 10^{3}$ cells per well. All cell lines were exposed to each tested agent at four different concentrations in the range $100-0.001 \mu \mathrm{g} / \mathrm{mL}$ for $72 \mathrm{~h}$. Cells were also exposed to the reference drug cisplatin (Teva Pharmaceuticals Polska, Warsaw, Poland) and doxorubicin (Accord Healthcare Limited, Middlesex, UK). Additionally, all cell lines were exposed to DMSO (solvent used for tested compounds) (POCh, Gliwice, Poland) at concentrations corresponding to those present in tested agents' dilutions. After $72 \mathrm{~h}$ sulforhodamine B assay (SRB) was performed. ${ }^{1}$

\section{SRB}

After $72 \mathrm{~h}$ of incubation with the tested compounds, cells were fixed in situ by gently adding of $30 \mu \mathrm{L}$ per well of cold 50\% trichloroacetic acid TCA (POCh, Gliwice, Poland) and were incubated at $4{ }^{\circ} \mathrm{C}$ for one hour. Following, wells were washed four times with water and air dried. Next, $25 \mu \mathrm{L}$ of $0.1 \%$ solution of sulforhodamine B (Sigma-Aldrich, Merck KGaA, Saint Louis, MO, USA) in 1\% acetic acid (POCh, Gliwice, Poland) were added to each well and plates were incubated at room temperature for $0.5 \mathrm{~h}$. After incubation time, unbound dye was removed by washing plates four times with $1 \%$ acetic acid whereas stain bound to cells was solubilized with $10 \mathrm{mM}$ Tris base (Sigma-Aldrich, Steinheim, Germany). Absorbance of each solution was read at Synergy H4 Hybrid Multi-Mode Microplate Reader (BioTek Instruments, Inc., Winooski, VT, USA) at the $540 \mathrm{~nm}$ wavelength.

Results are presented as mean $\mathrm{IC}_{50}$ (concentration of the tested compound, that inhibits cell proliferation by $50 \%$ ) \pm standard deviation. $\mathrm{IC}_{50}$ values were calculated in Cheburator 0.4, Dmitry Nevozhay software (version 1.2.0 software by Dmitry Nevozhay, 20042014, http://www.cheburator.nevozhay.com, freely available) for each experiment. ${ }^{2}$ Compounds at each concentration were tested in triplicates in single experiment and each experiment was repeated at least three times independently.

\section{Photochemical measurements}

Femtosecond transient absorption (TA) measurements were carried out using the Solstice Ti:Sapphire regenerative amplifier from Spectra Physics and an optical detection system provided by Ultrafast Systems (Helios). The source for the pump and probe pulses was the fundamental emission at $800 \mathrm{~nm}$. The fundamental output was split into two beams: a pump $(95 \%)$ and a probe $(5 \%)$. The pump beam was directed through the TOPAS-Prime automated optical parametric amplifier (from Light Conversion) to tune the desired excitation 
wavelength (e.g. $330 \mathrm{~nm}$ ). The probe continuum beam was directed to the Helios, a CCDbased pump-probe TA spectrometer from Ultrafast Systems LLC with an optical delay line allowing delays between the pump and probe up to $3 \mathrm{~ns}$. For the detection of the transients, a white light continuum was used, which was generated from $5 \%$ of the fundamental beam by passing it through a sapphire or calcium fluoride crystal. The setup is described in more detail in ref. [3]. ${ }^{3}$

\section{X-ray measurements}

The single crystals were obtained from the solutions of $\beta$-lumicolchicine, 2,3 , 4b-UV and $4 \mathrm{f}$ UV in chloroform:acetone 1:1 mixture. The X-ray diffraction measurements at room temperature of above mentioned compounds were carried out on two different diffractometers. First one equipped with $\operatorname{MoK} \alpha(\lambda=0.7108 \AA)$ source, Eos Xcalibur, and the second one, with microfocus $\operatorname{CuK} \alpha(\lambda=1.5418 \AA)$ radiation source, SuperNova Agilent diffractometer. For data collections and their preliminary reduction, CrysAlisPro 171.37.31 software was used. ${ }^{4}$ The crystal structures were solved by direct methods in Shelxs and refined by full-matrix least squares by Shelxl; ${ }^{5,6}$ implemented in the Olex2. ${ }^{7}$ The position of hydrogen atoms were located at their best geometrical positions. Molecules $\mathbf{2}$ and $\mathbf{3}$ crystallizes as a acetone solvates with one and half disordered acetone molecule per formula unit respectively. The final crystal data are summarized in Table S1 and have been deposited in the Cambridge Structural Database as a supplementary publications CCSD No. 2033156, 2033158, 2033157, 2033154 and 2033155 for compound $\beta$-lumicolchicine, 2, 3, 4b-UV and 4f-UV, respectively. Copies of this information may be obtained free of charge from http://www.ccdc.cam.ac.uk 


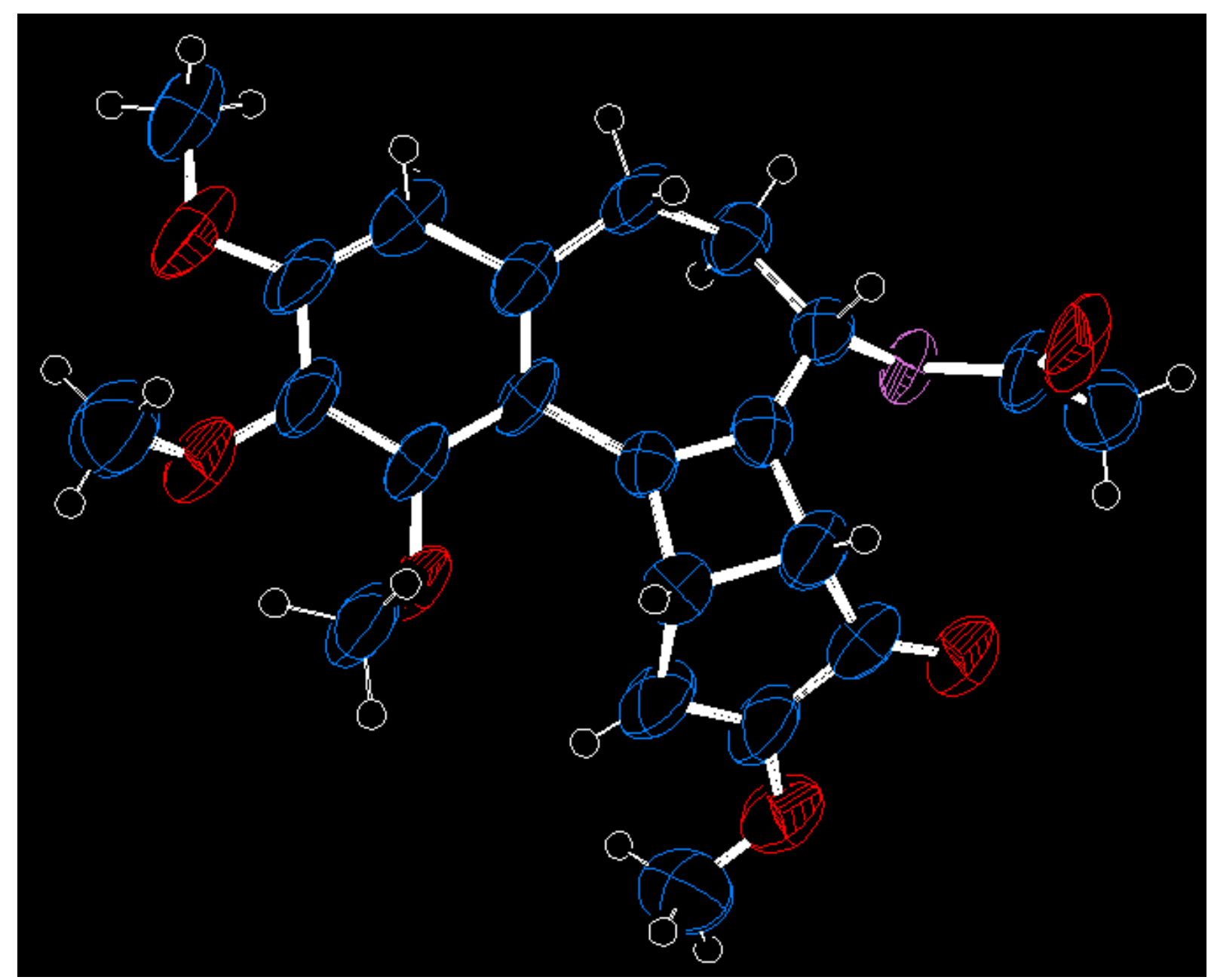

Figure S1. Crystallographically determined X-ray structure representations of $\beta$-lumicolchicine. The thermal ellipsoid plot were drawn at 50\% probability level. Atom colour code: carbon, blue; nitrogen, magenta; oxygen, red; hydrogen, white. 


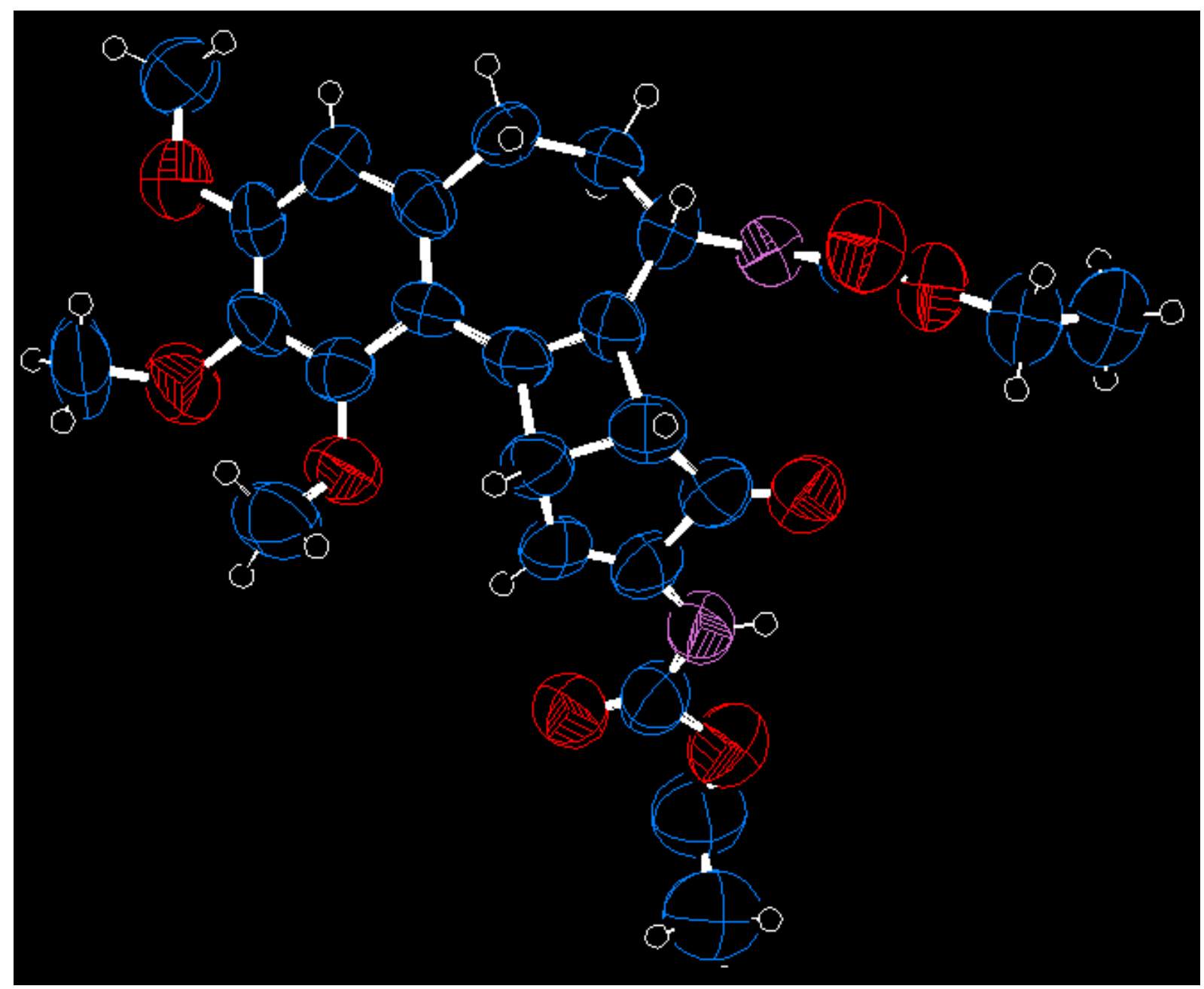

Figure S2. Crystallographically determined X-ray structure representations of $4 f$. The thermal ellipsoid plot were drawn at 50\% probability level. Atom colour code: carbon, blue; nitrogen, magenta; oxygen, red; hydrogen, white. 


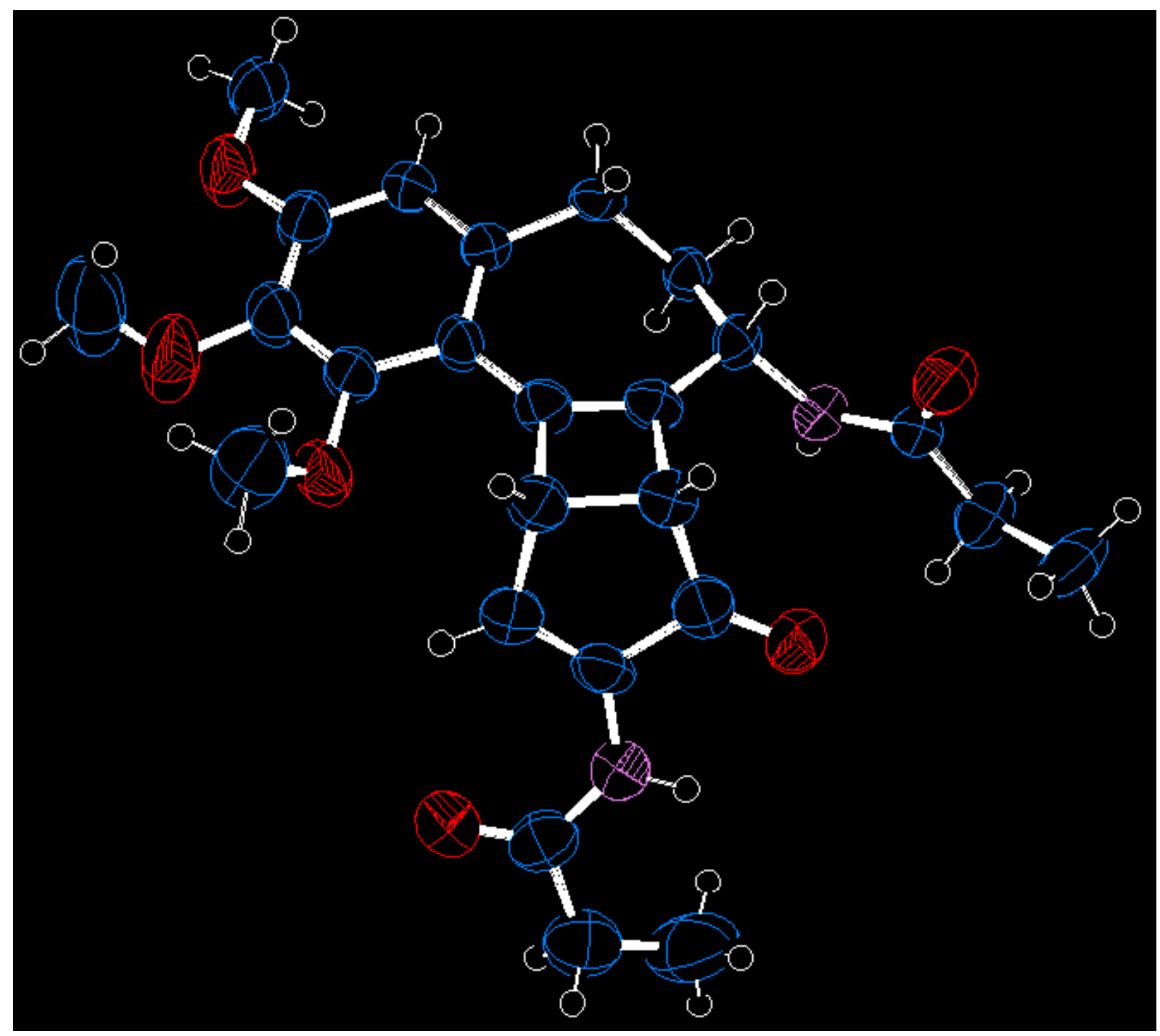

Figure S3. Crystallographically determined X-ray structure representations of $\mathbf{4 b}$. The thermal ellipsoid plot were drawn at 50\% probability level. Atom colour code: carbon, blue; nitrogen, magenta; oxygen, red; hydrogen, white. 


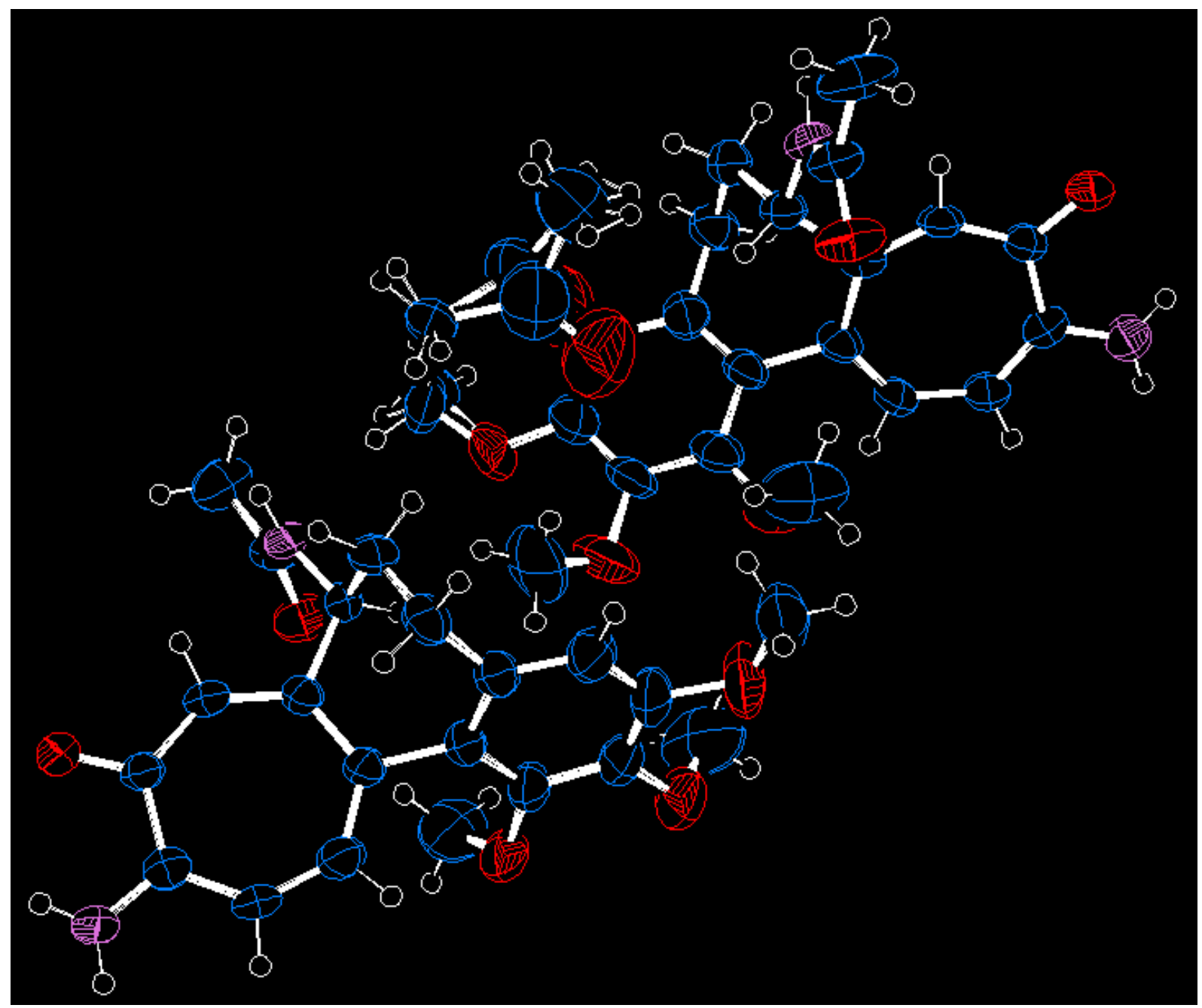

Figure S4. Crystallographically determined X-ray structure representations of 3.0.5 Ac. The thermal ellipsoid plot were drawn at 50\% probability level. Atom colour code: carbon, blue; nitrogen, magenta; oxygen, red; hydrogen, white. 


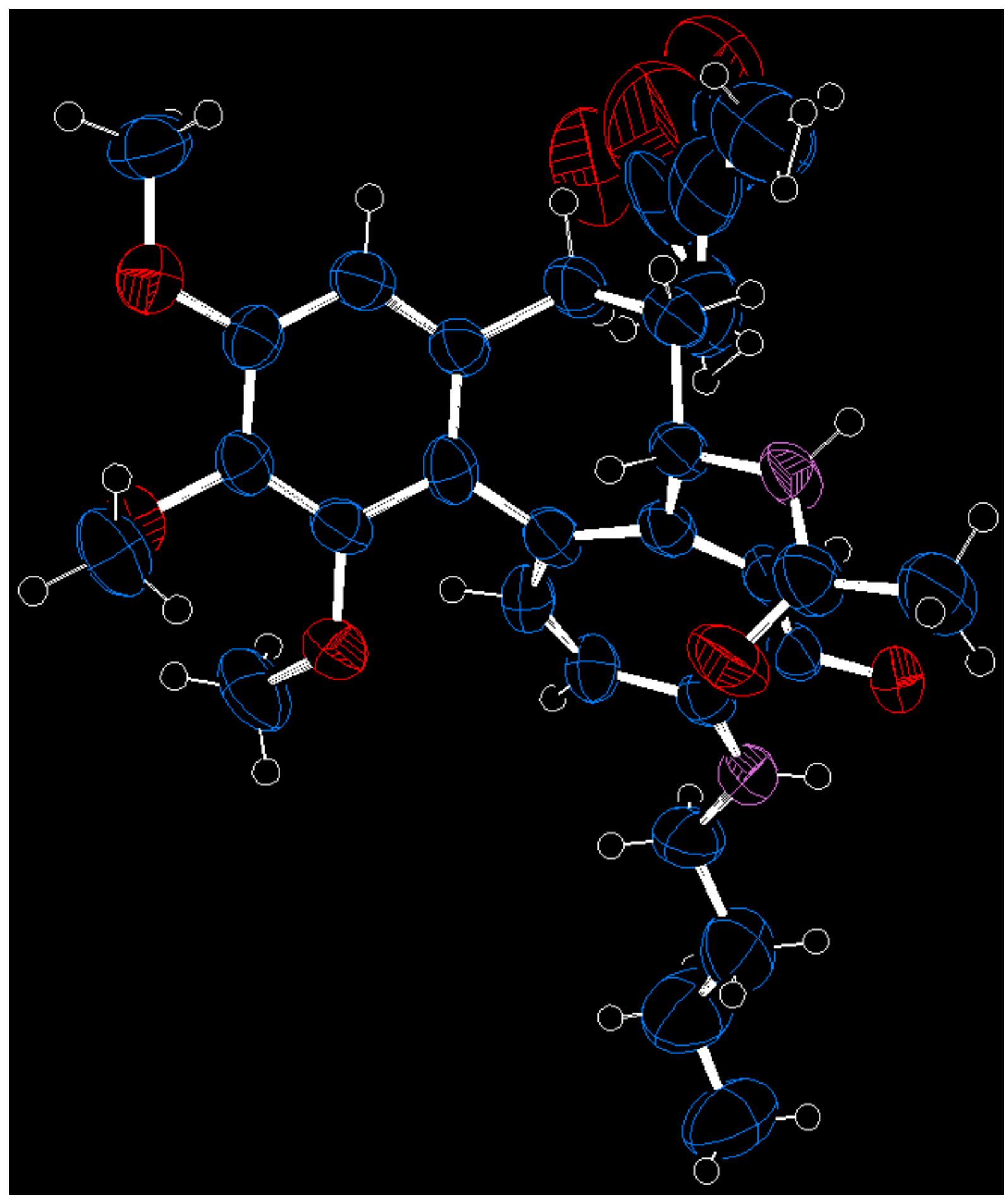

Figure S5. Crystallographically determined X-ray structure representations of $2 \cdot A c$. The thermal ellipsoid plot were drawn at 50\% probability level. Atom colour code: carbon, blue; nitrogen, magenta; oxygen, red; hydrogen, white. 
Table S1. Detailed crystallographic data compounds $\beta$-lumicolchicine, 2,3 and $4 \mathrm{~b}-\mathrm{UV}$ and $4 \mathrm{f}-\mathrm{UV}$.

\begin{tabular}{|c|c|c|c|c|c|c|}
\hline \multicolumn{2}{|l|}{ Name } & $\beta$-lumicolchicine & 2 & 3 & 4b-UV & $4 \mathrm{f}-\mathrm{UV}$ \\
\hline \multicolumn{2}{|l|}{ Formula } & $\mathrm{C}_{22} \mathrm{H}_{2} 5 \mathrm{NO}_{6}$ & $\mathrm{C}_{25} \mathrm{H}_{32} \mathrm{~N}_{2} \mathrm{O}_{5} \cdot \mathrm{Ac}$ & $\mathrm{C}_{21} \mathrm{H}_{24} \mathrm{~N}_{2} \mathrm{O}_{5} \cdot 0.5 \mathrm{Ac}$ & $\mathrm{C}_{25} \mathrm{H}_{30} \mathrm{~N}_{2} \mathrm{O}_{6}$ & $\mathrm{C}_{25} \mathrm{H}_{30} \mathrm{~N}_{2} \mathrm{O}_{8}$ \\
\hline \multicolumn{2}{|c|}{ Crystal system } & orthorhombic & tetragonal & monoclinic & orthorhombic & monoclinic \\
\hline \multicolumn{2}{|l|}{ Space group } & $P 2_{1} 2_{1} 2_{1}$ & $P 4_{3} 2_{1} 2$ & $P 2_{1}$ & $P 2_{1} 2_{1} 2_{1}$ & $P 2_{1}$ \\
\hline \multirow{6}{*}{$\begin{array}{l}\text { Unit cell } \\
\text { dimensions }\end{array}$} & $a(\AA)$ & $5.0076(15)$ & $9.0814(4)$ & $8.827(17)$ & $5.1856(4)$ & $15.6750(15)$ \\
\hline & $b(\AA)$ & $12.3940(14)$ & $9.0814(4)$ & 27.10(3) & $18.4774(9)$ & $5.0498(5)$ \\
\hline & $c(\AA)$ & $32.017(19)$ & $61.5763(18)$ & $10.21(2)$ & $23.8235(15)$ & $16.5812(17)$ \\
\hline & $\alpha\left(^{\circ}\right)$ & 90 & 90 & 90 & 90 & 90 \\
\hline & $\beta\left(^{\circ}\right)$ & 90 & 90 & 115.3(3) & 90 & $106.585(10)$ \\
\hline & $\gamma\left({ }^{\circ}\right)$ & 90 & 90 & 90 & 90 & 90 \\
\hline \multicolumn{2}{|l|}{ Volume $\left(\AA^{3}\right)$} & 1987.1(13) & $5078.3(4)$ & $2207(8)$ & $2282.7(3)$ & $1257.9(2)$ \\
\hline \multicolumn{2}{|l|}{$Z / Z^{\prime}$} & $4 / 1$ & $8 / 1$ & $4 / 2$ & $4 / 1$ & $2 / 1$ \\
\hline \multicolumn{2}{|c|}{ Calculated density $\left(\mathrm{g} / \mathrm{cm}^{3}\right)$} & 1.335 & 1.223 & 1.245 & 1.323 & 1.282 \\
\hline \multicolumn{2}{|c|}{ Radiation type } & $\mathrm{Cu} \mathrm{K} \alpha(\lambda=1.54184)$ & $\mathrm{Cu} \mathrm{K \alpha}(\lambda=1.54184)$ & Mo $\mathrm{K} \alpha(\lambda=0.71073)$ & $\mathrm{Cu} \mathrm{K} \alpha(\lambda=1.54184)$ & $\mathrm{Cu} \mathrm{K} \alpha(\lambda=1.54184)$ \\
\hline \multicolumn{2}{|c|}{ Absorption $\left(\mathrm{mm}^{-1}\right)$} & 0.803 & 0.697 & 0.089 & 0.778 & 0.802 \\
\hline \multicolumn{2}{|l|}{$\mathrm{F}(000)$} & 848.0 & 2000.0 & 880 & 968.0 & 515.9 \\
\hline \multicolumn{2}{|c|}{ Crystal size (mm) } & $0.088 \times 0.03 \times 0.017$ & $0.25 \times 0.25 \times 0.1$ & $0.622 \times 0.389 \times 0.171$ & $0.05 \times 0.024 \times 0.01$ & $0.4 \times 0.15 \times 0.05$ \\
\hline \multicolumn{2}{|c|}{$2 \theta$-range for data collection $\left({ }^{\circ}\right)$} & 5.52 to 118.104 & 5.926 to 117.818 & 5.926 to 51.362 & 6.054 to 117.85 & 11.5 to 117.86 \\
\hline \multicolumn{2}{|c|}{ Min/max indices: $\mathrm{h}, \mathrm{k}, 1$} & $-5 \leq \mathrm{h} \leq 4,-13 \leq \mathrm{k} \leq 11,-31 \leq 1 \leq 34$ & $-10 \leq \mathrm{h} \leq 7,-5 \leq \mathrm{k} \leq 9,-68 \leq 1 \leq 42$ & $-10 \leq \mathrm{h} \leq 10,-33 \leq \mathrm{k} \leq 33,-12 \leq 1 \leq 12$ & $-5 \leq \mathrm{h} \leq 5,-20 \leq \mathrm{k} \leq 20,-26 \leq 1 \leq 24$ & $-17 \leq \mathrm{h} \leq 17,-5 \leq \mathrm{k} \leq 5,-18 \leq 1 \leq 18$ \\
\hline \multicolumn{2}{|c|}{ Reflect. Collected/unique } & $4834 / 2698$ & $4188 / 2520$ & $77577 / 8349$ & $4384 / 2788$ & $13112 / 1509$ \\
\hline \multicolumn{2}{|c|}{ Data/restrains/parameters } & $2698 / 293 / 265$ & $2520 / 80 / 337$ & $8349 / 183 / 581$ & $2788 / 0 / 303$ & $1509 / 139 / 322$ \\
\hline \multicolumn{2}{|c|}{ Goodness-of-fit on F2 } & 0.850 & 1.079 & 1.028 & 0.992 & 1.158 \\
\hline \multicolumn{2}{|c|}{ Final R1/wR2 (I>2б1) } & $0.1176 / 0.1831$ & $0.0396 / 0.1016$ & $0.0638 / 0.1658$ & $0.0641 / 0.0923$ & $0.0876 / 0.2038$ \\
\hline \multicolumn{2}{|c|}{ R1/wR2 (all data) } & $0.3972 / 0.3767$ & $0.0453 / 0.1053$ & $0.0743 / 0.1769$ & $0.1221 / 0.1184$ & $0.0970 / 0.2161$ \\
\hline \multicolumn{2}{|c|}{ Largest diff. peak/hole $\left(\mathrm{e} . \AA^{-3}\right)$} & $0.20 /-0.26$ & $0.18 /-0.17$ & $0.42 /-0.35$ & $0.19 /-0.23$ & $0.23 /-0.20$ \\
\hline
\end{tabular}


${ }^{1} \mathrm{H}$ and ${ }^{13} \mathrm{C}$ NMR spectra of compounds $2,3,3 \mathrm{a}-\mathrm{f}$ and $4,4 \mathrm{~b}-\mathrm{f}$

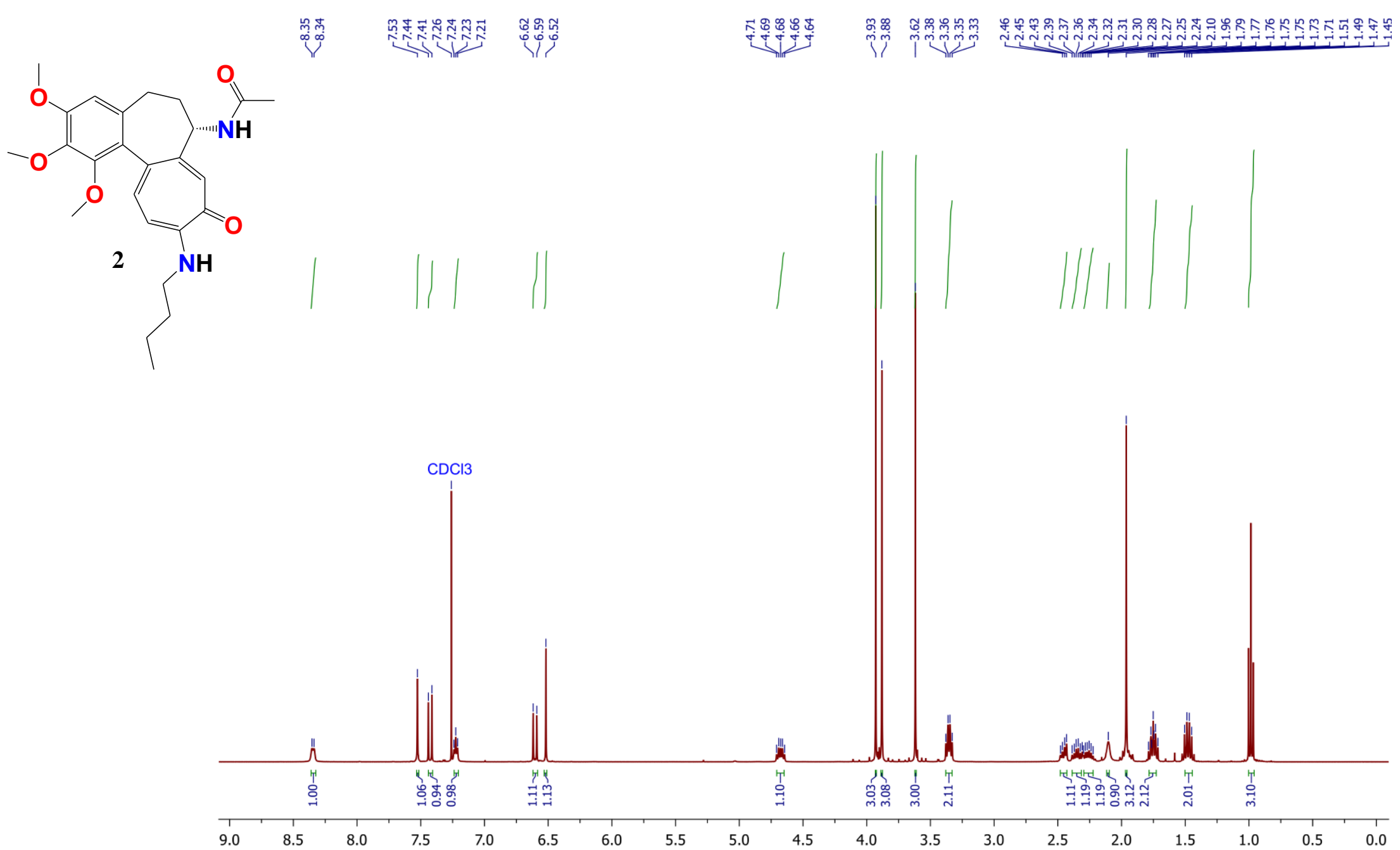

Figure S6. The $1 \mathrm{H}(400 \mathrm{MHz}) \mathrm{NMR}$ spectrum of 2 in $\mathrm{CDCl}_{3}$. 


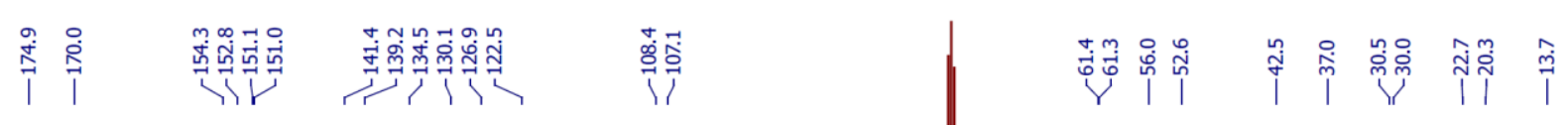
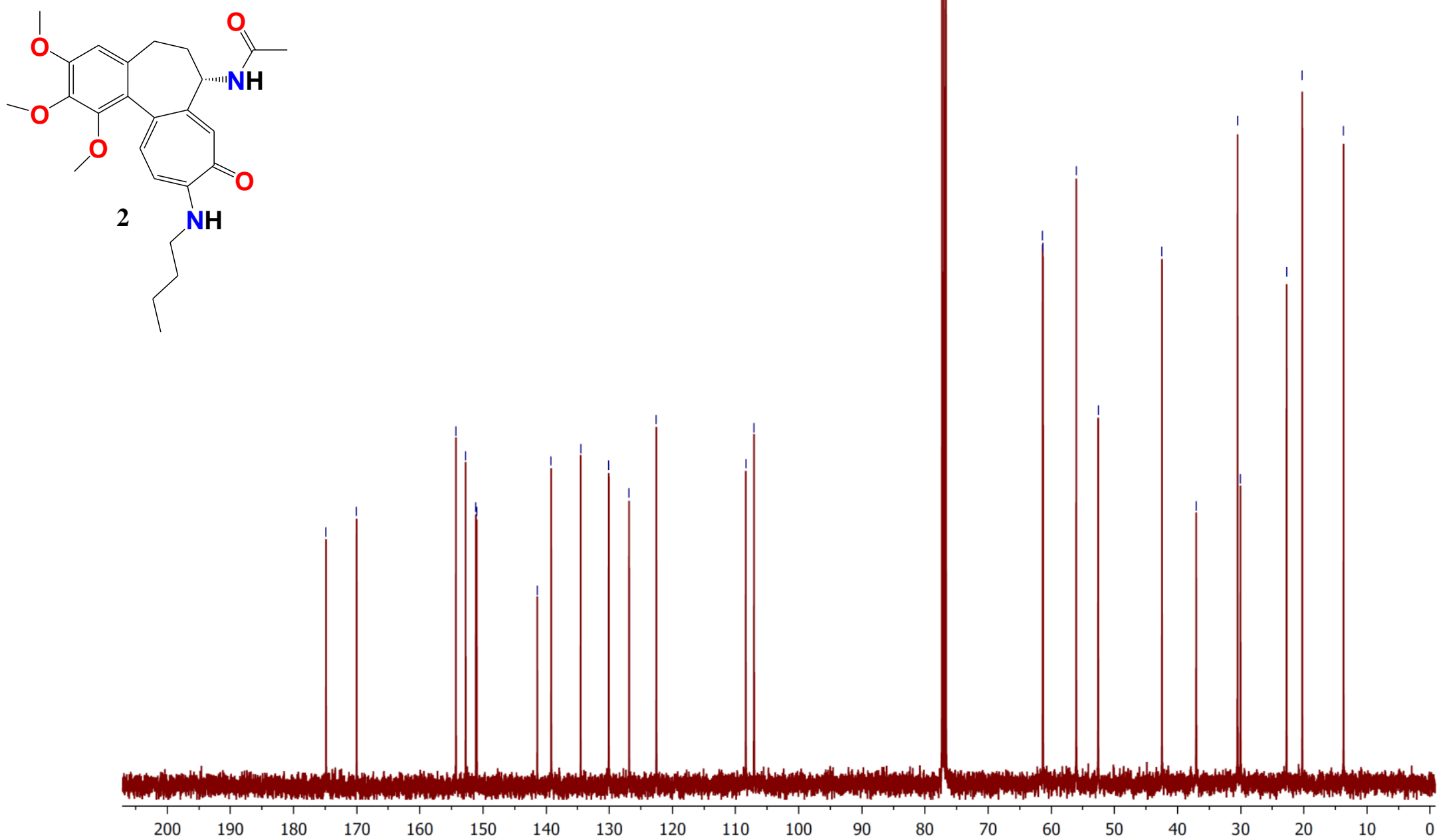

Figure S7. The ${ }^{13} \mathrm{C}(101 \mathrm{MHz}) \mathrm{NMR}$ spectrum of 2 in $\mathrm{CDCl}_{3}$. 


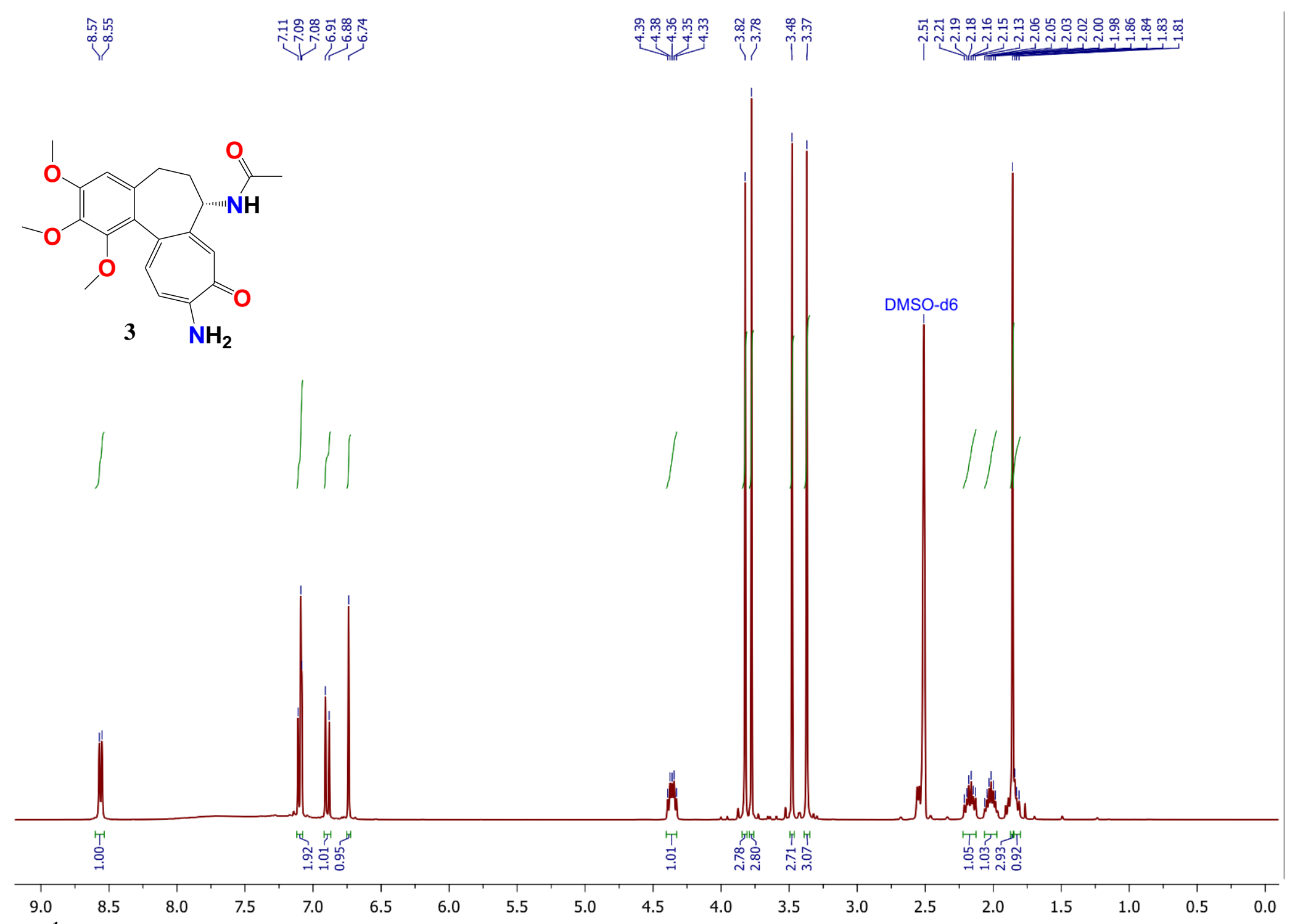

Figure S8. The ${ }^{1} \mathrm{H}(400 \mathrm{MHz})$ NMR spectrum of 3 in DMSO- $\boldsymbol{d}_{6}$. 


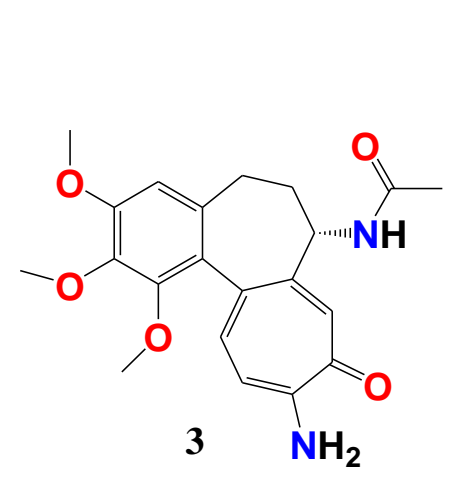

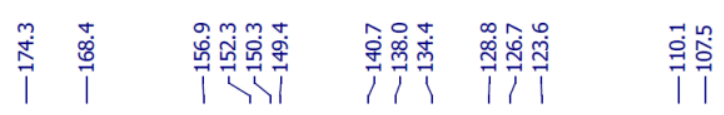

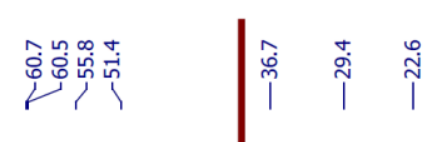

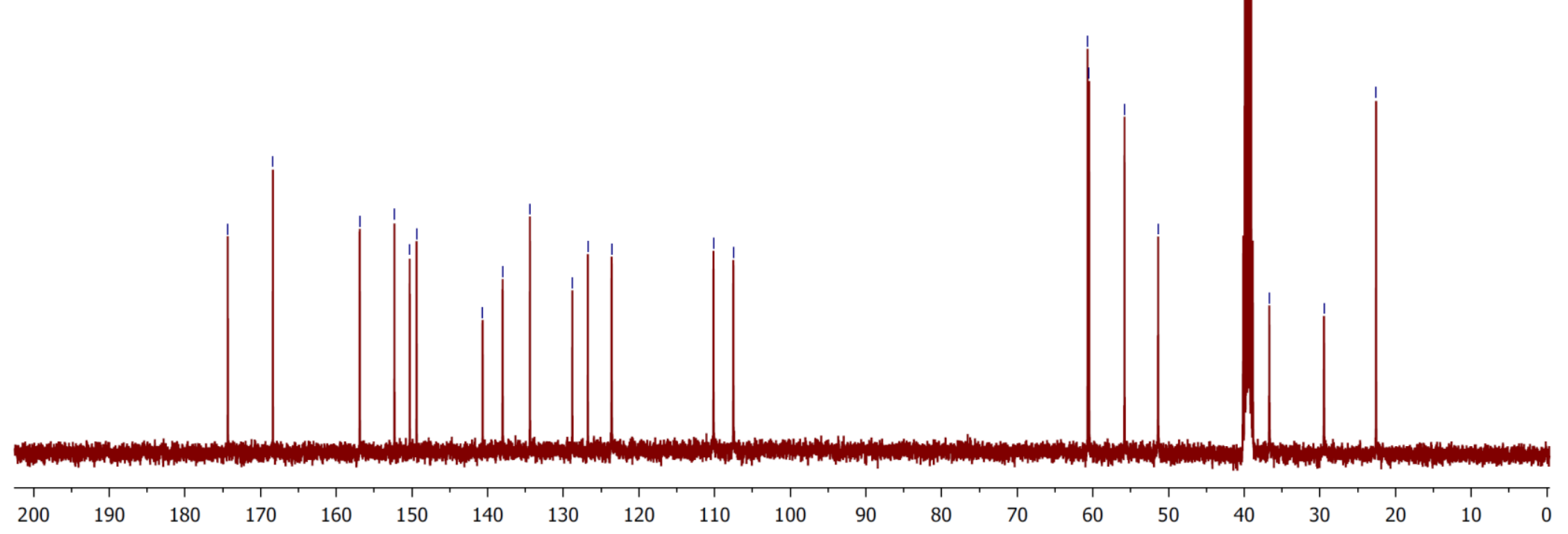

Figure S9. The ${ }^{13} \mathrm{C}(101 \mathrm{MHz})$ NMR spectrum of 3 in DMSO- $d_{6}$. 


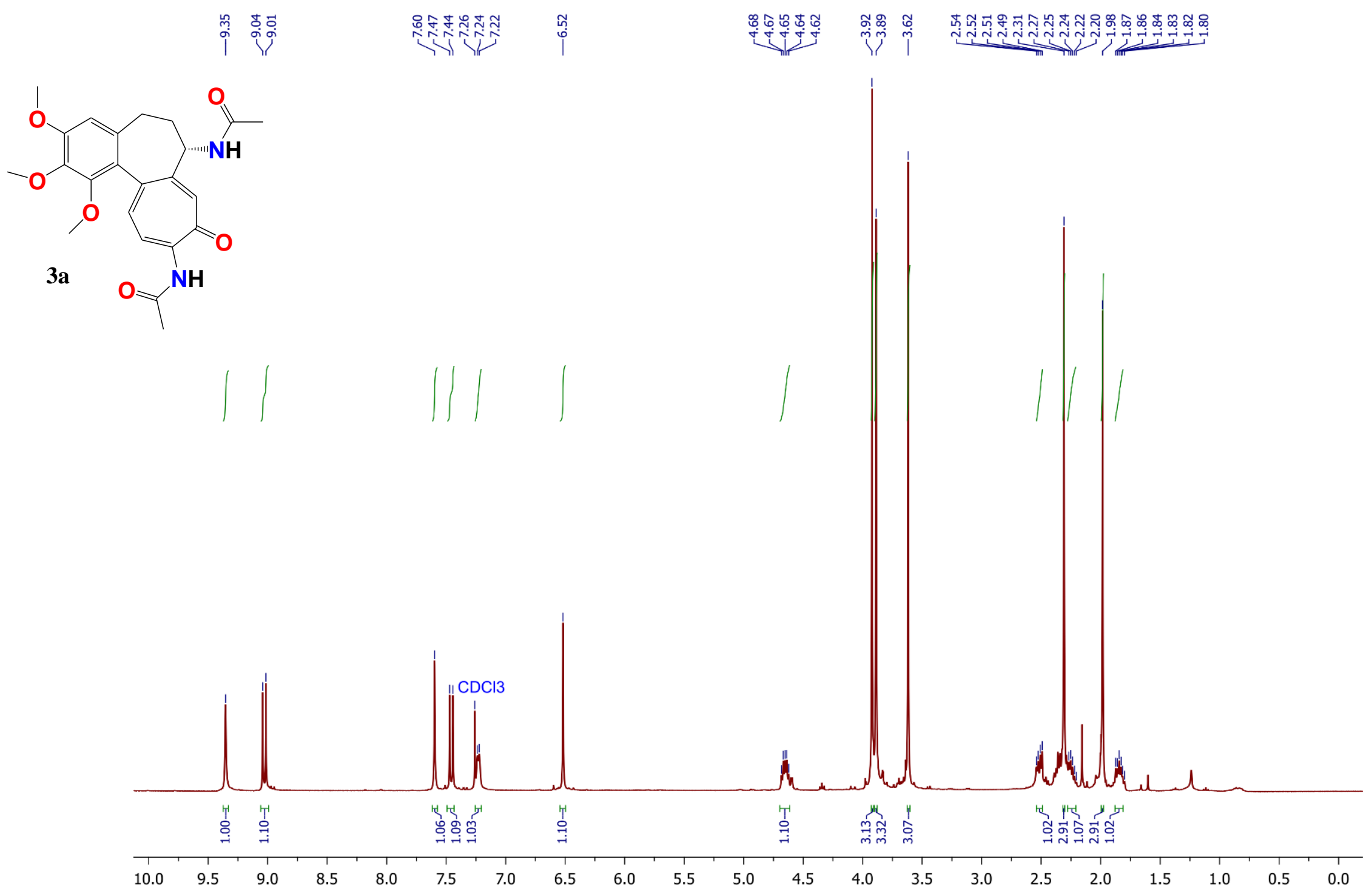

Figure S10. The ${ }^{1} \mathrm{H}(400 \mathrm{MHz})$ NMR spectrum of 3a in $\mathrm{CDCl}_{3}$. 


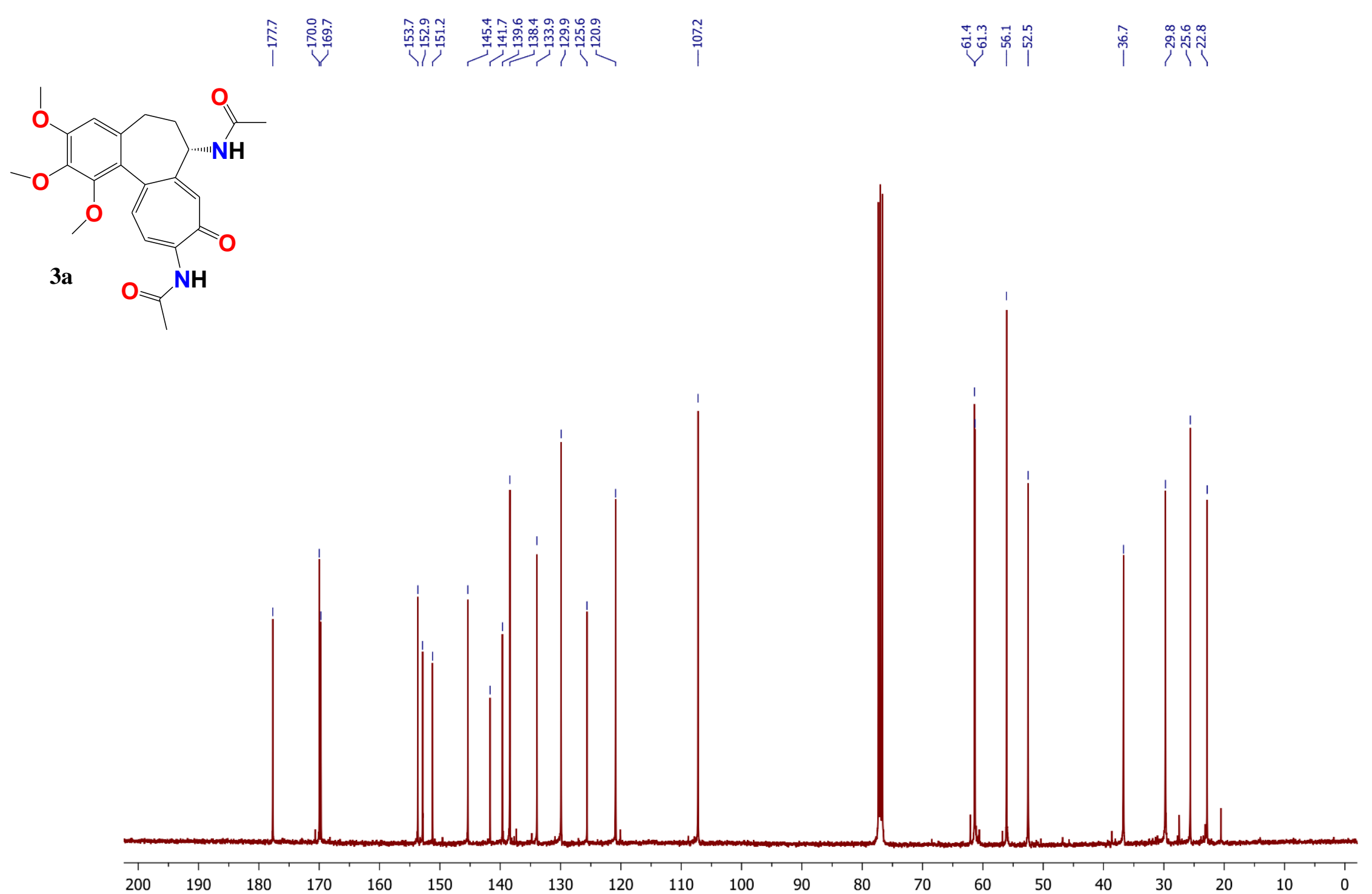

Figure S11. The ${ }^{13} \mathrm{C}(101 \mathrm{MHz})$ NMR spectrum of 3a in $\mathrm{CDCl}_{3}$. 


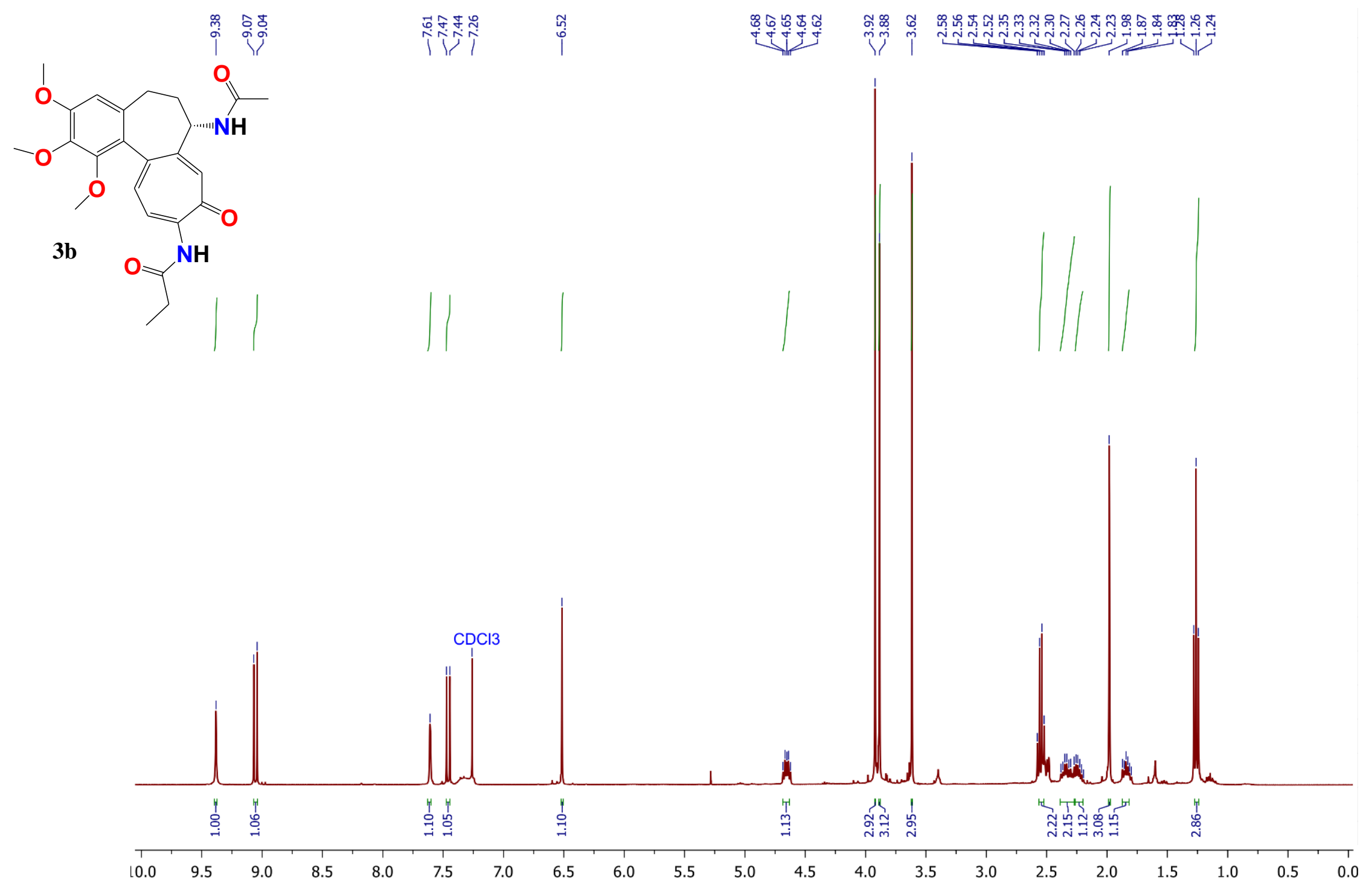

Figure S12. The ${ }^{1} \mathrm{H}(400 \mathrm{MHz})$ NMR spectrum of $3 \mathrm{~b}$ in $\mathrm{CDCl}_{3}$. 


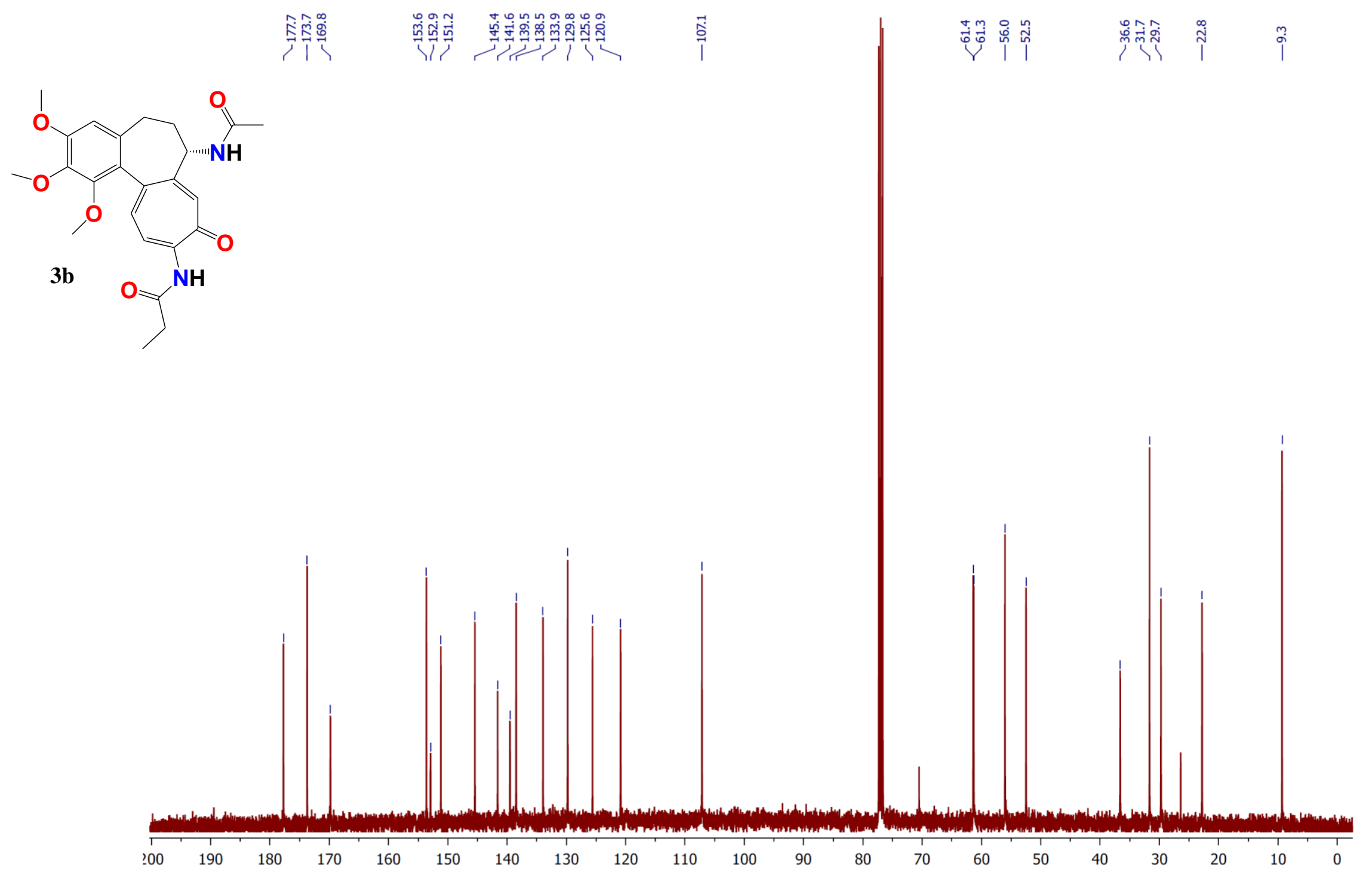

Figure S13. The ${ }^{13} \mathrm{C}(101 \mathrm{MHz}) \mathrm{NMR}$ spectrum of $3 \mathrm{~b}$ in $\mathrm{CDCl}_{3}$. 


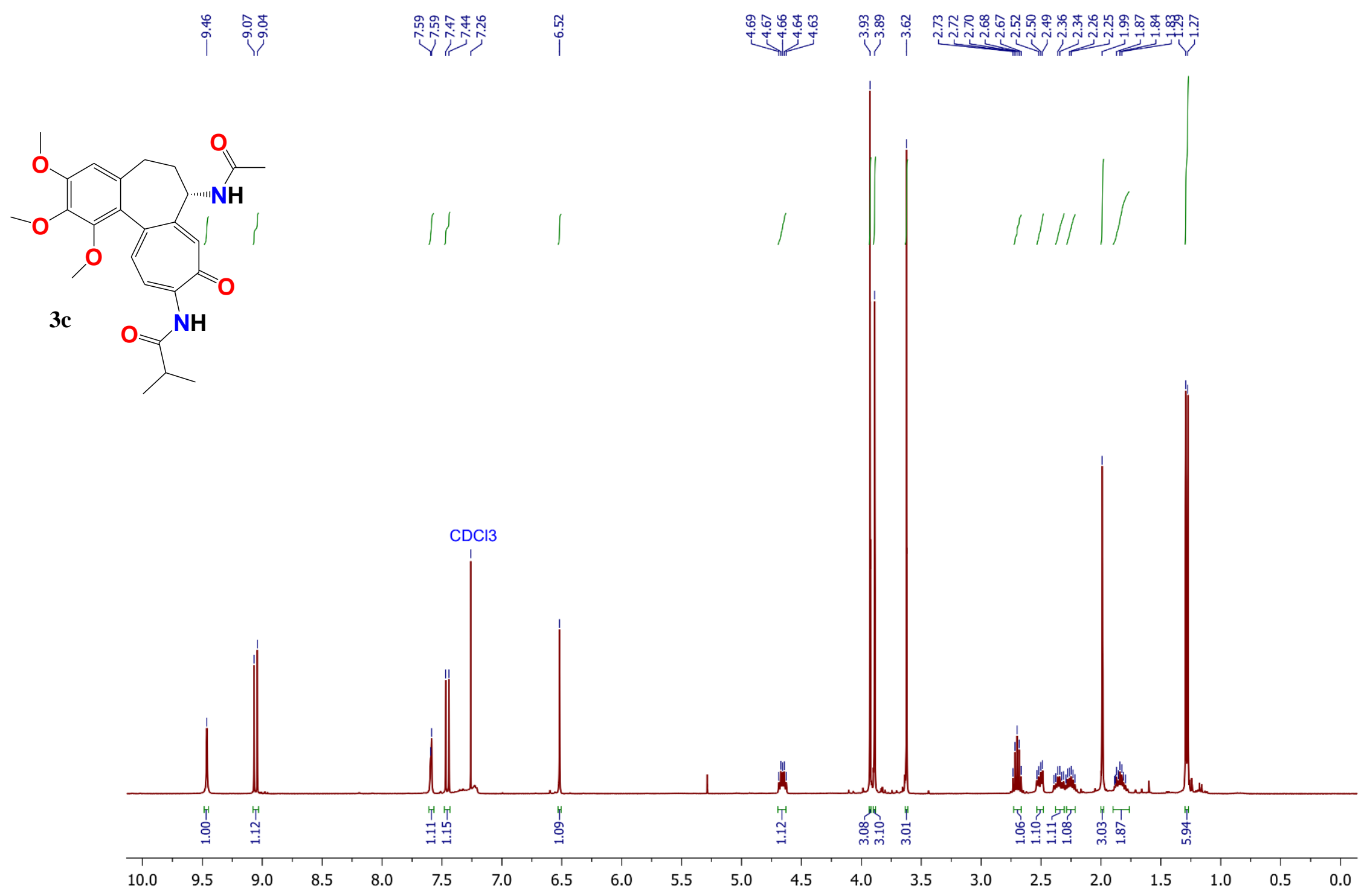

Figure S14. The ${ }^{1} \mathrm{H}$ (400 MHz) NMR spectrum of $3 \mathrm{c}$ in $\mathrm{CDCl}_{3}$. 


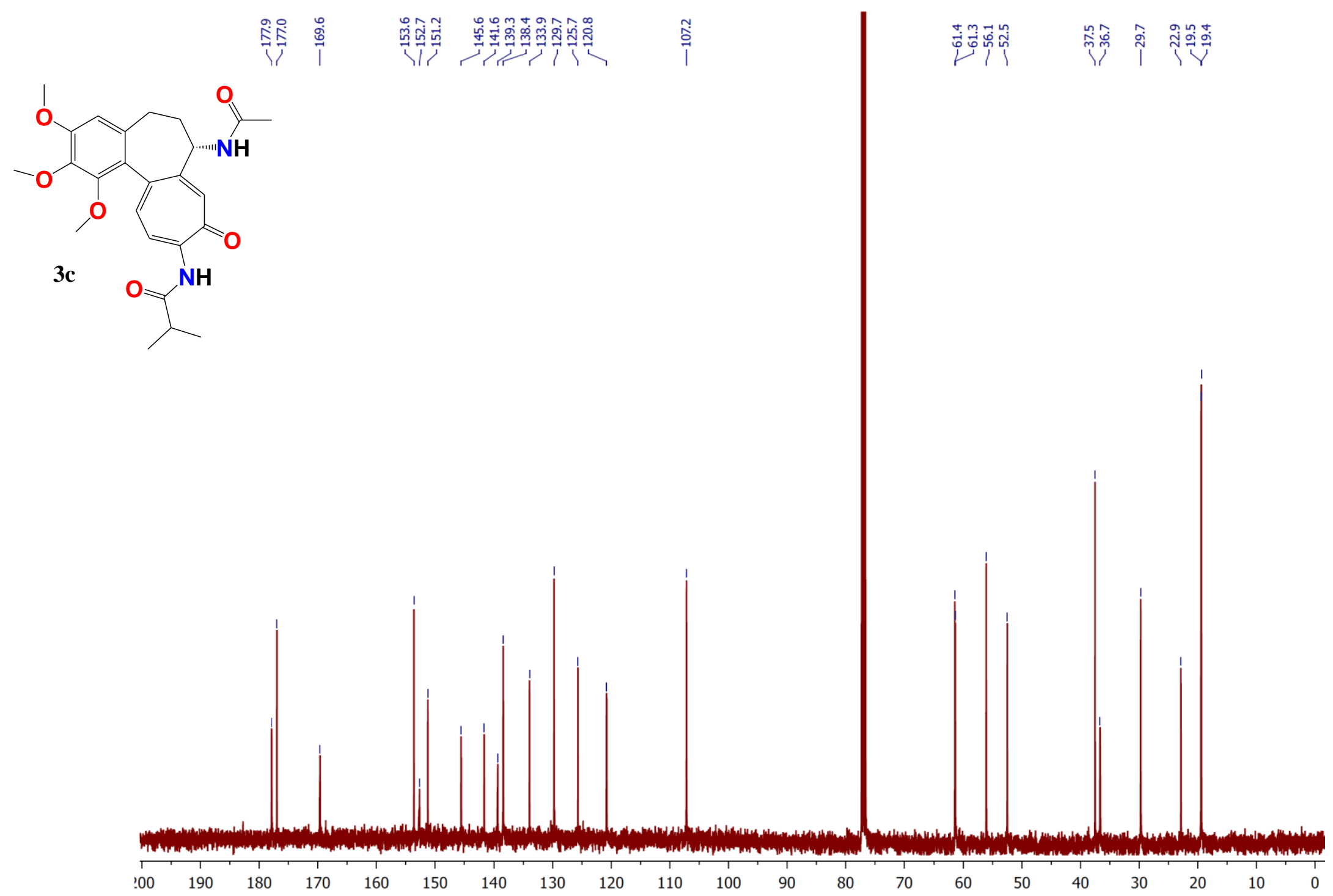

Figure S15. The ${ }^{13} \mathrm{C}(101 \mathrm{MHz})$ NMR spectrum of $3 \mathrm{c}$ in $\mathrm{CDCl}_{3}$. 


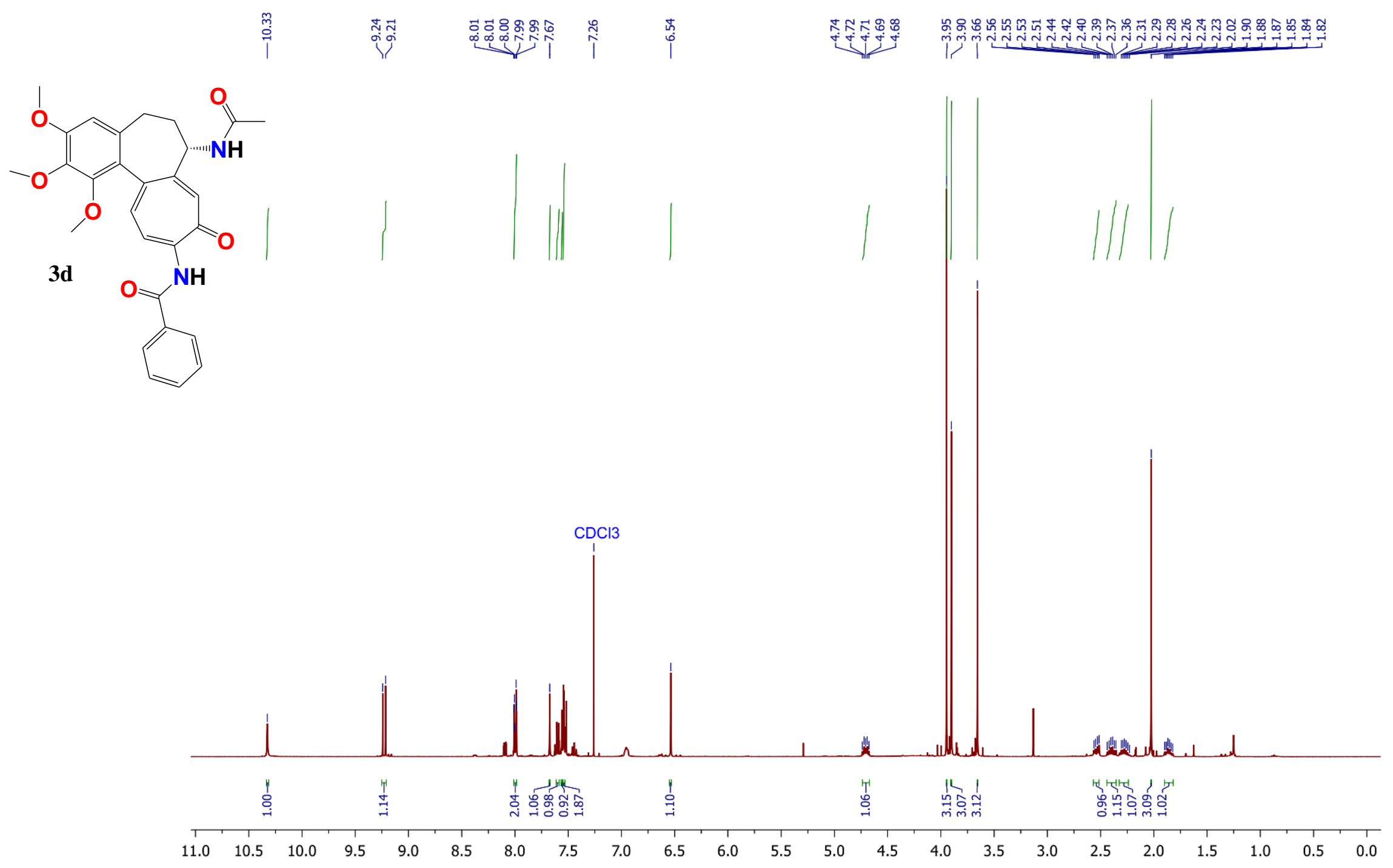

Figure S16. The ${ }^{1} \mathrm{H}(400 \mathrm{MHz})$ NMR spectrum of $3 \mathrm{~d}$ in $\mathrm{CDCl}_{3}$. 


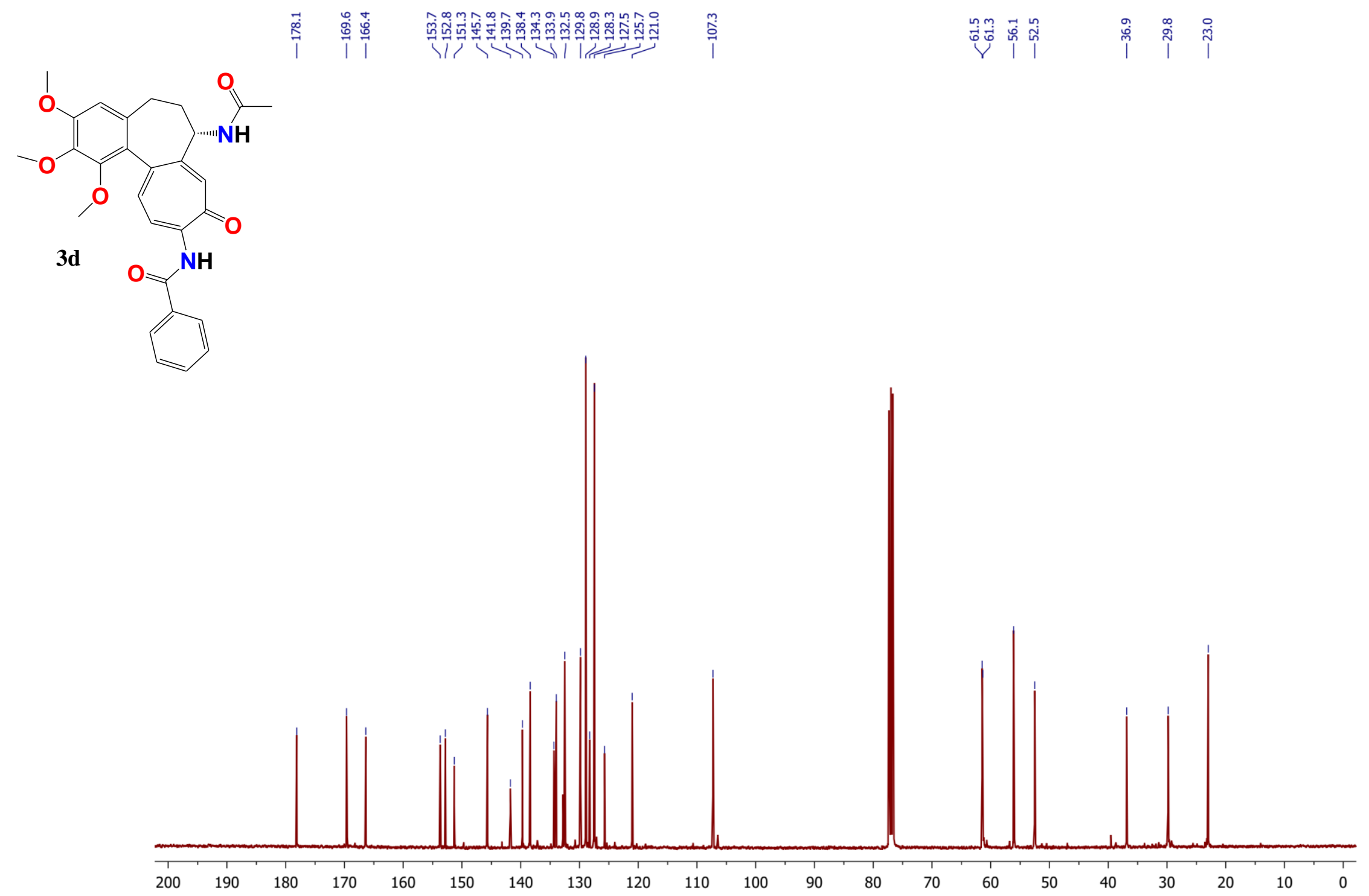

Figure S17. The ${ }^{13} \mathrm{C}(101 \mathrm{MHz})$ NMR spectrum of $3 \mathrm{~d}$ in $\mathrm{CDCl}_{3}$. 


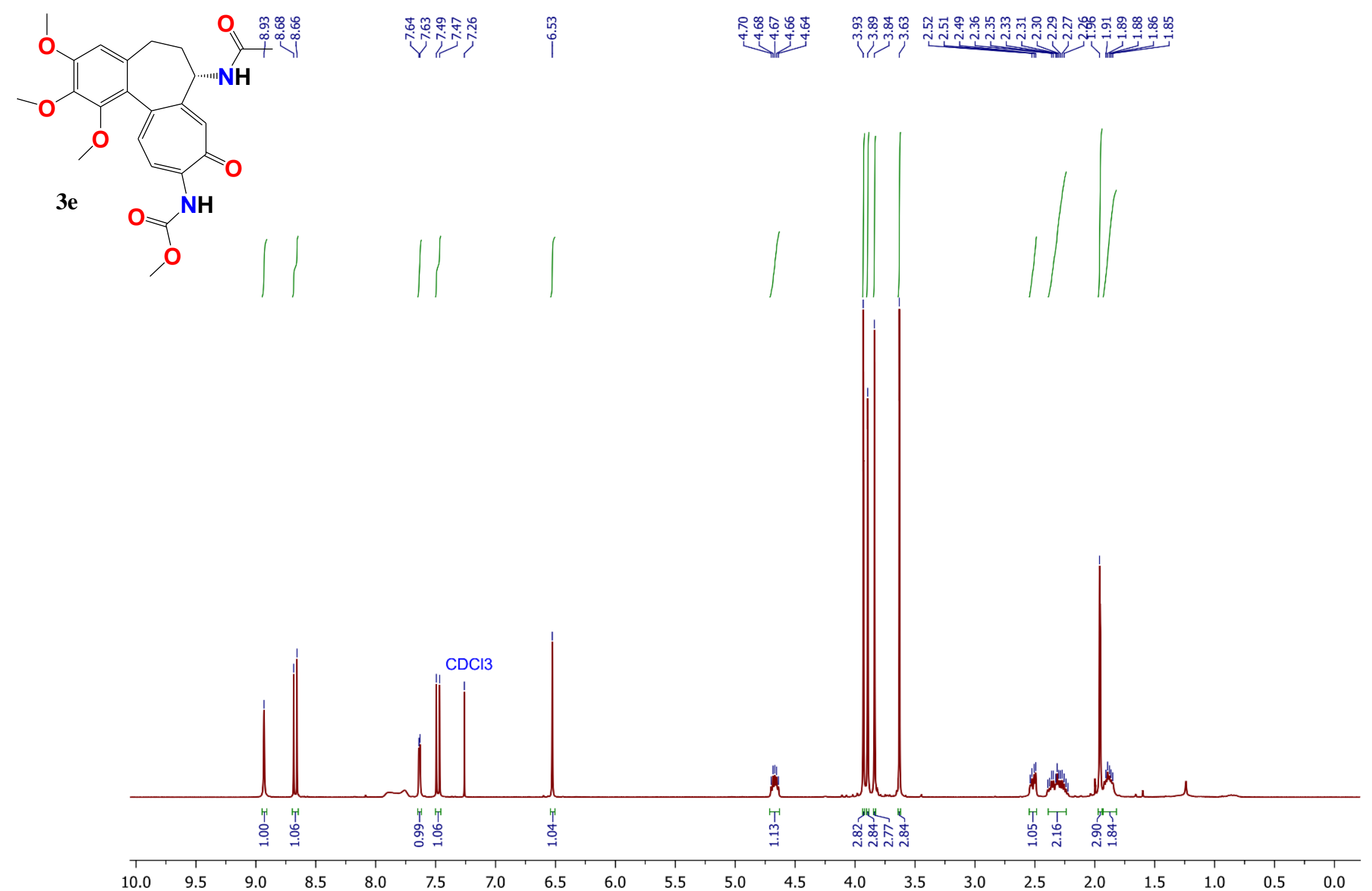

Figure S18. The ${ }^{1} \mathrm{H}(400 \mathrm{MHz})$ NMR spectrum of $3 \mathrm{e}$ in $\mathrm{CDCl}_{3}$. 


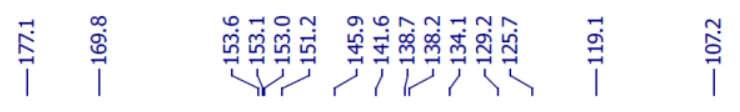

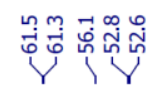

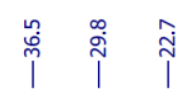<smiles>COC(=O)Nc1ccc2c(cc1=O)C(NC(C)=O)CCc1cc(OC)c(OC)c(OC)c1-2</smiles>

$3 e$

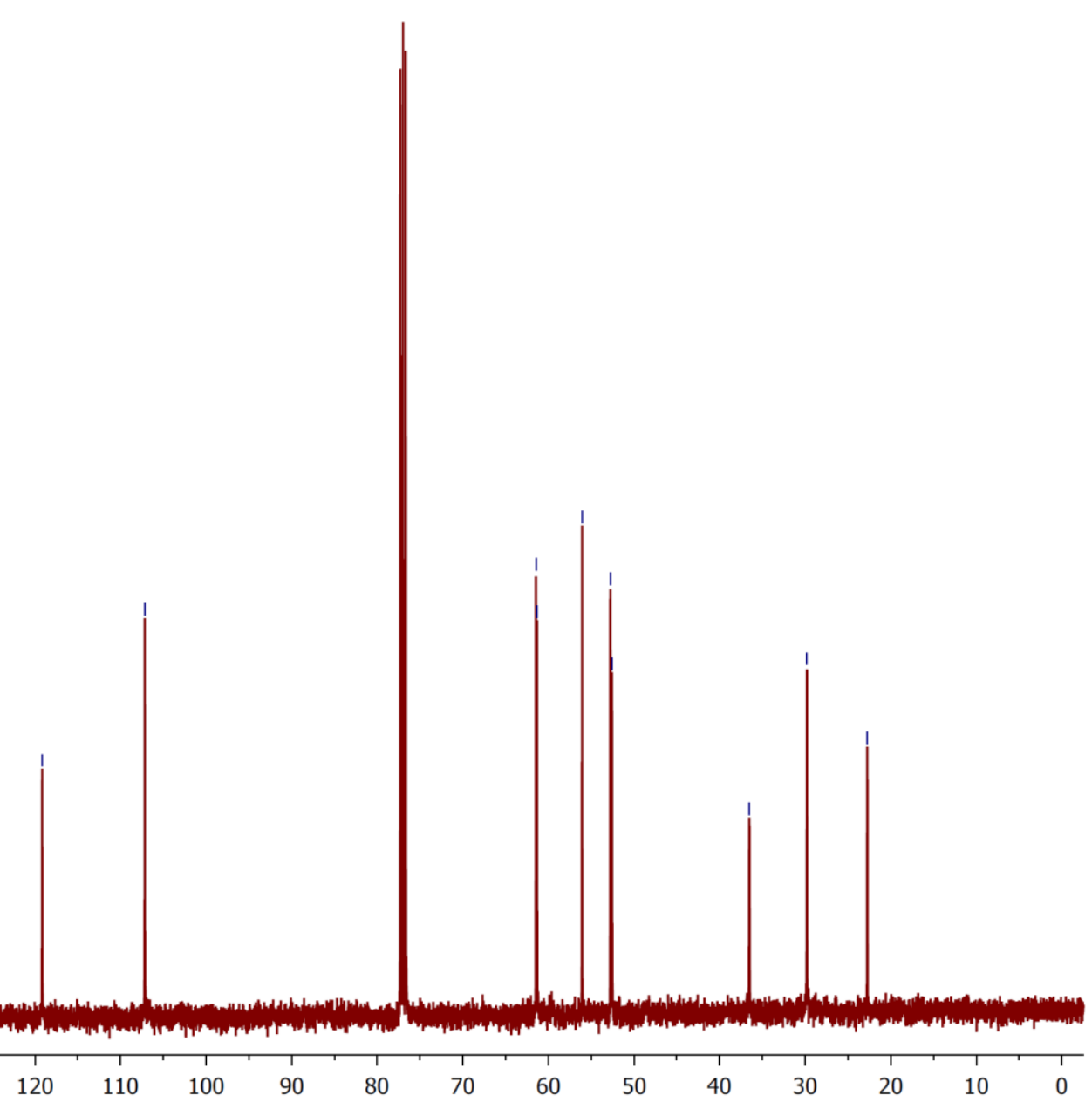

Figure S19. The ${ }^{13} \mathrm{C}(101 \mathrm{MHz})$ NMR spectrum of $3 \mathrm{e}$ in $\mathrm{CDCl}_{3}$.

S26 


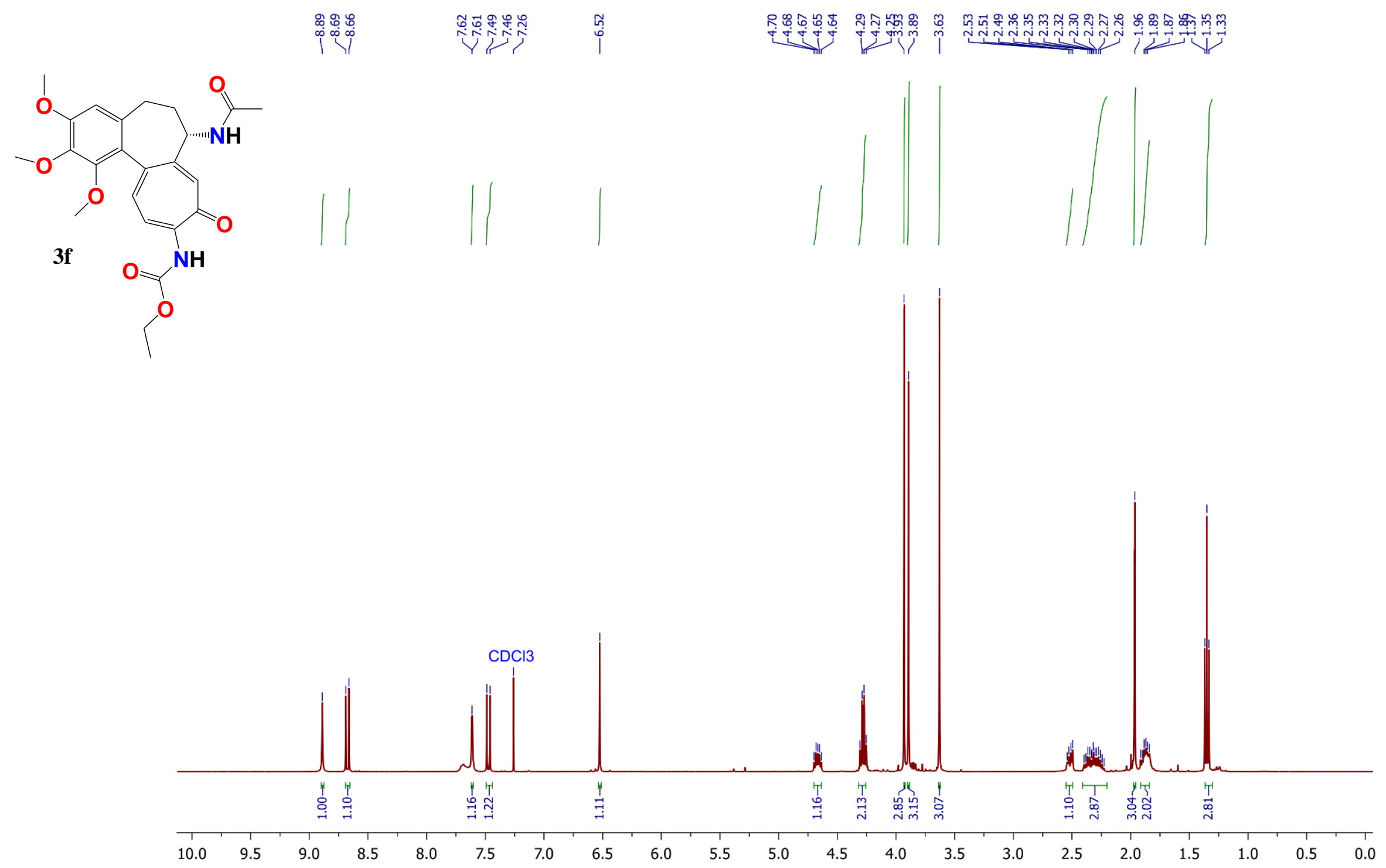

Figure S20. The ${ }^{1} \mathrm{H}(400 \mathrm{MHz})$ NMR spectrum of $3 \mathrm{f}$ in $\mathrm{CDCl}_{3}$. 


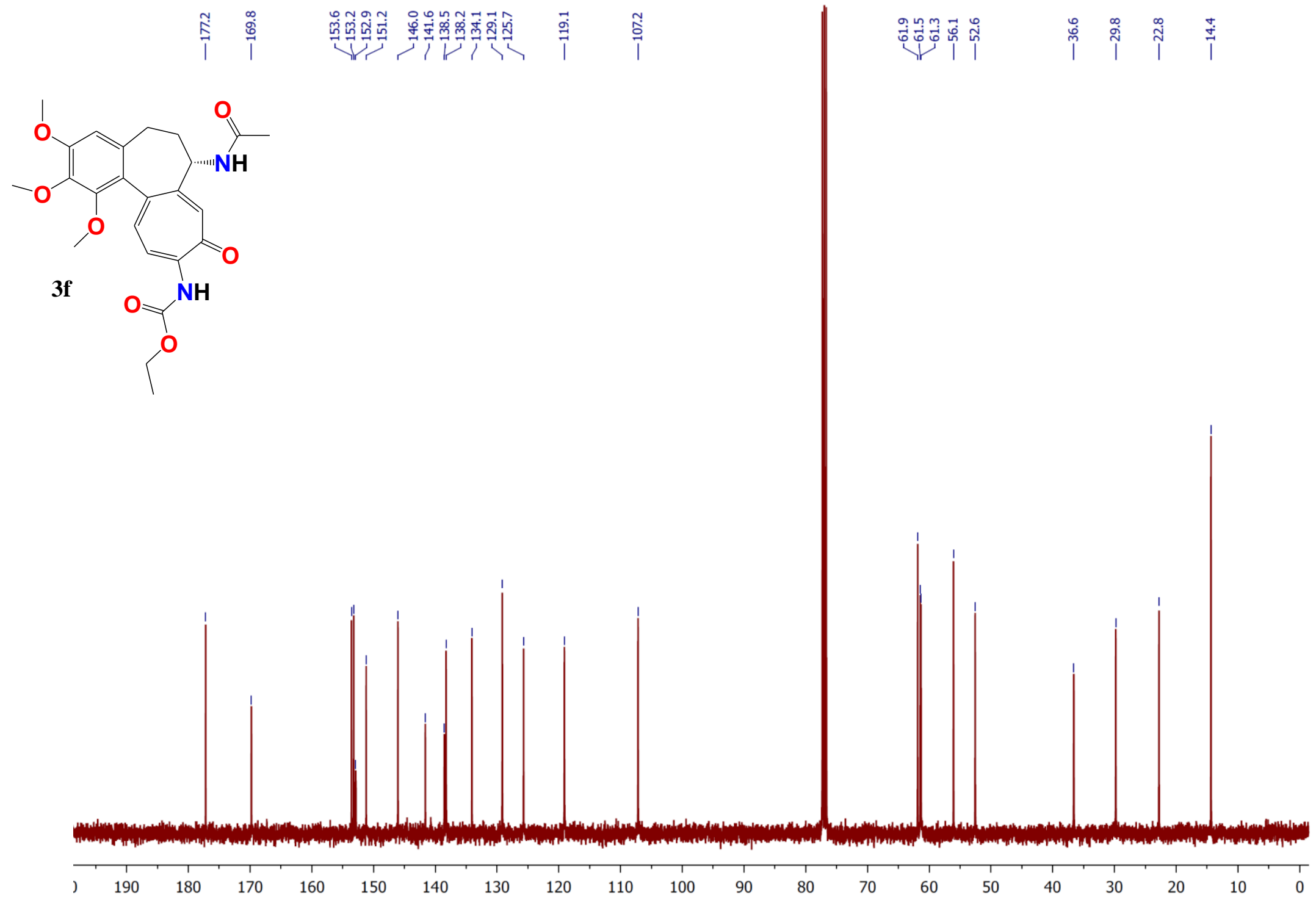

Figure S21. The ${ }^{13} \mathrm{C}(101 \mathrm{MHz}) \mathrm{NMR}$ spectrum of $3 \mathrm{f}$ in $\mathrm{CDCl}_{3}$ 


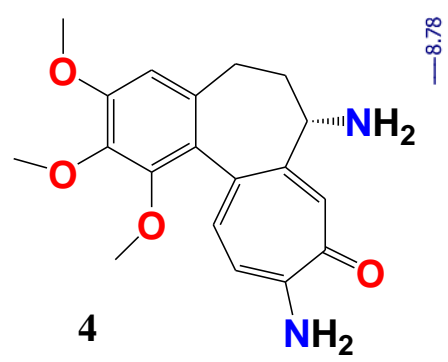

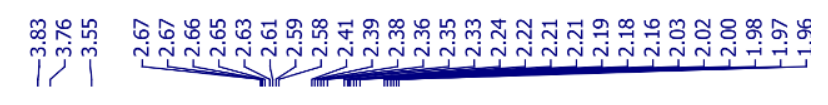
DMSO-d6

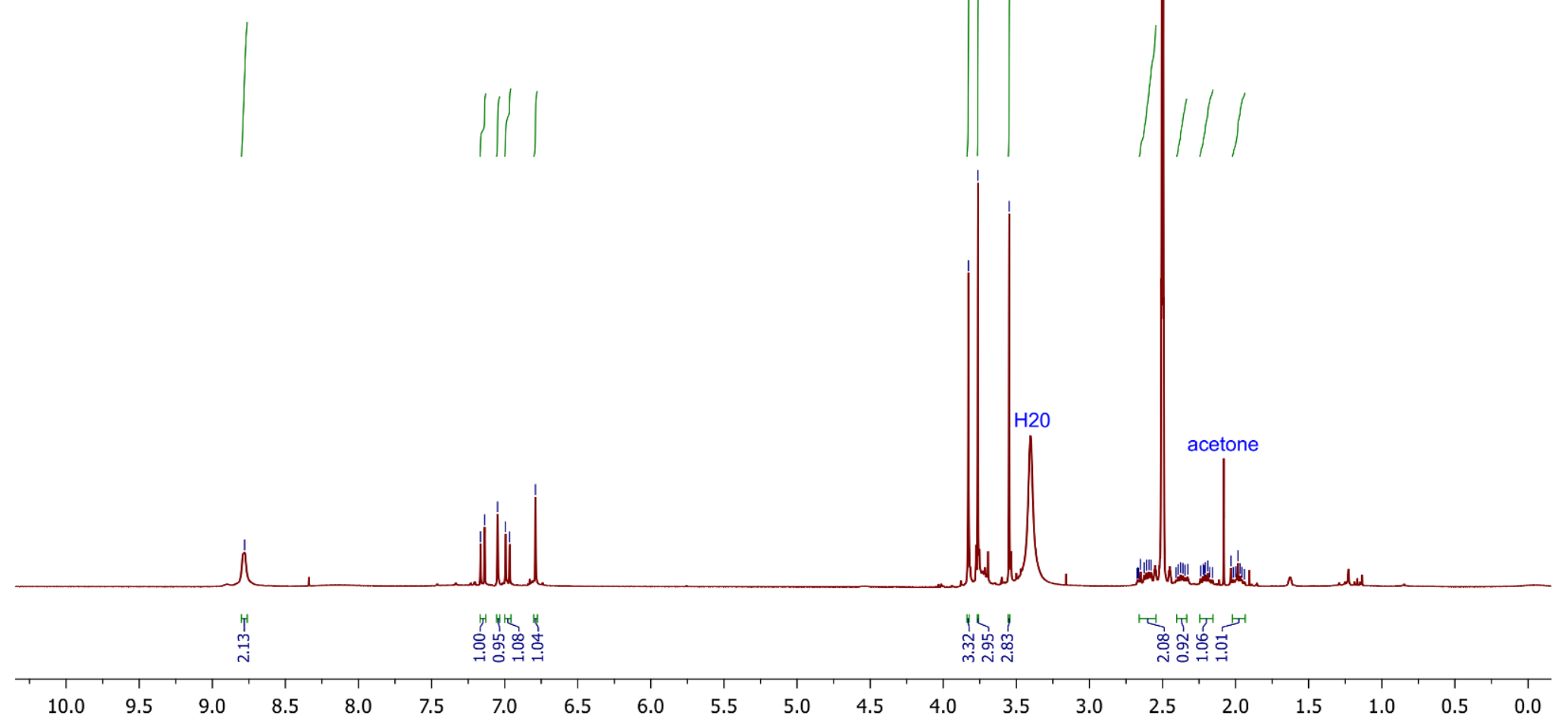

Figure S22. The ${ }^{1} \mathrm{H}(400 \mathrm{MHz})$ NMR spectrum of 4 in DMSO- $d_{6}$. 


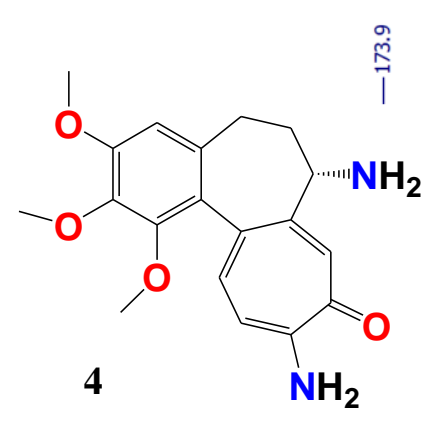

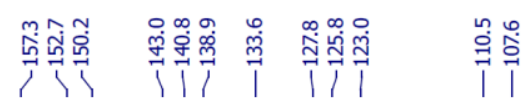
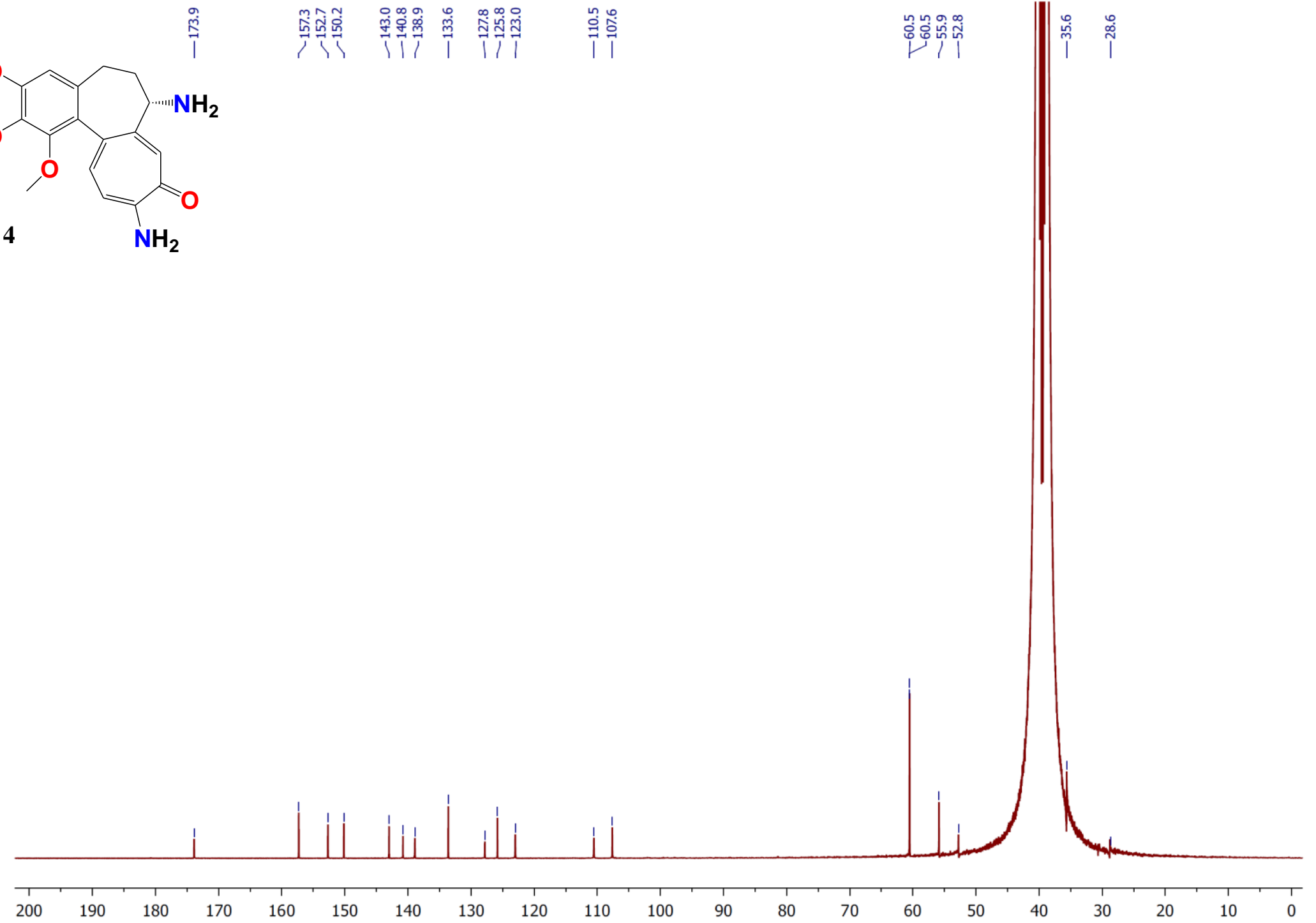

Figure S23. The ${ }^{13} \mathrm{C}$ (101 MHz) NMR spectrum of 4 in DMSO- $d_{6}$. 


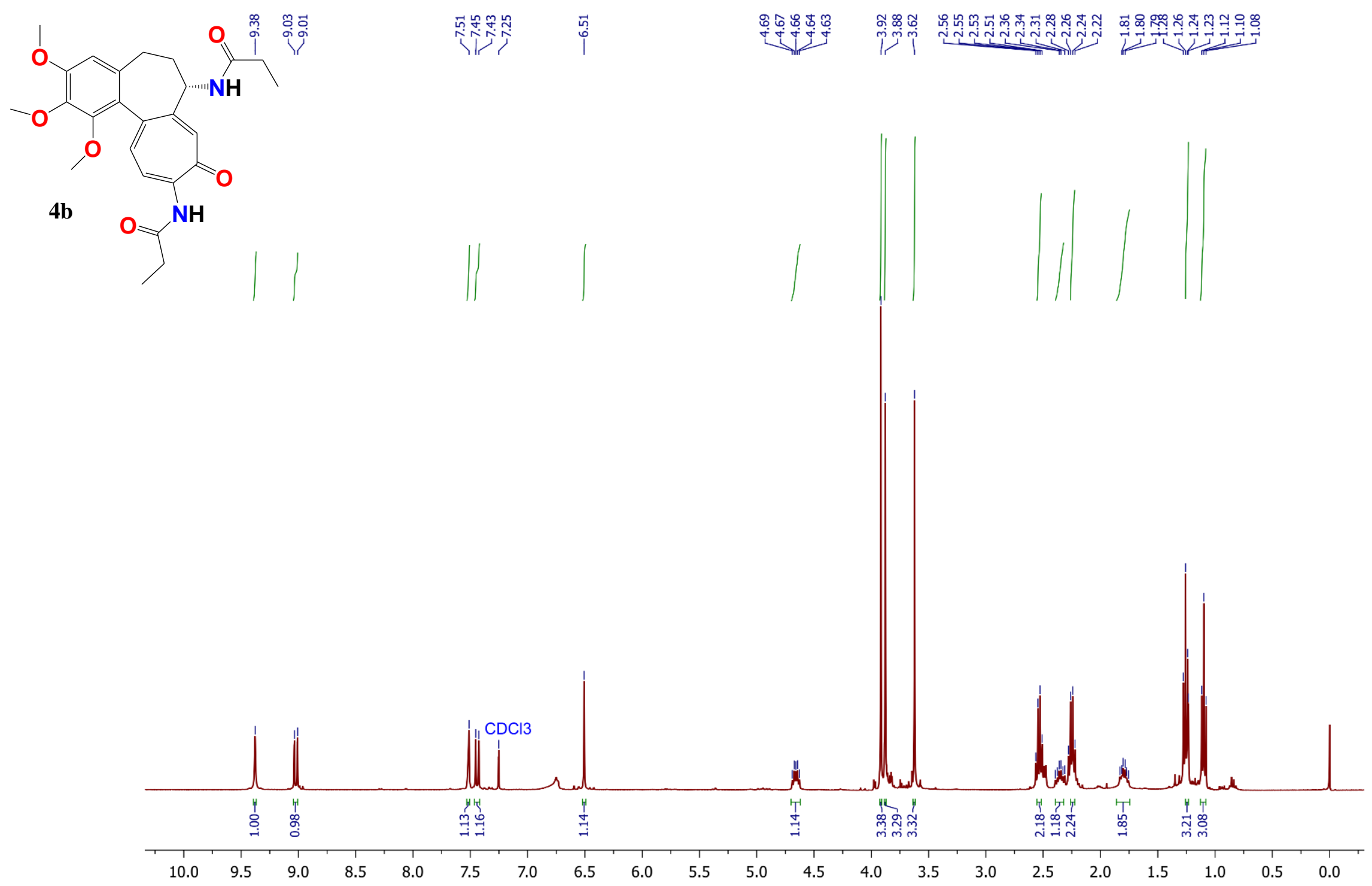

Figure S24. The ${ }^{1} \mathrm{H}(400 \mathrm{MHz})$ NMR spectrum of $4 \mathrm{~b}$ in $\mathrm{CDCl}_{3}$. 
ํํำำ

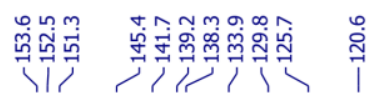

:

บำ

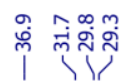

ตัต
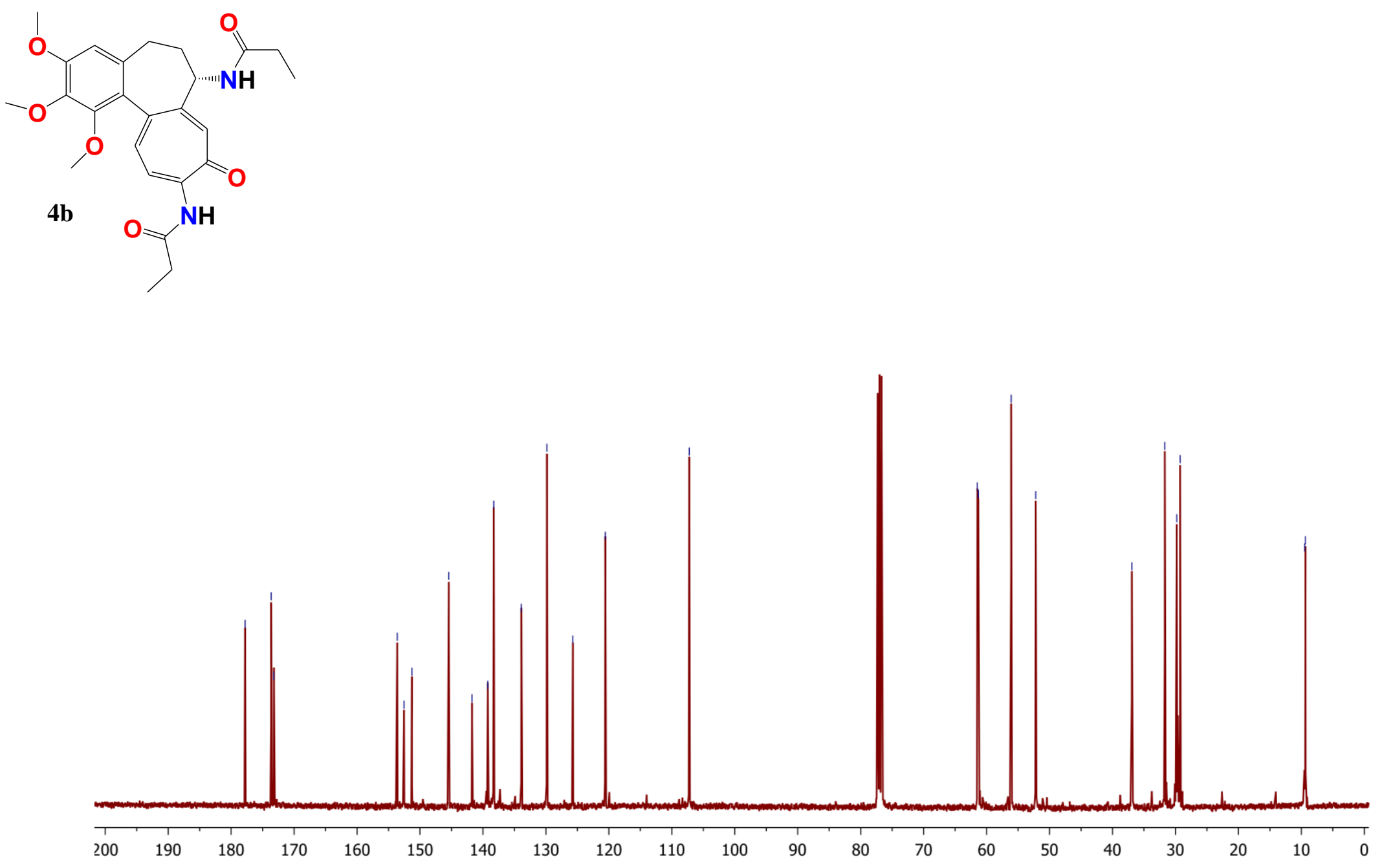

Figure S25. The ${ }^{13} \mathrm{C}(101 \mathrm{MHz})$ NMR spectrum of $4 \mathrm{~b}$ in $\mathrm{CDCl}_{3}$.

S32 


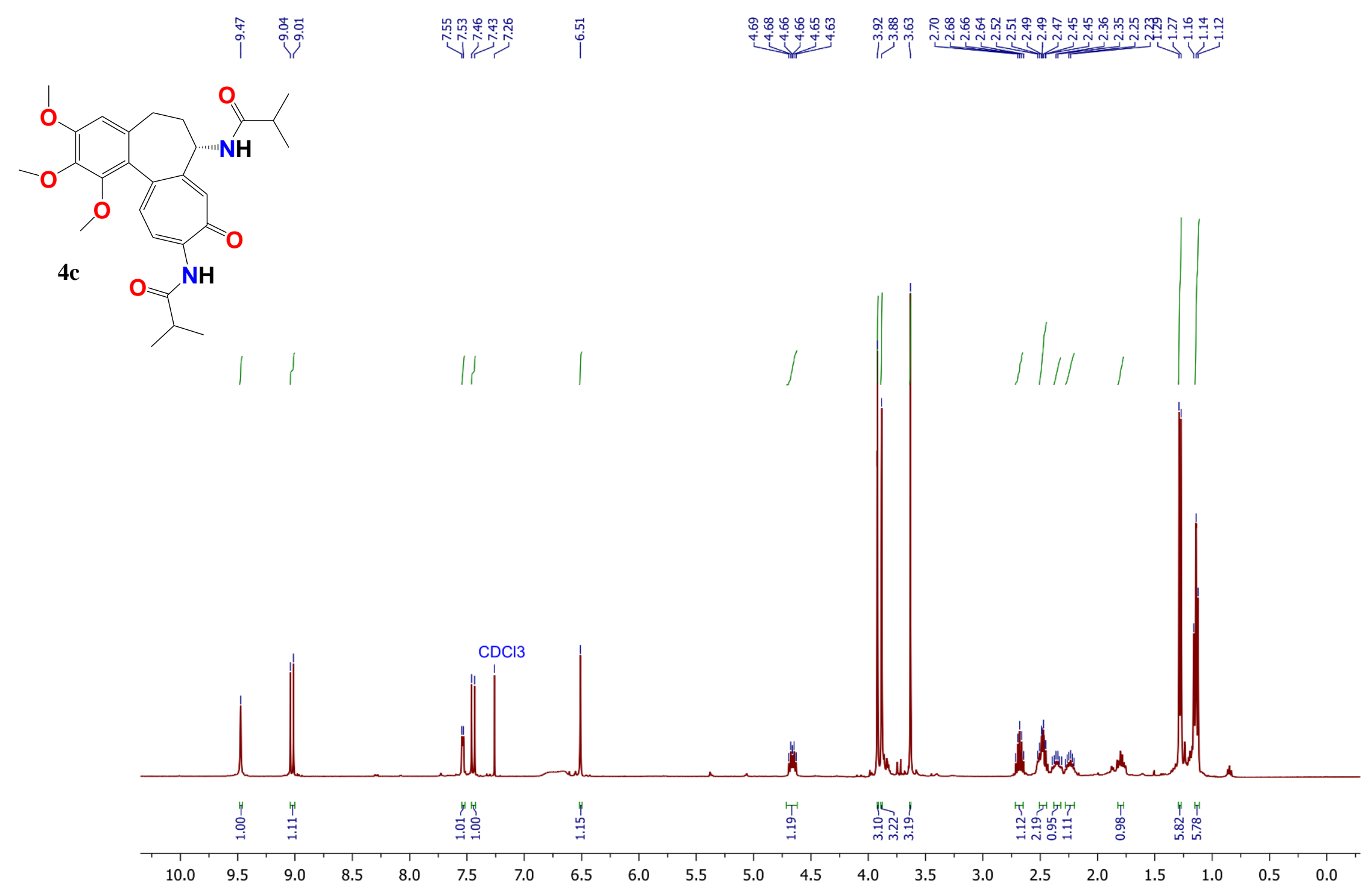

Figure S26. The ${ }^{1} \mathrm{H}$ (400 MHz) NMR spectrum of $4 \mathrm{c}$ in $\mathrm{CDCl}_{3}$. 


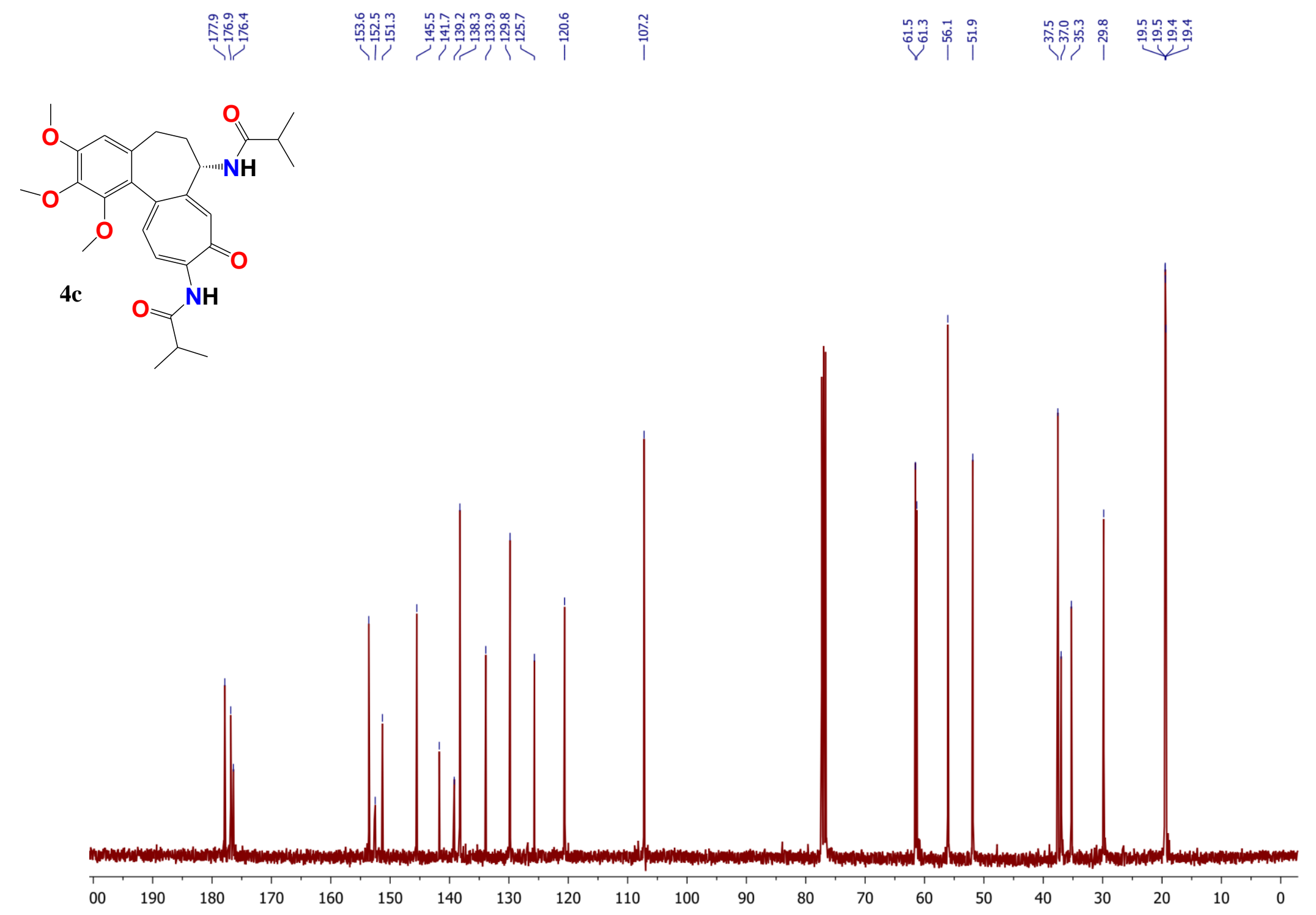

Figure S27. The ${ }^{13} \mathrm{C}(101 \mathrm{MHz}) \mathrm{NMR}$ spectrum of $4 \mathrm{c}$ in $\mathrm{CDCl}_{3}$. 


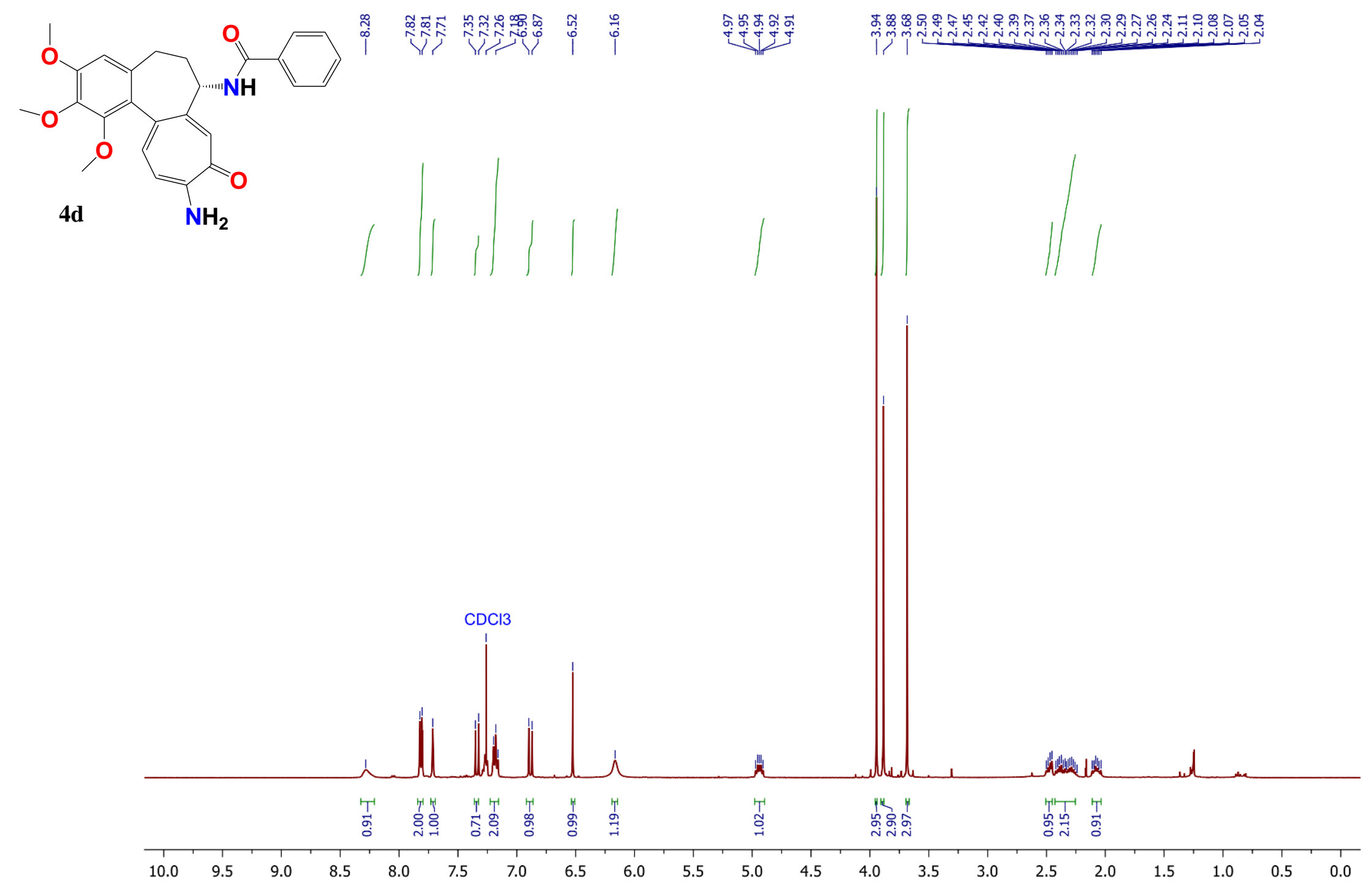

Figure S28. The ${ }^{1} \mathrm{H}(400 \mathrm{MHz})$ NMR spectrum of $4 \mathrm{~d}$ in $\mathrm{CDCl}_{3}$. 


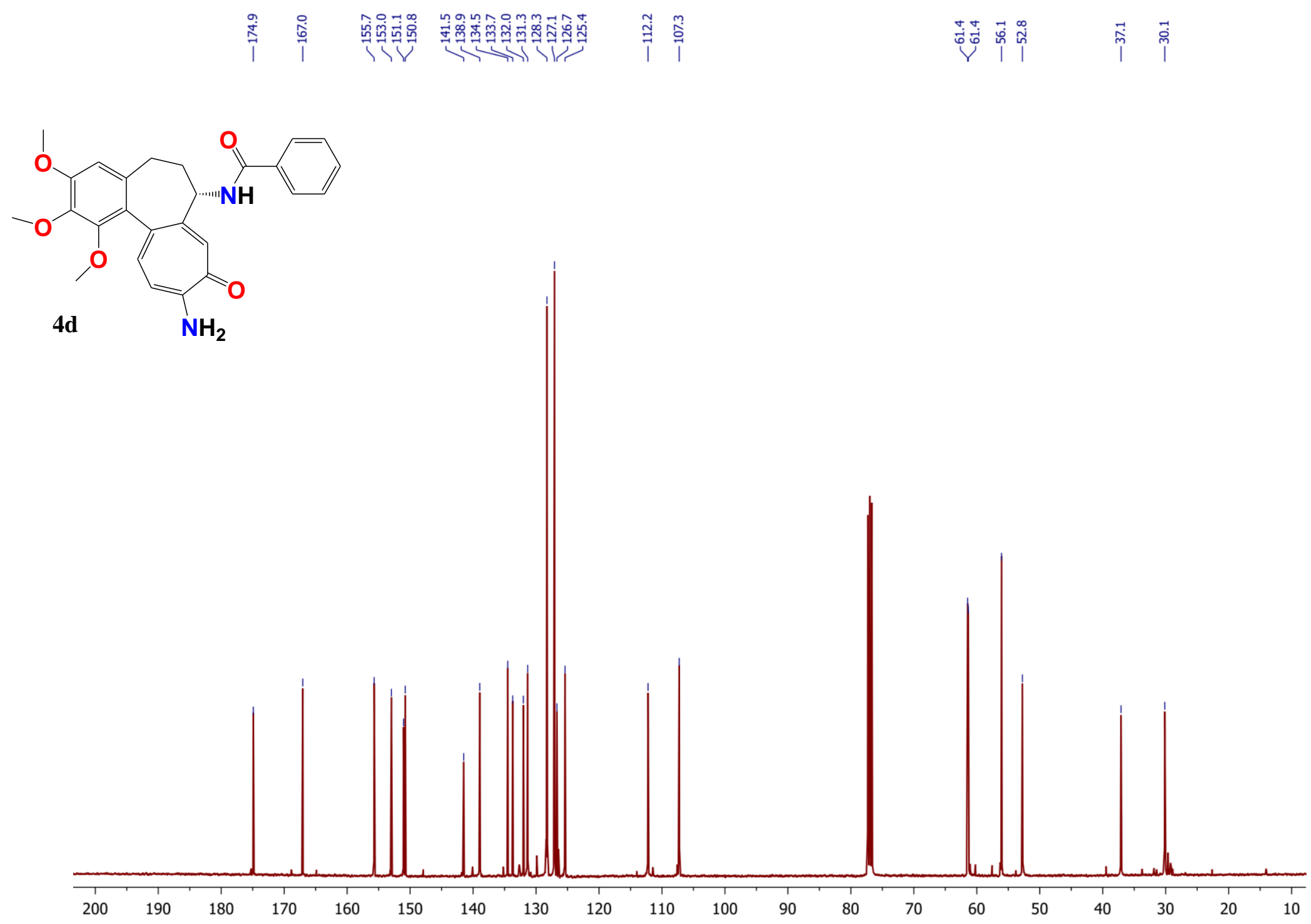

Figure S29. The ${ }^{13} \mathrm{C}(101 \mathrm{MHz})$ NMR spectrum of $4 \mathrm{~d}$ in $\mathrm{CDCl}_{3}$. 


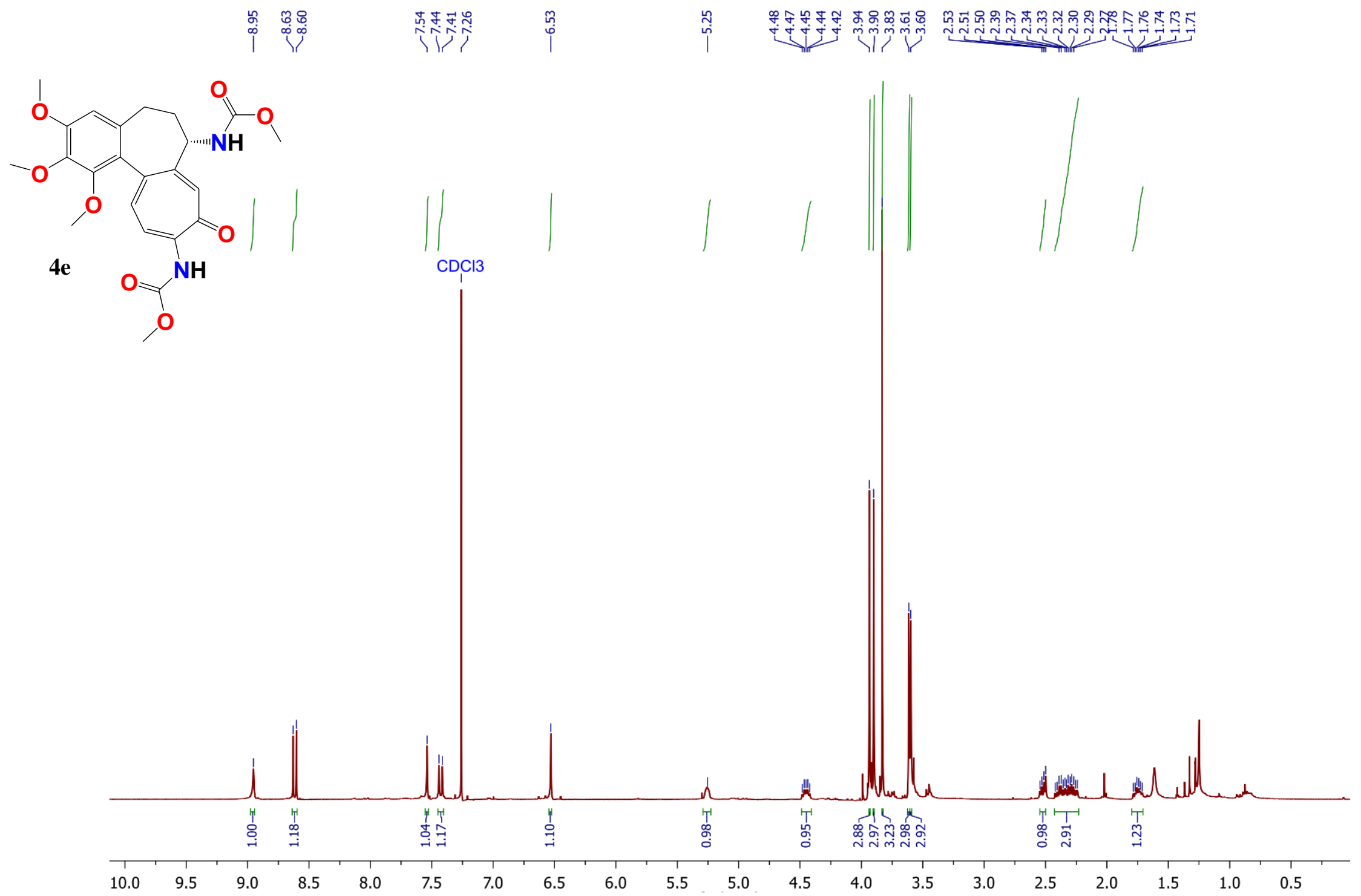

Figure S30. The ${ }^{1} \mathrm{H}(400 \mathrm{MHz})$ NMR spectrum of $4 \mathrm{e}$ in $\mathrm{CDCl}_{3}$. 

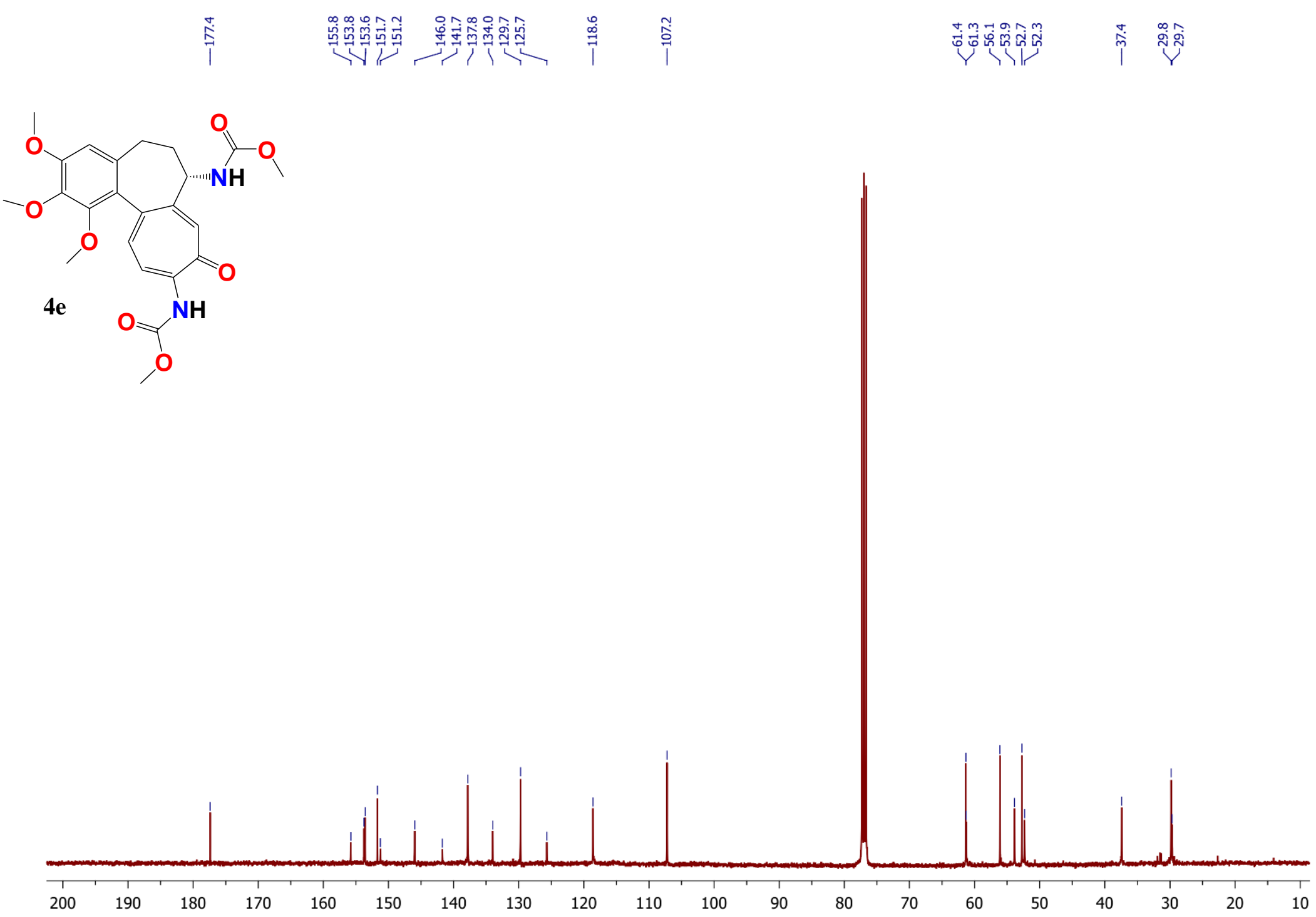

Figure S31. The ${ }^{13} \mathrm{C}(101 \mathrm{MHz})$ NMR spectrum of $4 \mathrm{e}$ in $\mathrm{CDCl}_{3}$. 


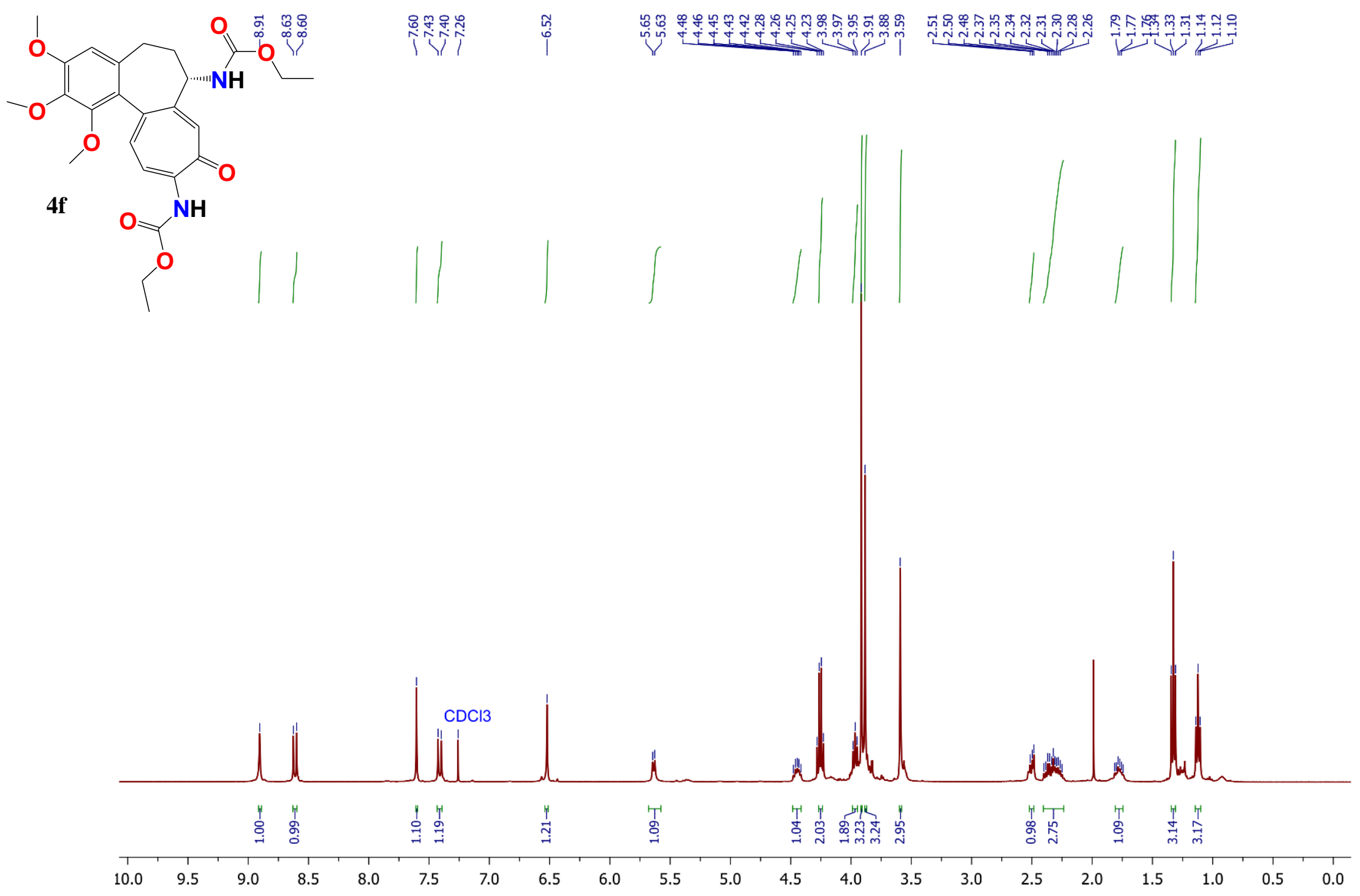

Figure S32. The ${ }^{1} \mathrm{H}(400 \mathrm{MHz})$ NMR spectrum of $4 \mathrm{f}$ in $\mathrm{CDCl}_{3}$. 


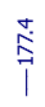

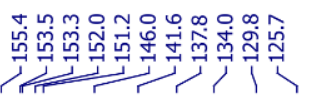

$\stackrel{\infty}{\stackrel{\infty}{1}}$

$\stackrel{1}{\stackrel{0}{1}}$

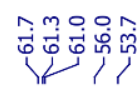

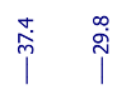

$\stackrel{m}{\mathfrak{y}^{m}}$
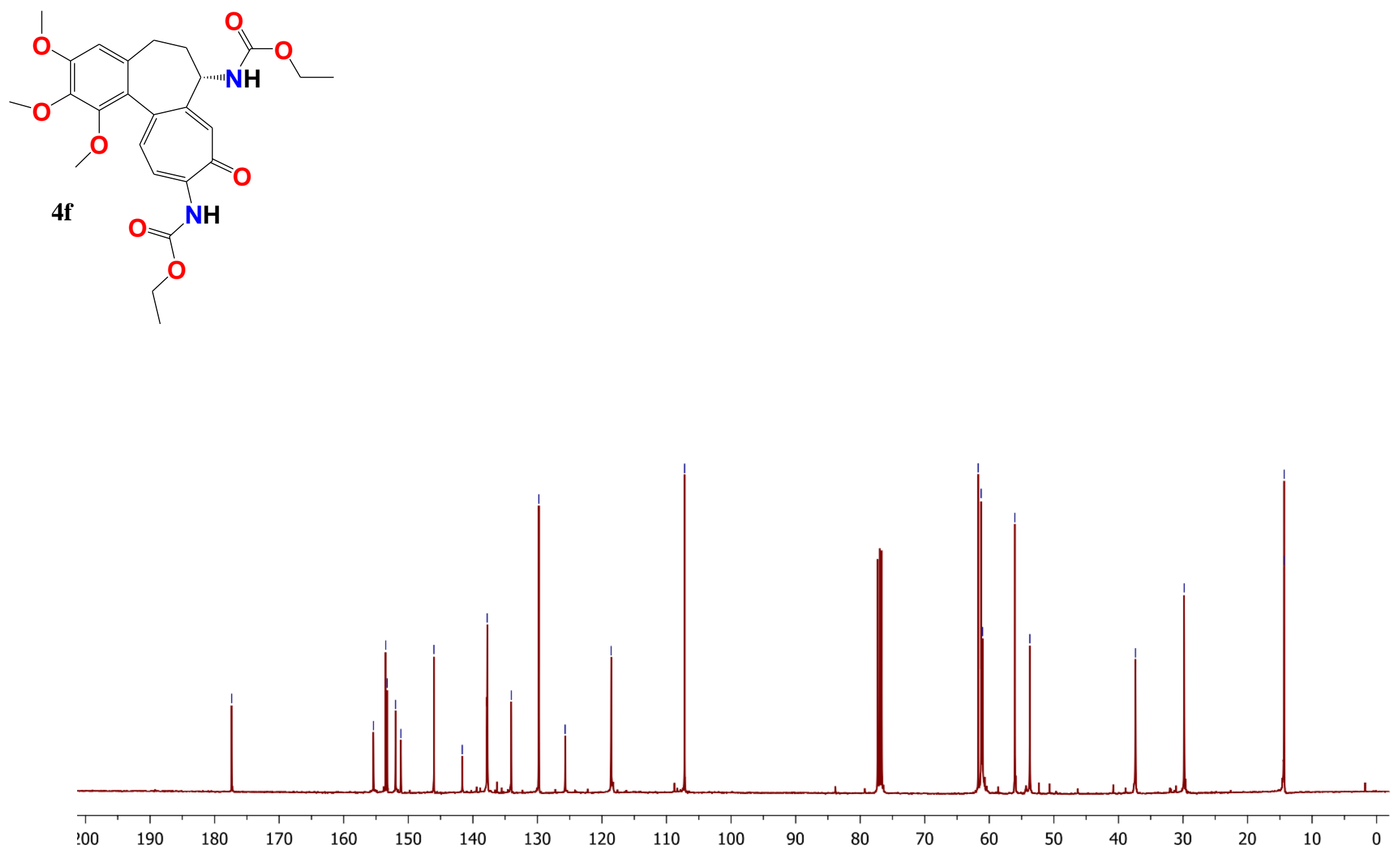

Figure S33. The ${ }^{13} \mathrm{C}(101 \mathrm{MHz})$ NMR spectrum of $4 \mathrm{f}$ in $\mathrm{CDCl}_{3}$.

S40 
${ }^{1} \mathrm{H}$ and ${ }^{13} \mathrm{C}$ NMR spectra of $\beta$-lumiderivatives: $\beta$-lumicolchicine, $2-\mathrm{UV}, 3-\mathrm{UV}, 3 \mathrm{~b}-\mathrm{UV}, 3 \mathrm{f}-\mathrm{UV}, \mathbf{4 b}-\mathrm{UV}, 4 \mathrm{f}-\mathrm{UV}$ )
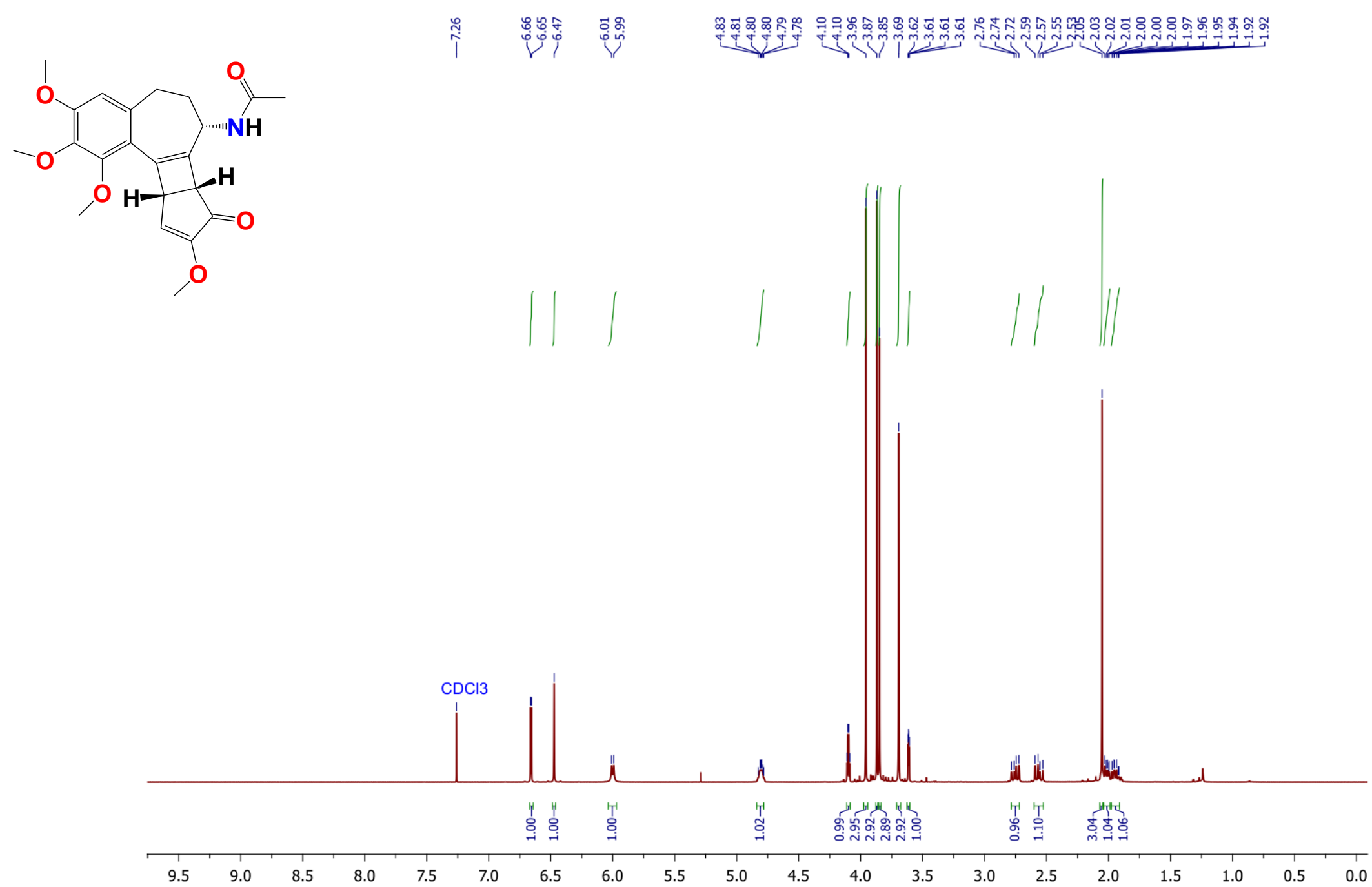

Figure S34. The ${ }^{1} \mathrm{H}(400 \mathrm{MHz})$ NMR spectrum of $\beta$-lumicolchicine in $\mathrm{CDCl}_{3}$. 

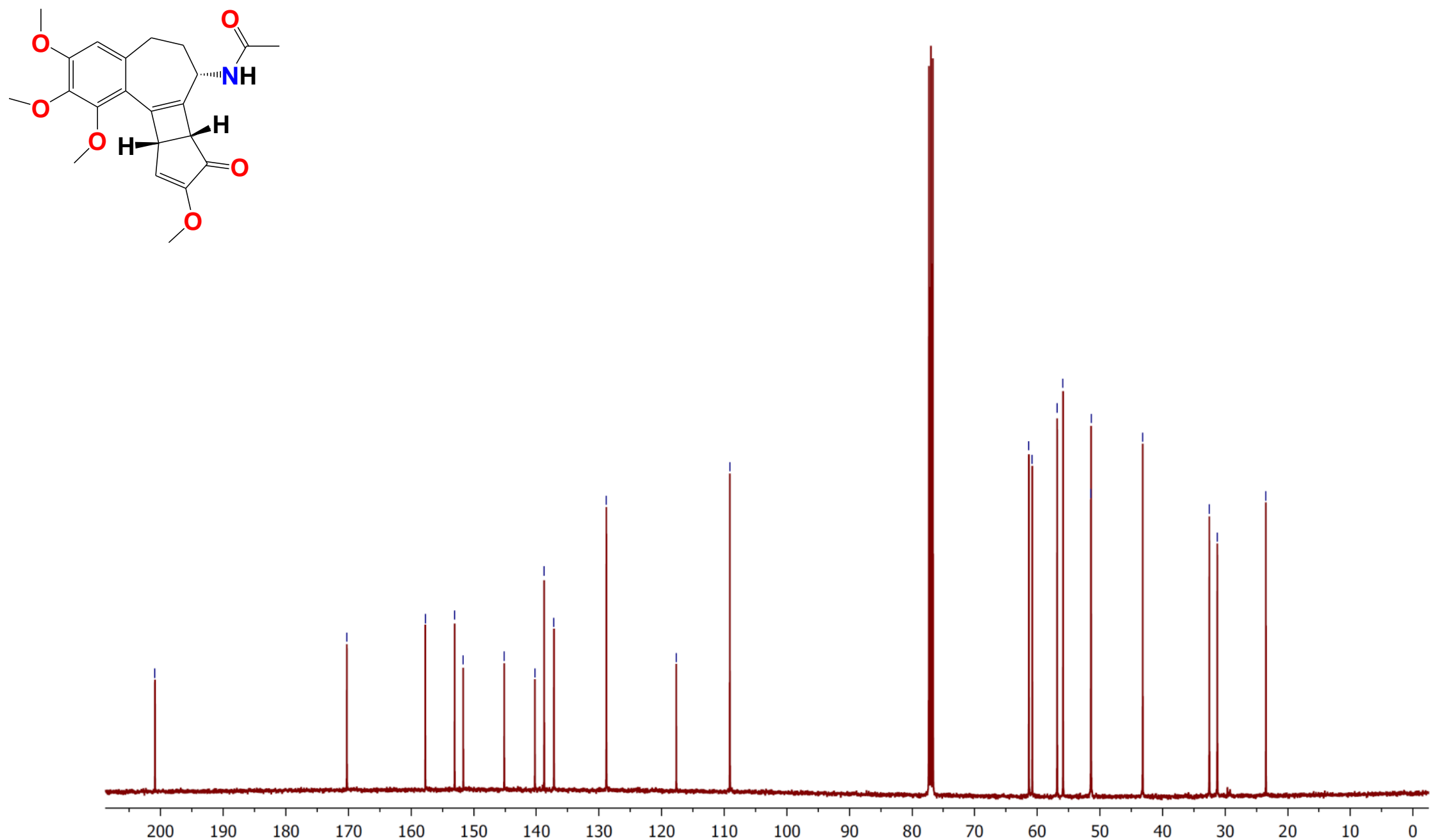

Figure S35. The ${ }^{13} \mathrm{C}(101 \mathrm{MHz}) \mathrm{NMR}$ spectrum of $\beta$-lumicolchicine in $\mathrm{CDCl}_{3}$. 

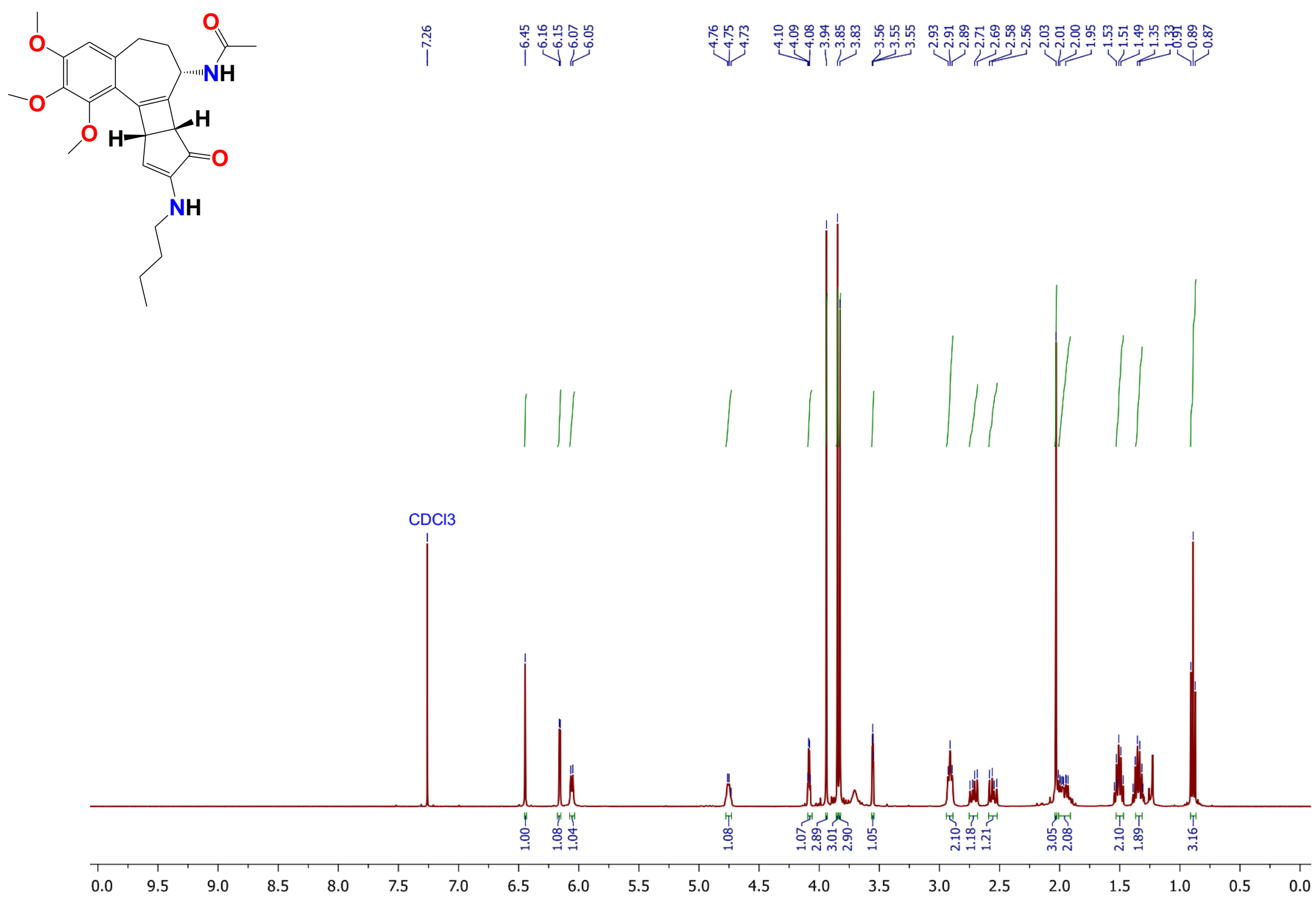

Figure S36. The ${ }^{1} \mathrm{H}(400 \mathrm{MHz}) \mathrm{NMR}$ spectrum of $2-\mathrm{UV}$ in $\mathrm{CDCl}_{3}$. 


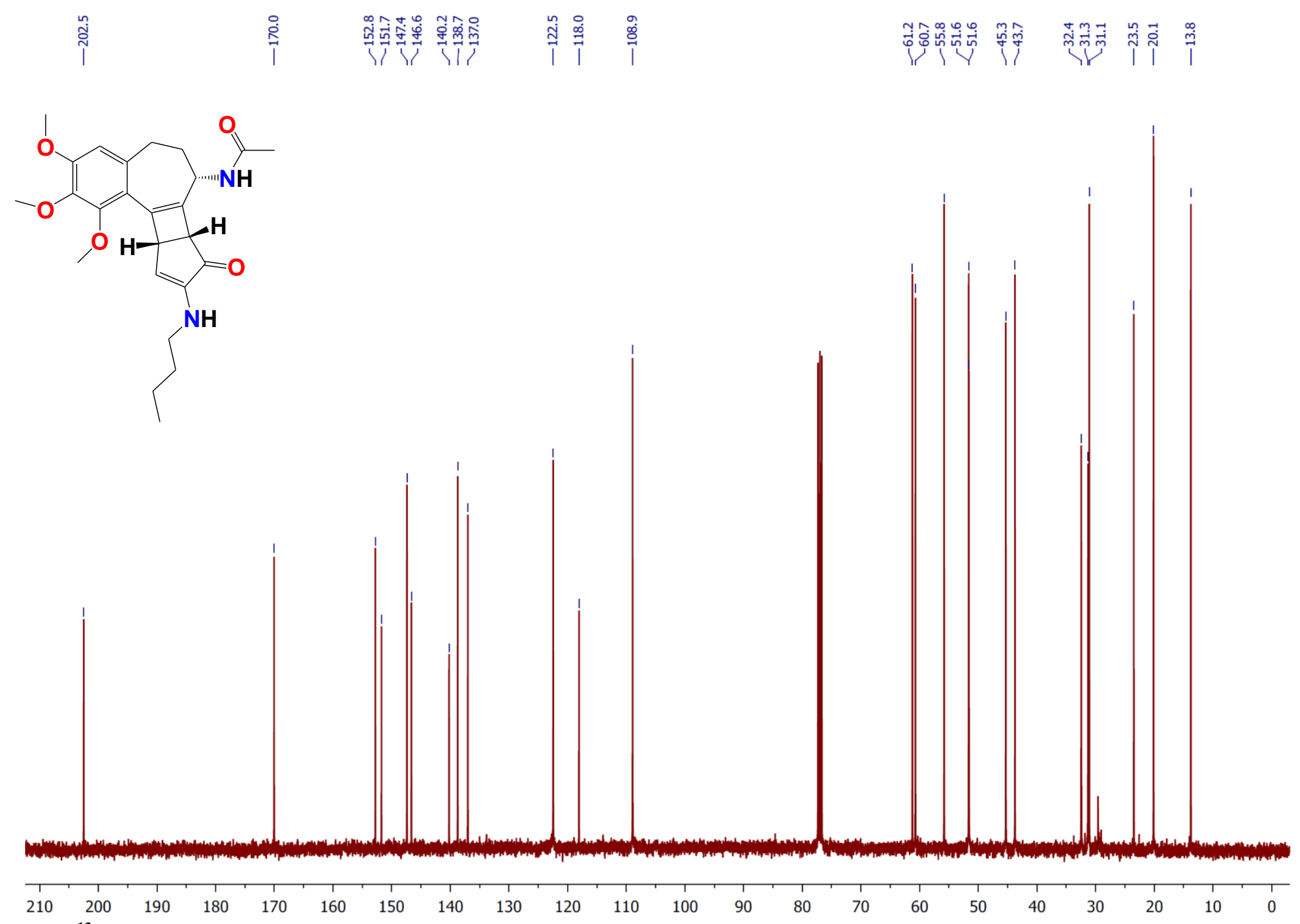

Figure S37. The ${ }^{13} \mathrm{C}(101 \mathrm{MHz}) \mathrm{NMR}$ spectrum of 2-UV in $\mathrm{CDCl}_{3}$. 


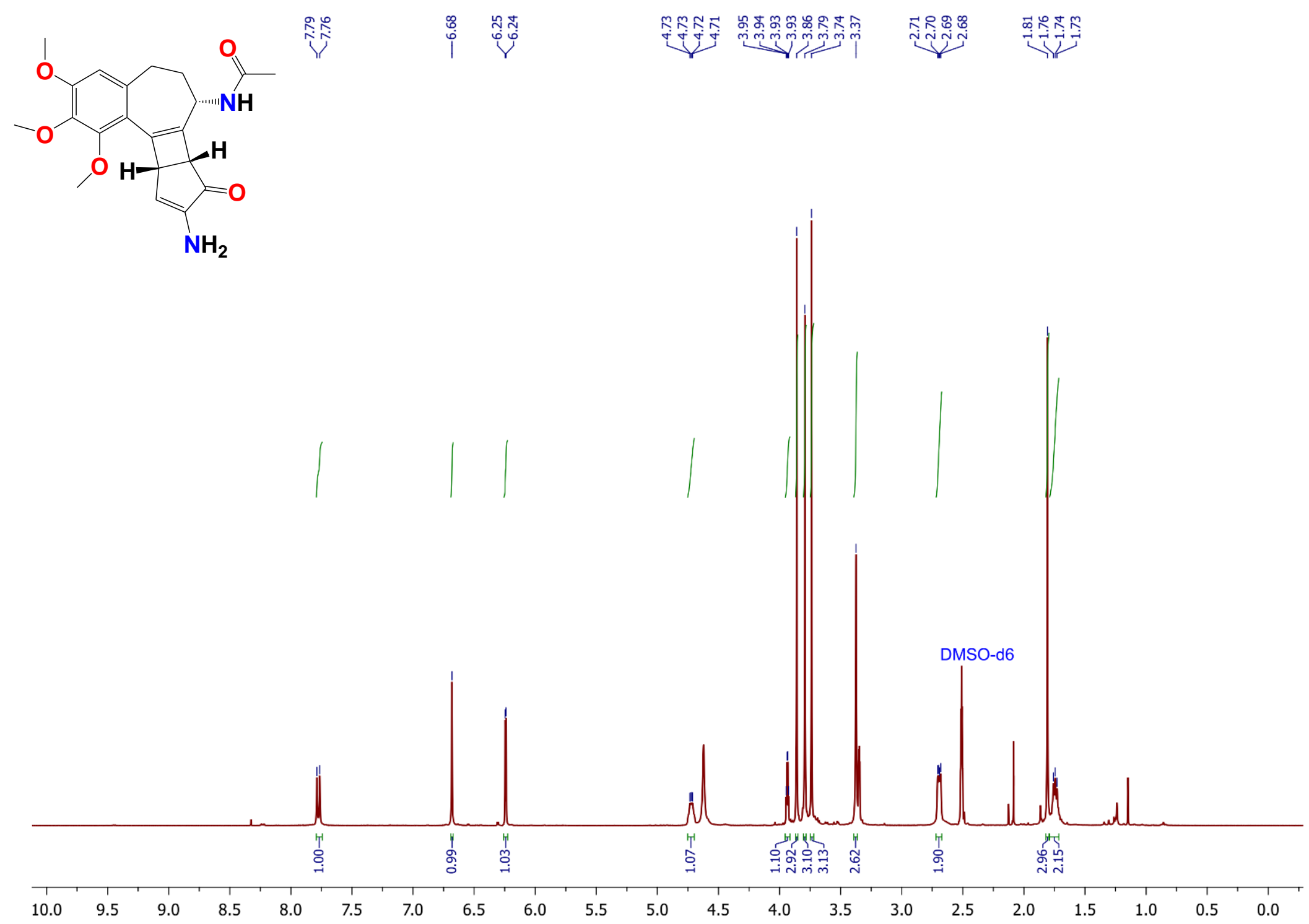

Figure S38. The ${ }^{1} \mathrm{H}$ (400 MHz) NMR spectrum of 3-UV in DMSO-d 6 . 


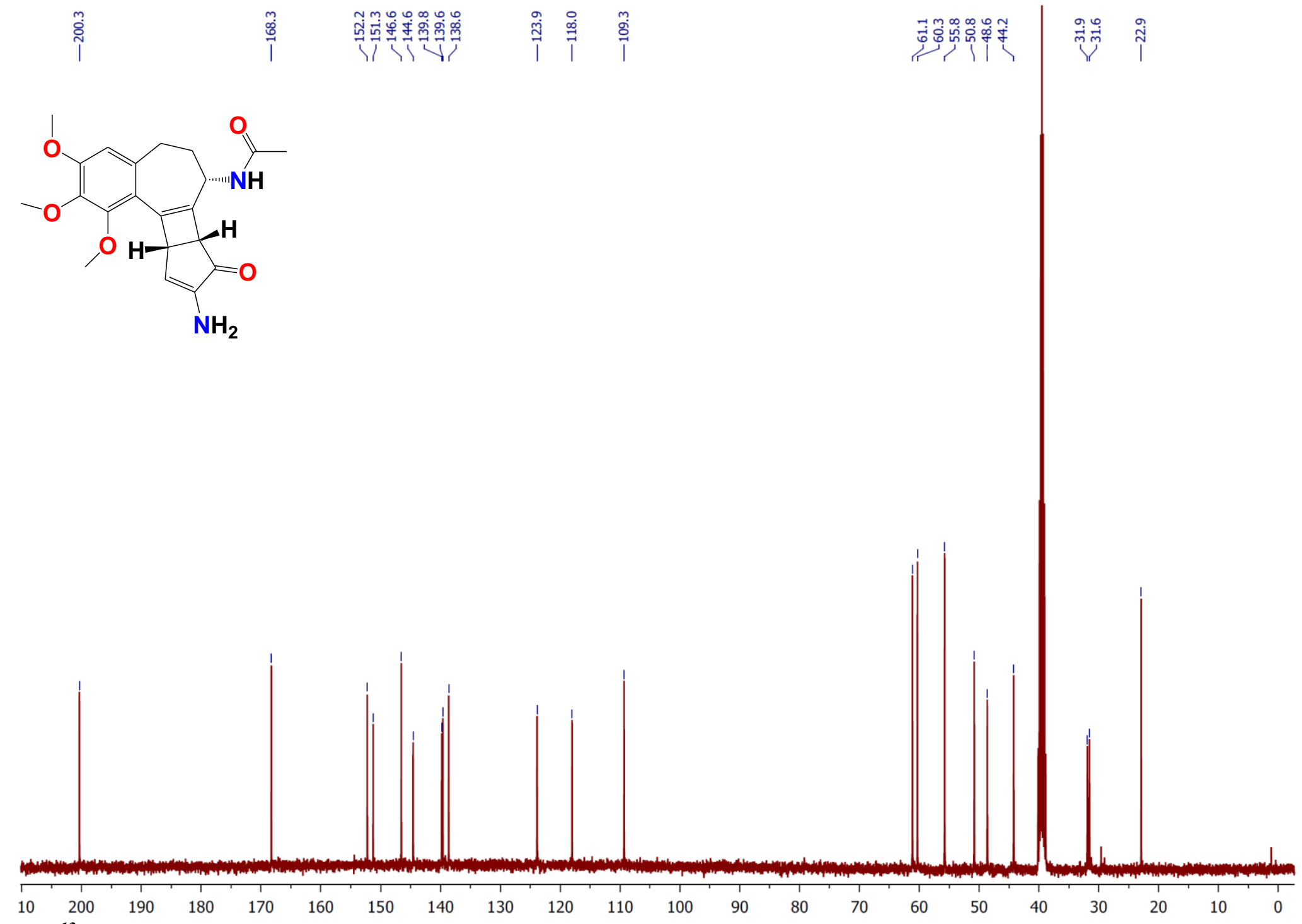

Figure S39. The ${ }^{13} \mathrm{C}(101 \mathrm{MHz})$ NMR spectrum of 3-UV in DMSO-d 6 . 


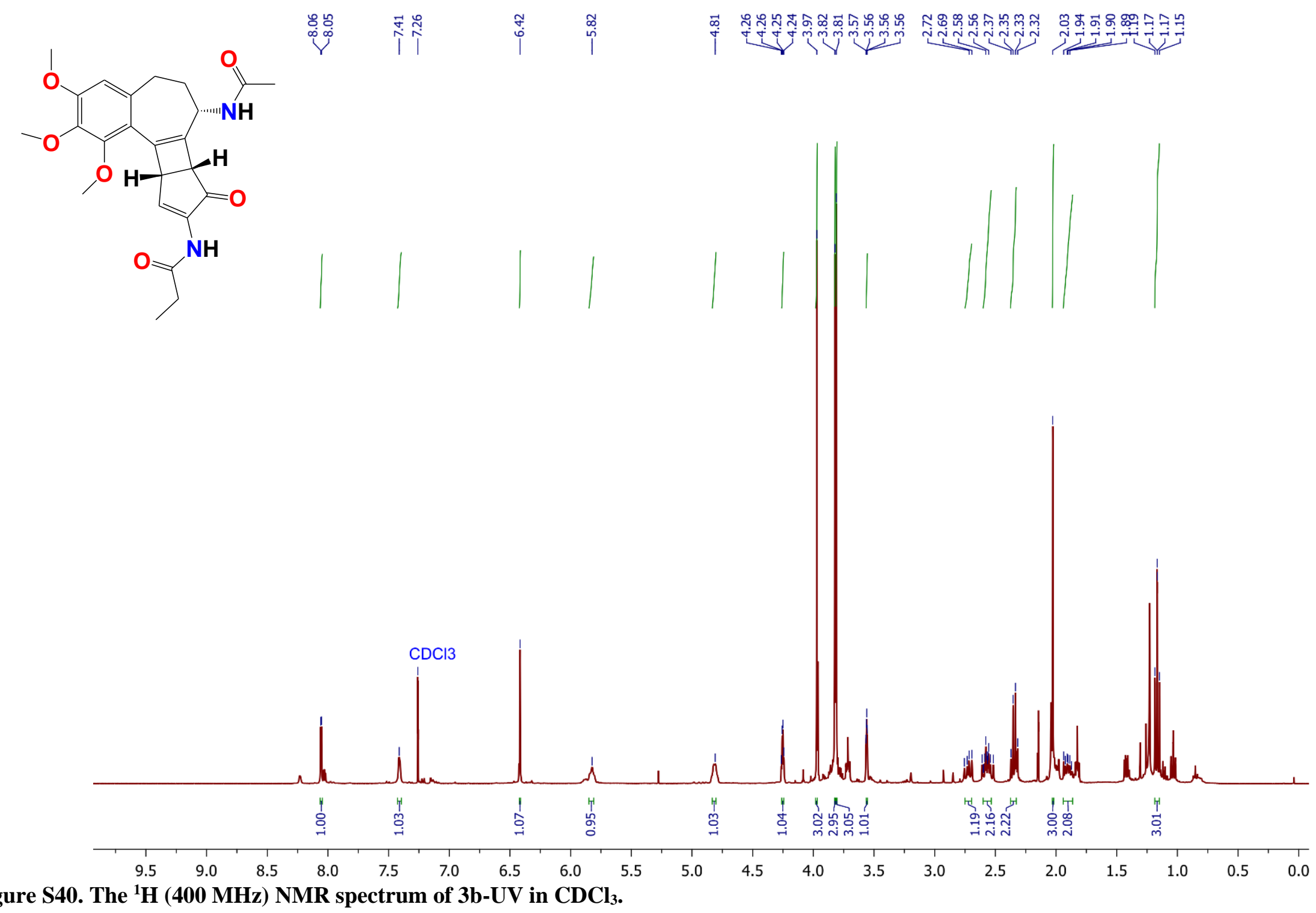

Figure S40. The ${ }^{1} \mathrm{H}$ (400 MHz) NMR spectrum of $3 \mathrm{~b}-\mathrm{UV}$ in $\mathrm{CDCl}_{3}$. 


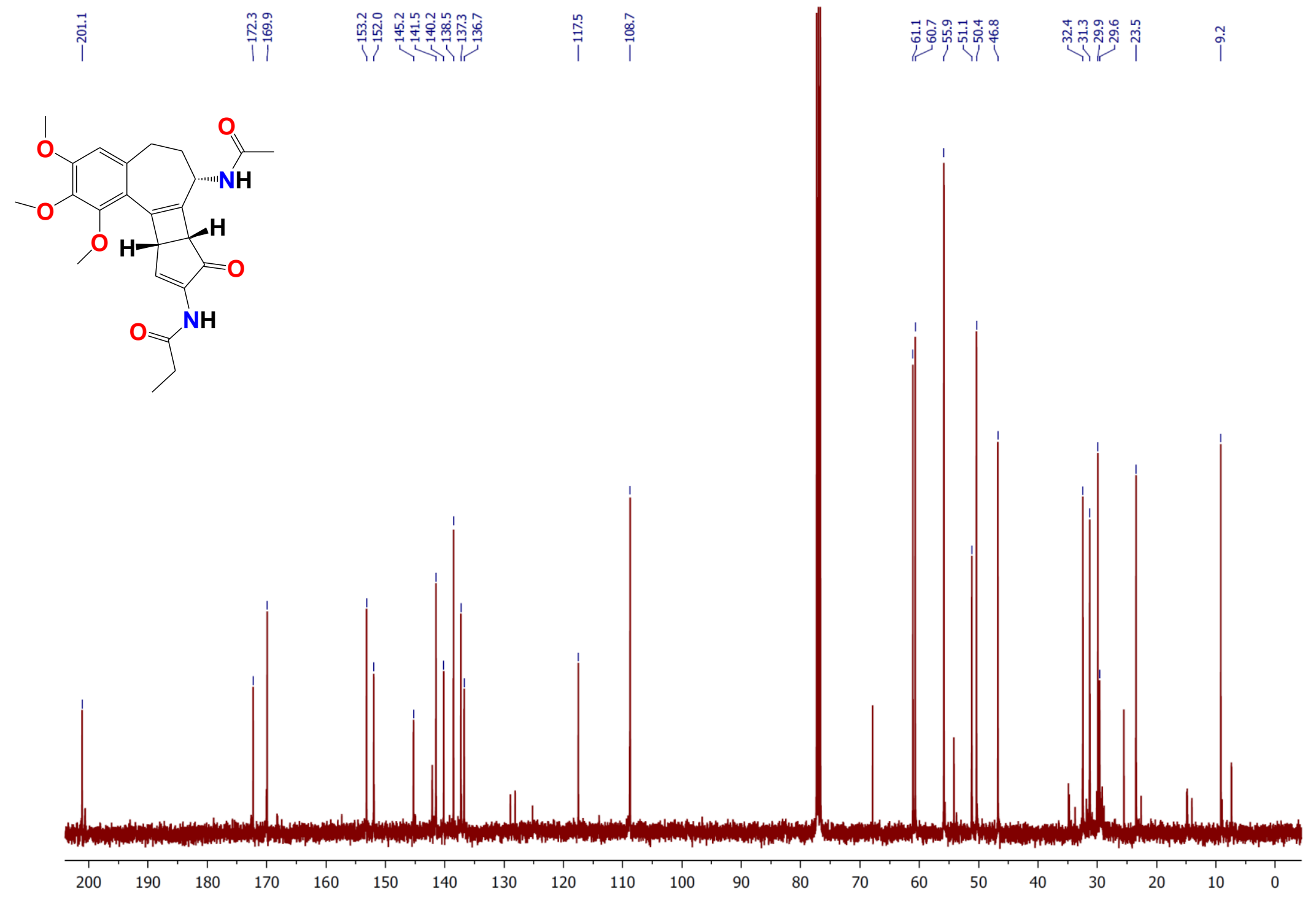

Figure S41. The ${ }^{13} \mathrm{C}(101 \mathrm{MHz}) \mathrm{NMR}$ spectrum of $3 \mathrm{~b}-\mathrm{UV}$ in $\mathrm{CDCl}_{3}$. 


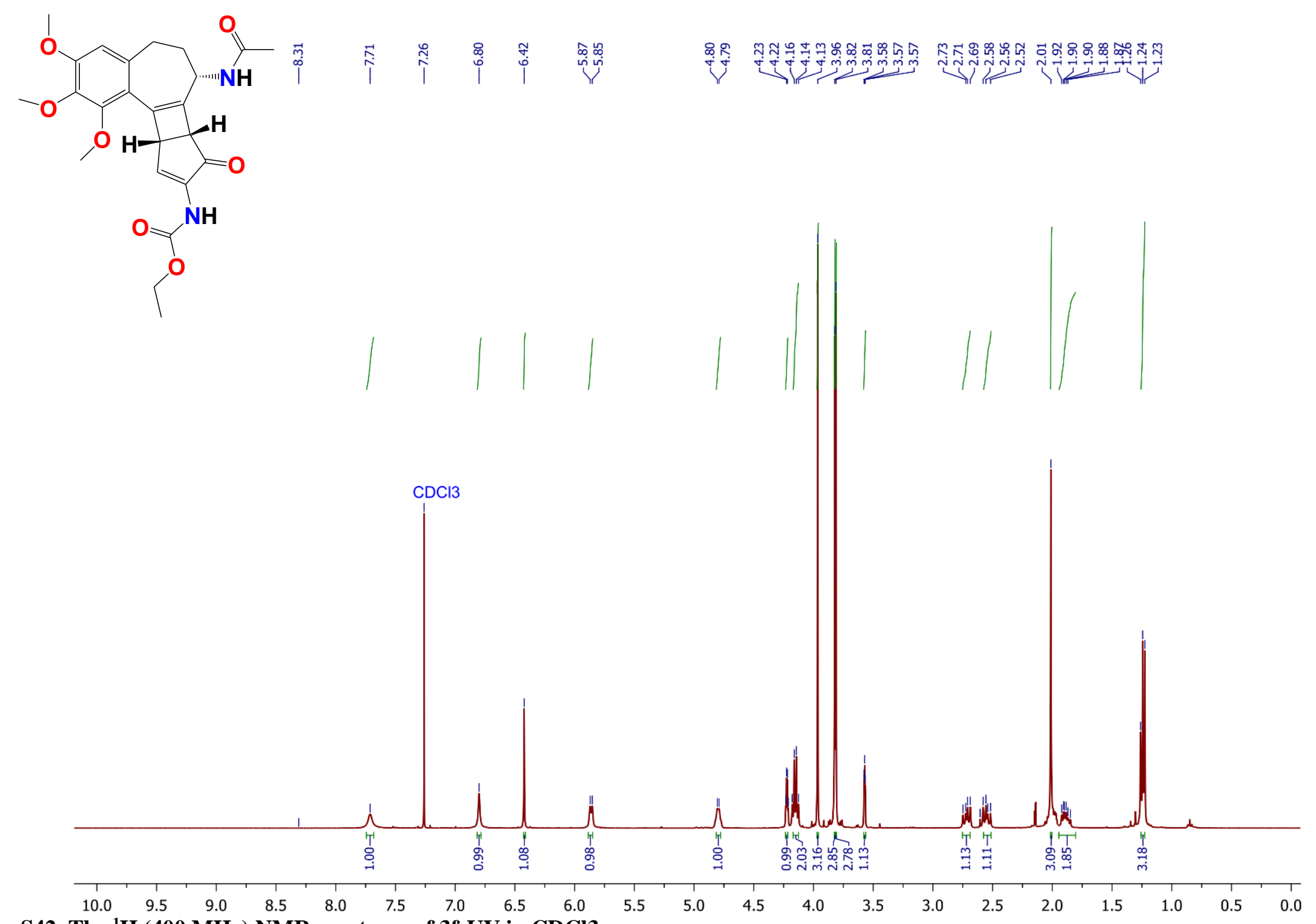

Figure S42. The ${ }^{\mathbf{1}} \mathrm{H}$ (400 MHz) NMR spectrum of $3 \mathrm{f}-\mathrm{UV}$ in CDCl3. 

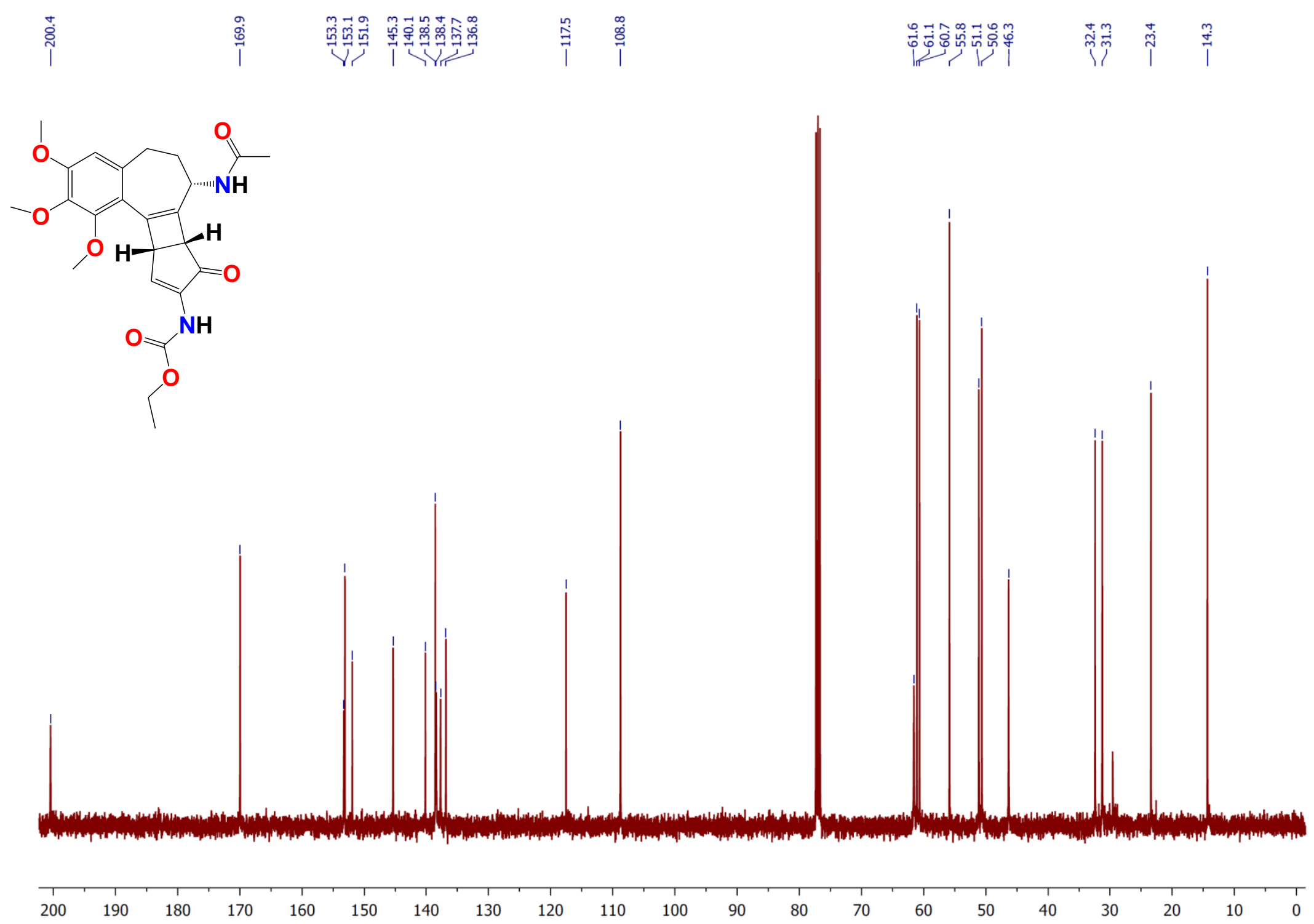

$60 \quad 50$

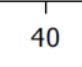

$30 \quad 20$

$10 \quad 0$

Figure S43. The ${ }^{13} \mathrm{C}(101 \mathrm{MHz}) \mathrm{NMR}$ spectrum of $3 f-U V$ in $\mathrm{CDCl}_{3}$. 


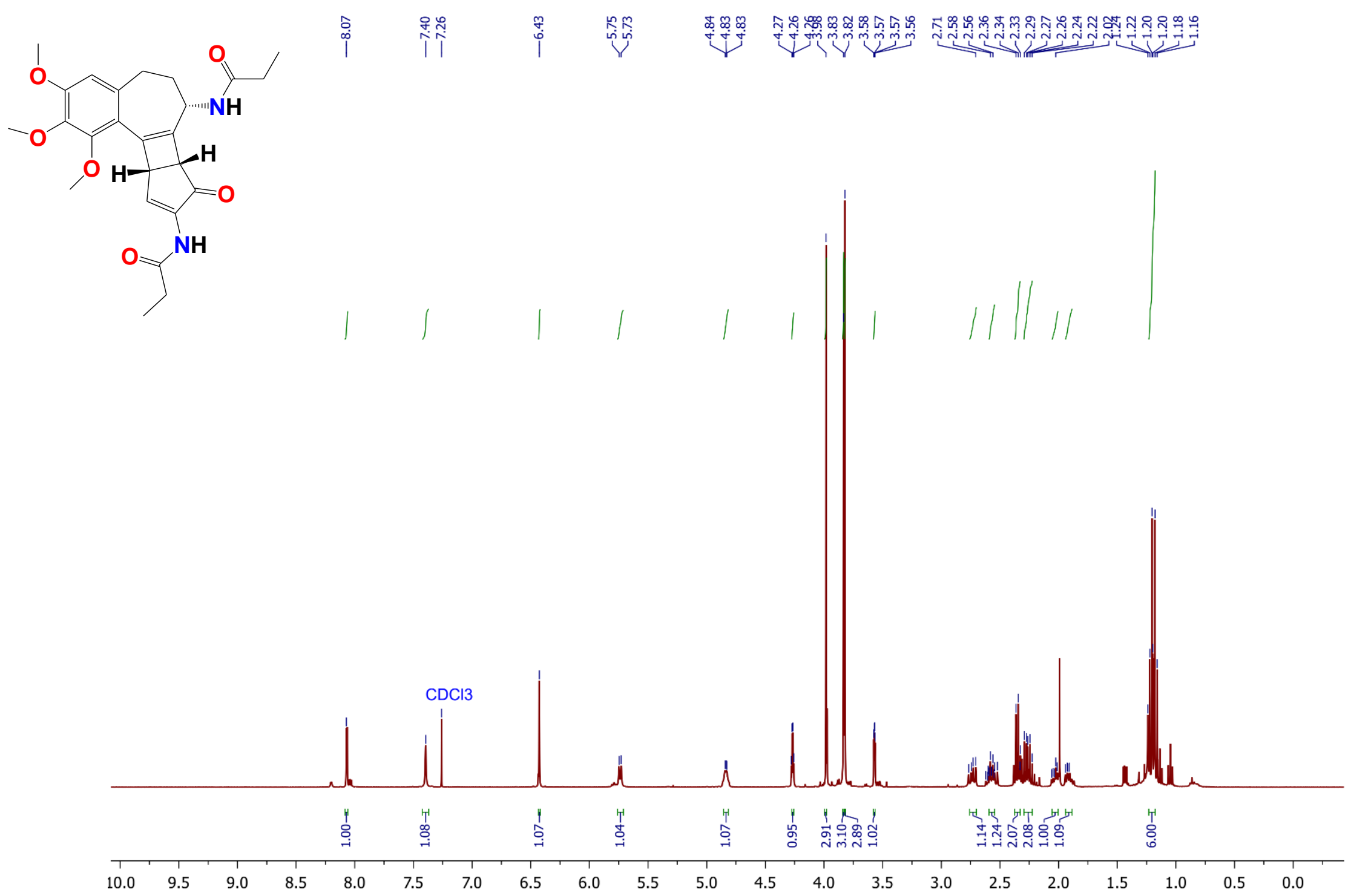

Figure S44. The ${ }^{1} \mathrm{H}(400 \mathrm{MHz})$ NMR spectrum of $4 \mathrm{~b}-\mathrm{UV}$ in $\mathrm{CDCl}_{3}$. 


$$
\text { Inelin }
$$




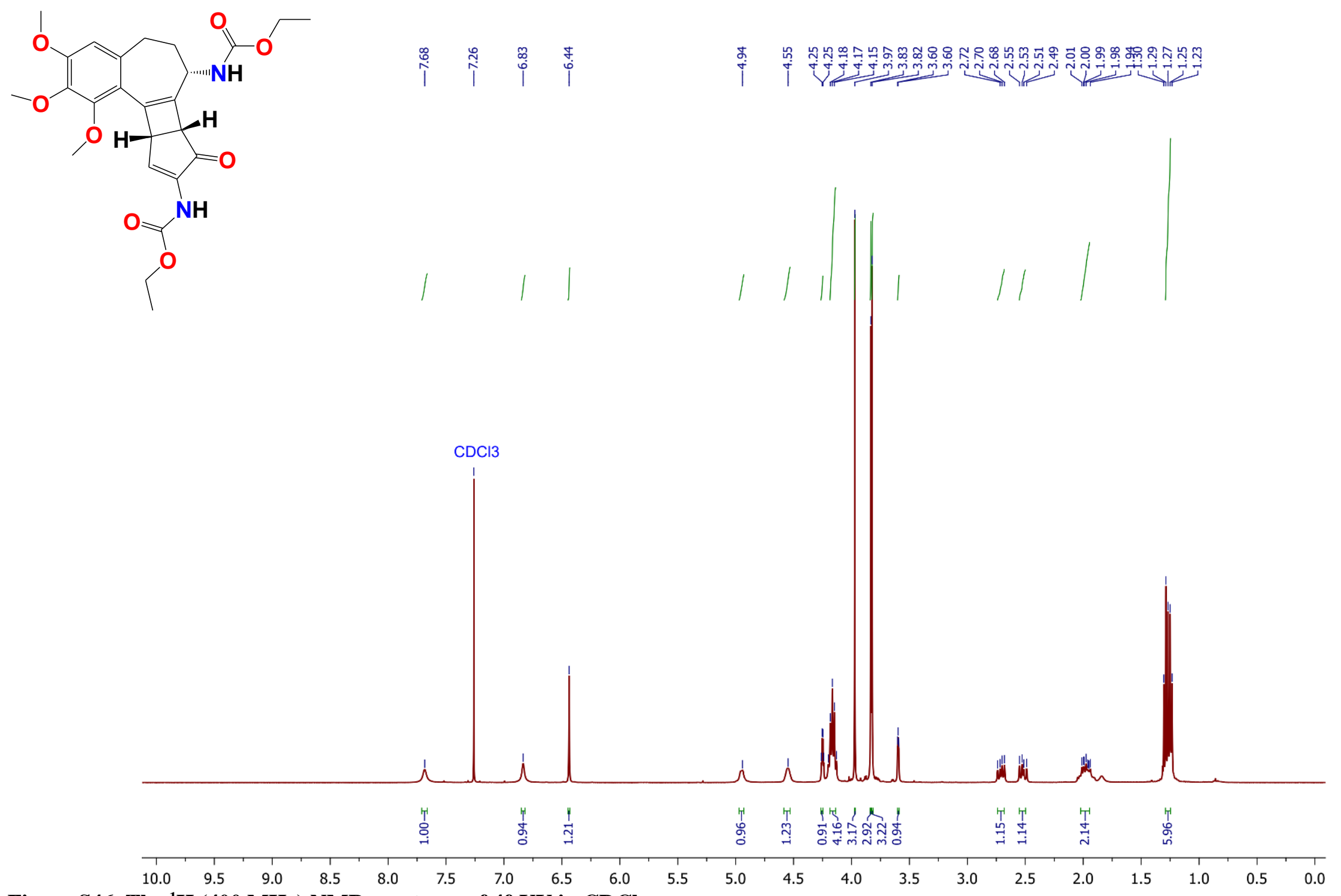

Figure S46. The ${ }^{1} \mathrm{H}(400 \mathrm{MHz}) \mathrm{NMR}$ spectrum of $4 \mathrm{f}-\mathrm{UV}$ in $\mathrm{CDCl}_{3}$. 

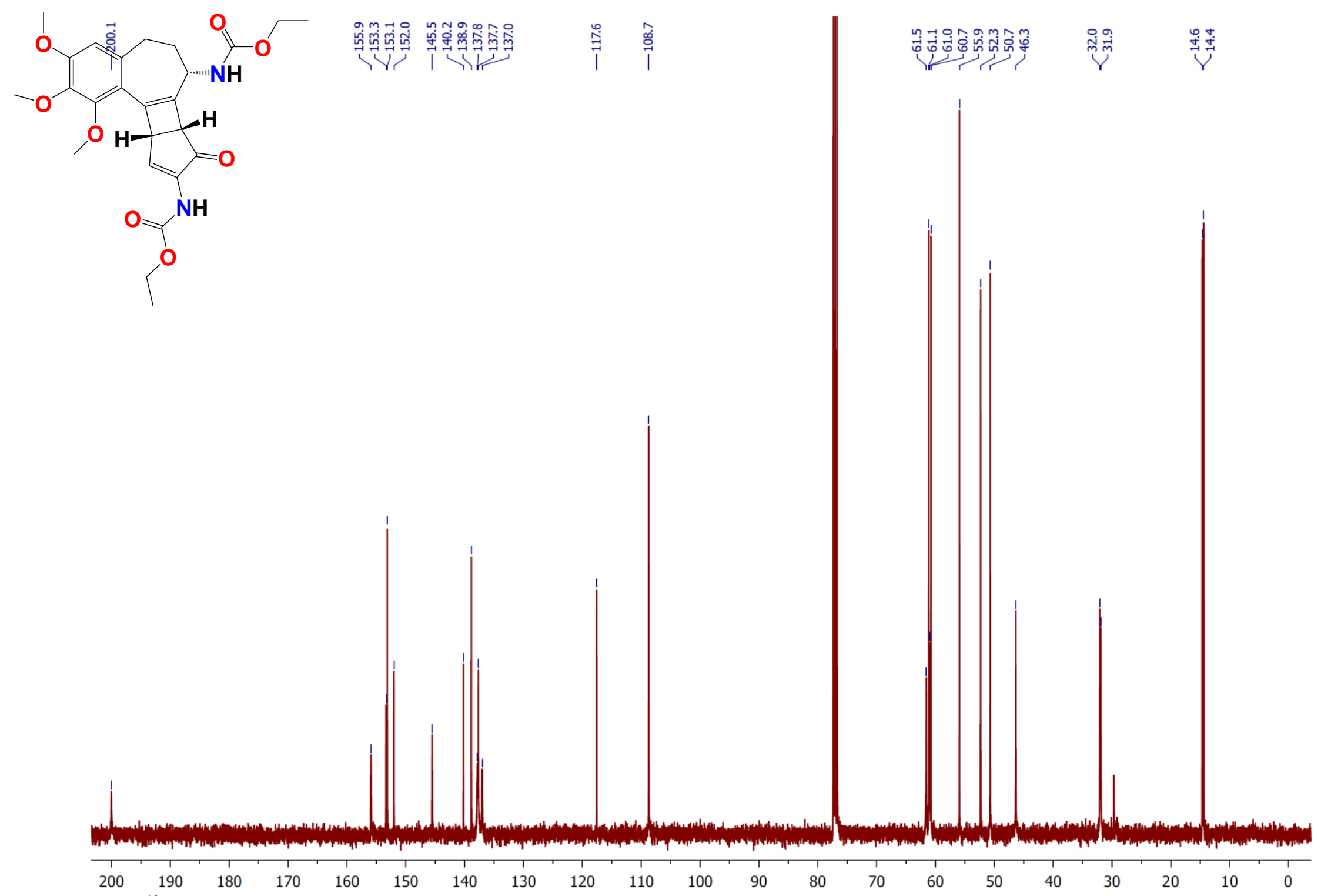

Figure S47. The ${ }^{13} \mathrm{C}(101 \mathrm{MHz}) \mathrm{NMR}$ spectrum of $4 \mathrm{f}-\mathrm{UV}$ in $\mathrm{CDCl}_{3}$ 
2

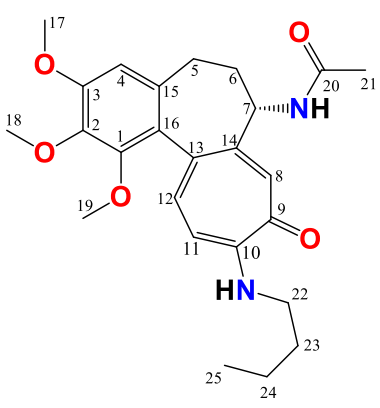

2-UV

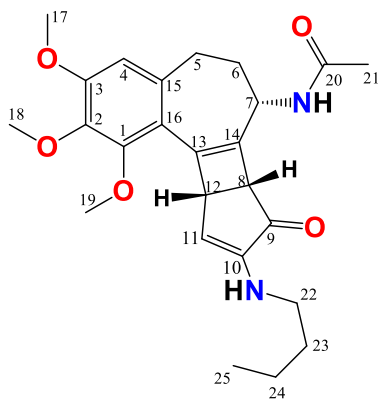

Table S2. The ${ }^{1} \mathbf{H}$ and ${ }^{13} \mathbf{C}$ NMR chemical shifts $\delta$ (ppm) of 2 and 2-UV in chloroform-d, assigned based on 2D NMR.

\begin{tabular}{|c|c|c|c|c|c|c|}
\hline \multirow{2}{*}{$\begin{array}{c}\text { No. } \\
\text { atoms }\end{array}$} & \multicolumn{2}{|l|}{2} & \multicolumn{2}{|l|}{ 2-UV } & \multirow[t]{2}{*}{$\Delta{ }^{1} \mathrm{H}$ NMR } & \multirow[t]{2}{*}{$\Delta{ }^{13} \mathrm{C} \mathrm{NMR}$} \\
\hline & $\delta^{1} \mathrm{H}$ NMR & $\delta^{13} \mathrm{C} \mathrm{NMR}$ & $\delta^{1} \mathrm{H}$ NMR & $\delta^{13} \mathrm{C}$ NMR & & \\
\hline 1 & - & 151.1 & - & 151.7 & - & 0.6 \\
\hline 2 & - & 141.5 & - & 140.2 & - & -1.3 \\
\hline 3 & - & 152.8 & - & 152.8 & - & 0 \\
\hline 4 & $6.53(s, 1 \mathrm{H})$ & 107.1 & $6.45(s, 1 \mathrm{H})$ & 108.9 & -0.08 & 1.8 \\
\hline \multirow[t]{2}{*}{5} & $\begin{array}{l}2.47(d d, J=12.4,5.6 \mathrm{~Hz}, 1 \mathrm{H}) \\
2.41-2.32(m, 1 \mathrm{H})\end{array}$ & 30.1 & $2.72(d d, J=15.3,8.8 \mathrm{~Hz}, 1 \mathrm{H}$ & 32.4 & 0.25 & 1.3 \\
\hline & $2.32-2.21(m, 1 \mathrm{H})$ & 37.2 & $\begin{array}{l}2.56(d d, J=15.3,9.2 \mathrm{~Hz}, 1 \mathrm{H}) \\
2.01-1.86(m, 2 \mathrm{H})\end{array}$ & 31.3 & $\begin{array}{l}0.15 \\
-0.33\end{array}$ & -5.9 \\
\hline 6 & $1.97-1.91(m, 1 \mathrm{H})$ & & & & 0.005 & \\
\hline 7 & $4.74-4.65(m, 1 \mathrm{H})$ & 52.6 & $4.78-4.73(m, 1 \mathrm{H})$ & $51.6^{*}$ & 006 & -1.0 \\
\hline 8 & $7.54(s, 1 \mathrm{H})$ & 122.6 & $4.09(d d, J=5.7,2.9 \mathrm{~Hz}, 1 \mathrm{H})$ & 45.4 & -3.45 & -77.2 \\
\hline 9 & - & 175.5 & - & 202.5 & - & 27.0 \\
\hline 10 & - & 154.3 & - & 147.4 & - & -6.9 \\
\hline 11 & $6.62(d, J=11.3 \mathrm{~Hz}, 1 \mathrm{H})$ & 108.7 & $6.17(d, J=3.3 \mathrm{~Hz}, 1 \mathrm{H})$ & 122.5 & -0.45 & 13.8 \\
\hline 12 & $7.45(d, J=11.2 \mathrm{~Hz}, 1 \mathrm{H})$ & 139.4 & $3.58-3.54(\mathrm{~m}, 1 \mathrm{H})$ & $51.6 *$ & -3.89 & -87.8 \\
\hline 13 & - & 134.6 & - & 146.7 & - & 12.1 \\
\hline 14 & - & 151.0 & - & 137.0 & - & -14.0 \\
\hline 15 & - & 130.3 & - & 138.7 & - & 8.4 \\
\hline 16 & - & 126.8 & - & 118.1 & - & $-8,7$ \\
\hline 17 & $3.89(s, 3 \mathrm{H})$ & 56.1 & $3.84(s, 3 \mathrm{H})$ & 55.8 & -0.05 & -0.3 \\
\hline 18 & $3.94(s, 3 \mathrm{H})$ & 61.4 & $3.86(s, 3 \mathrm{H})$ & 60.7 & -0.08 & -0.7 \\
\hline 19 & $3.62(s, 3 \mathrm{H})$ & 61.3 & $3.95(s, 3 \mathrm{H})$ & 61.3 & 0.33 & 0 \\
\hline 20 & - & 169.9 & - & 170.1 & - & 0.2 \\
\hline 21 & $1.98(s, 3 \mathrm{H})$ & 22.8 & $2.04(s, 3 \mathrm{H})$ & 23.5 & 0.06 & 0.7 \\
\hline 22 & $3.36(t d, J=7.2,5.6 \mathrm{~Hz}, 2 \mathrm{H})$ & 42.5 & $2.92(t, J=7.1 \mathrm{~Hz}, 2 \mathrm{H})$ & 43.8 & -0.44 & 1.3 \\
\hline 23 & $1.81-1.70(m, 2 \mathrm{H})$ & 30.5 & $1.56-1.47(m, 2 \mathrm{H})$ & 31.1 & -0.24 & 0.6 \\
\hline 24 & $1.54-1.43(m, 2 \mathrm{H})$ & 20.3 & $1.41-1.29(m, 2 \mathrm{H})$ & 21.1 & -0.135 & 0.8 \\
\hline 25 & $0.99(t, J=7.3 \mathrm{~Hz}, 3 \mathrm{H})$ & 13.7 & $0.90(t, J=7.3 \mathrm{~Hz}, 3 \mathrm{H})$ & 13.8 & -0.09 & 0.1 \\
\hline
\end{tabular}


IR spectra
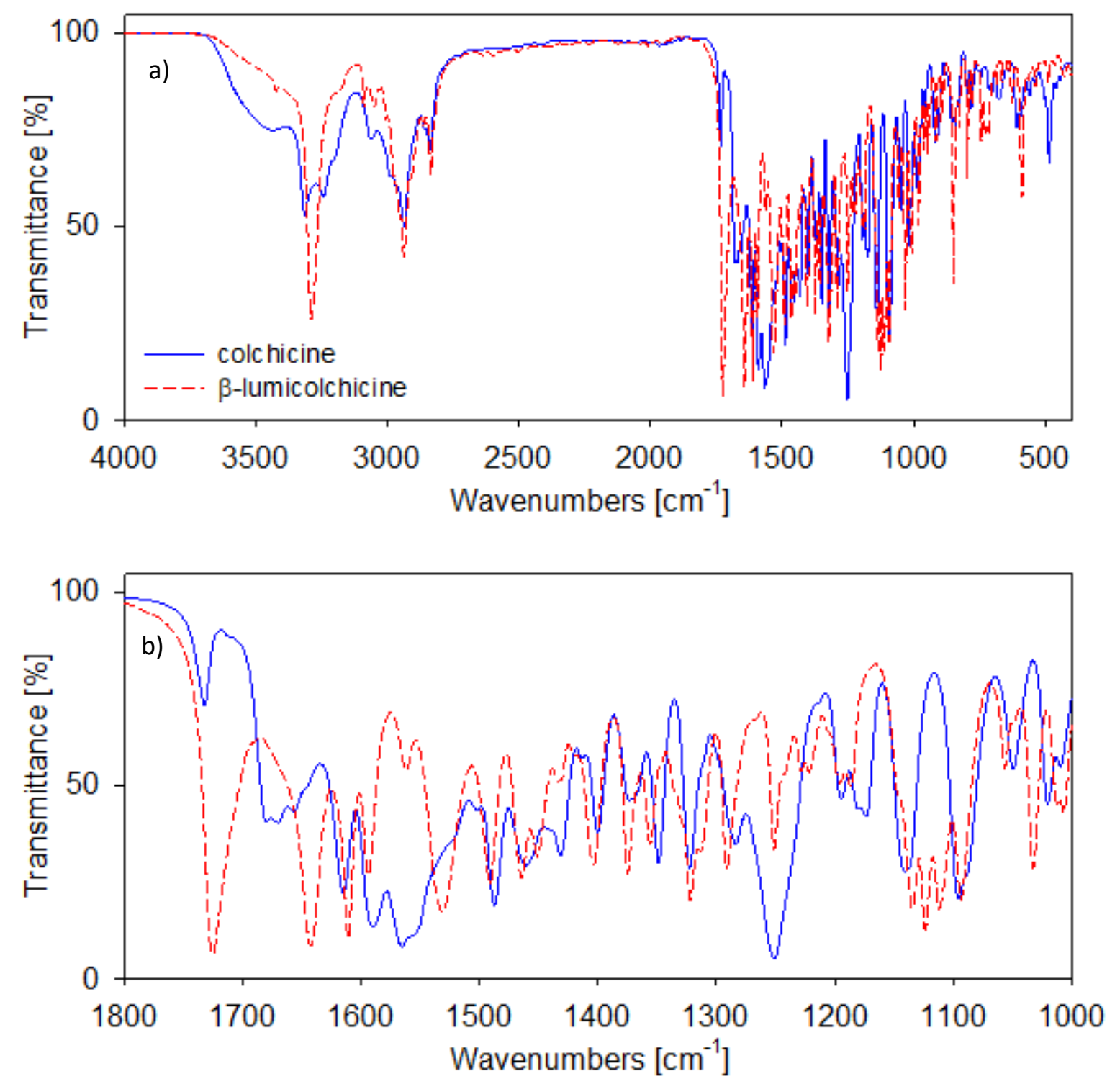

Figure S48. The stacked FT-IR spectra of colchicine (blue solid line) and $\boldsymbol{\beta}$-lumicolchicine (red dashed line) in KBr: (a) 4000-500 $\mathrm{cm}^{-1}$, (b) 1800-1000 $\mathrm{cm}^{-1}$. 

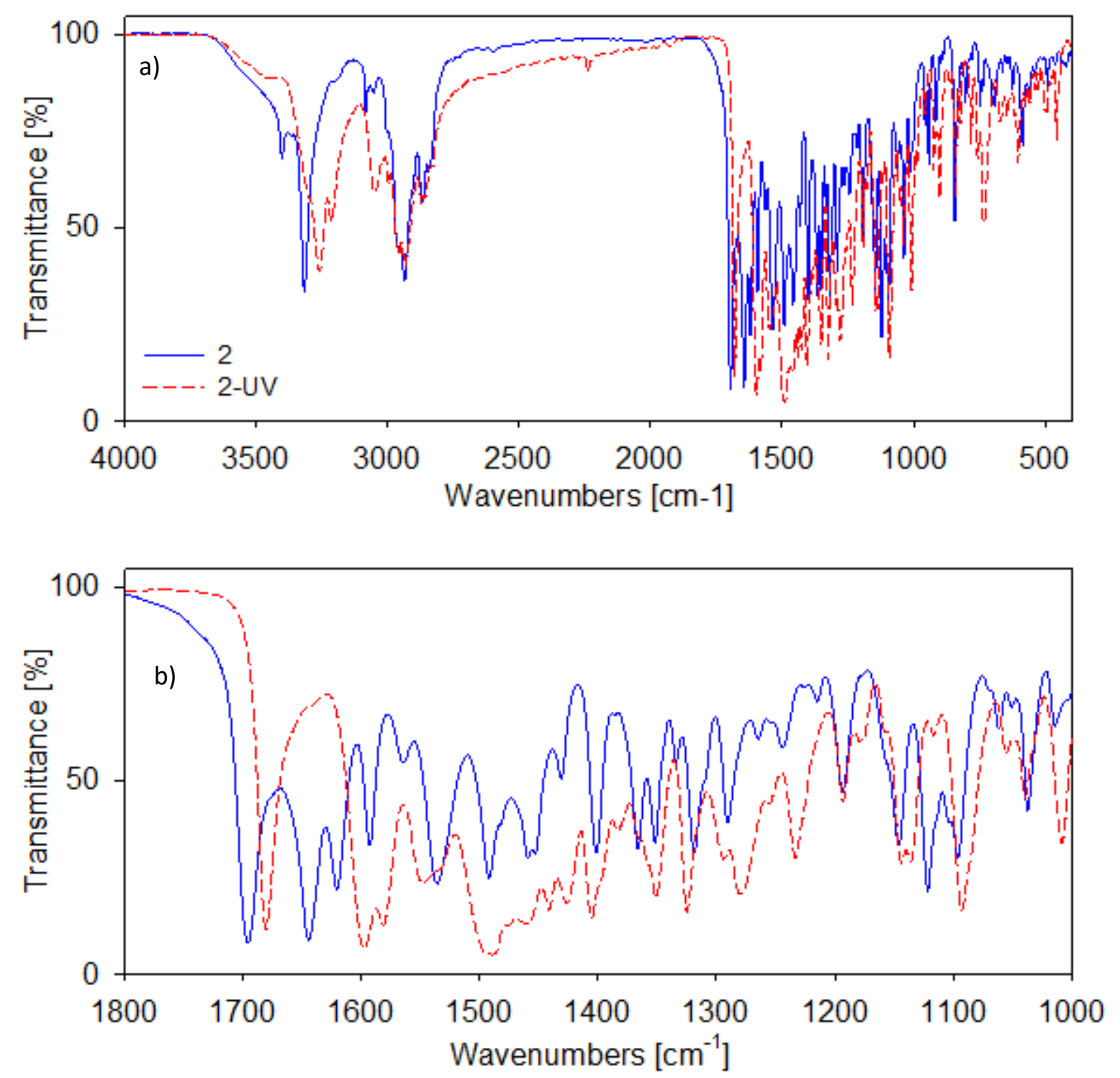

Figure S49. The stacked FT-IR spectra of 2 (blue solid line) and 2-UV (red dashed line) in KBr: (a) $4000-500 \mathrm{~cm}^{-1}$, (b) $1800-1000 \mathrm{~cm}^{-1}$. 

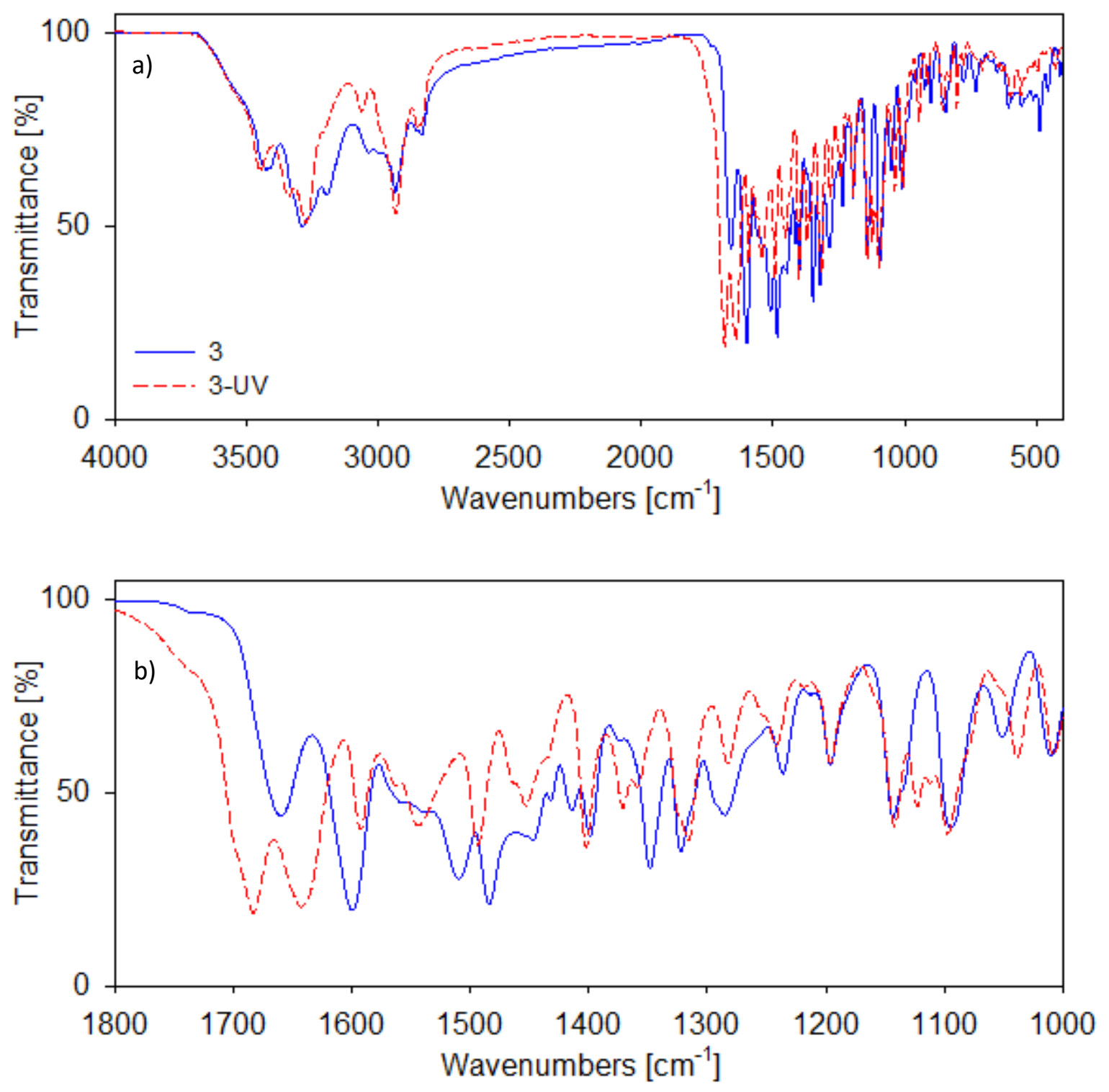

Figure S50. The stacked FT-IR spectra of 3 (blue solid line) and 3-UV (red dashed line) in KBr: (a) $4000-500 \mathrm{~cm}^{-1}$, (b) $1800-1000 \mathrm{~cm}^{-1}$. 

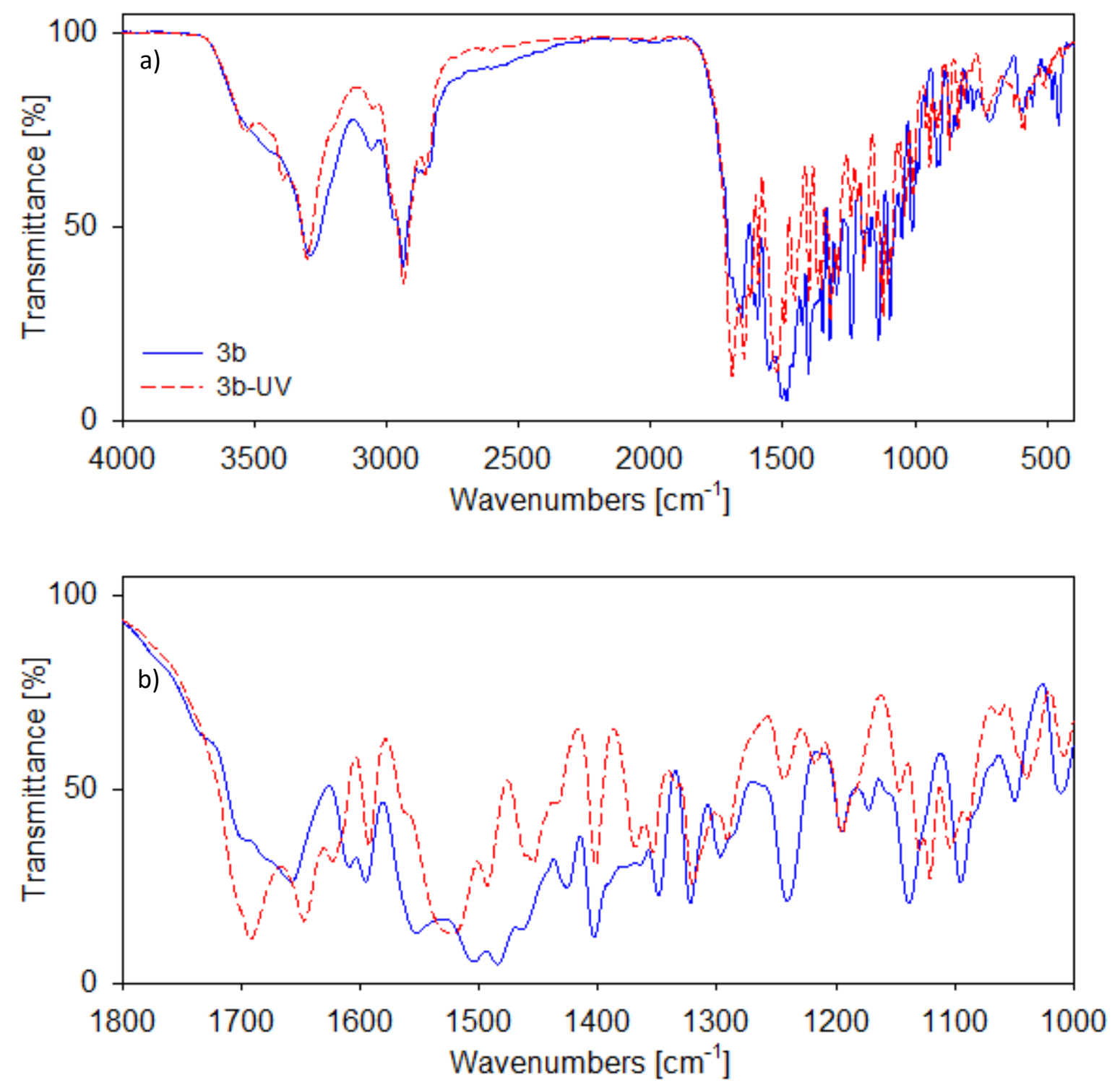

Figure S51. The stacked FT-IR spectra of 3b (blue solid line) and 3b-UV (red dashed line) in KBr: (a) 4000-500 $\mathrm{cm}^{-1}$, (b) $1800-1000 \mathrm{~cm}^{-1}$. 

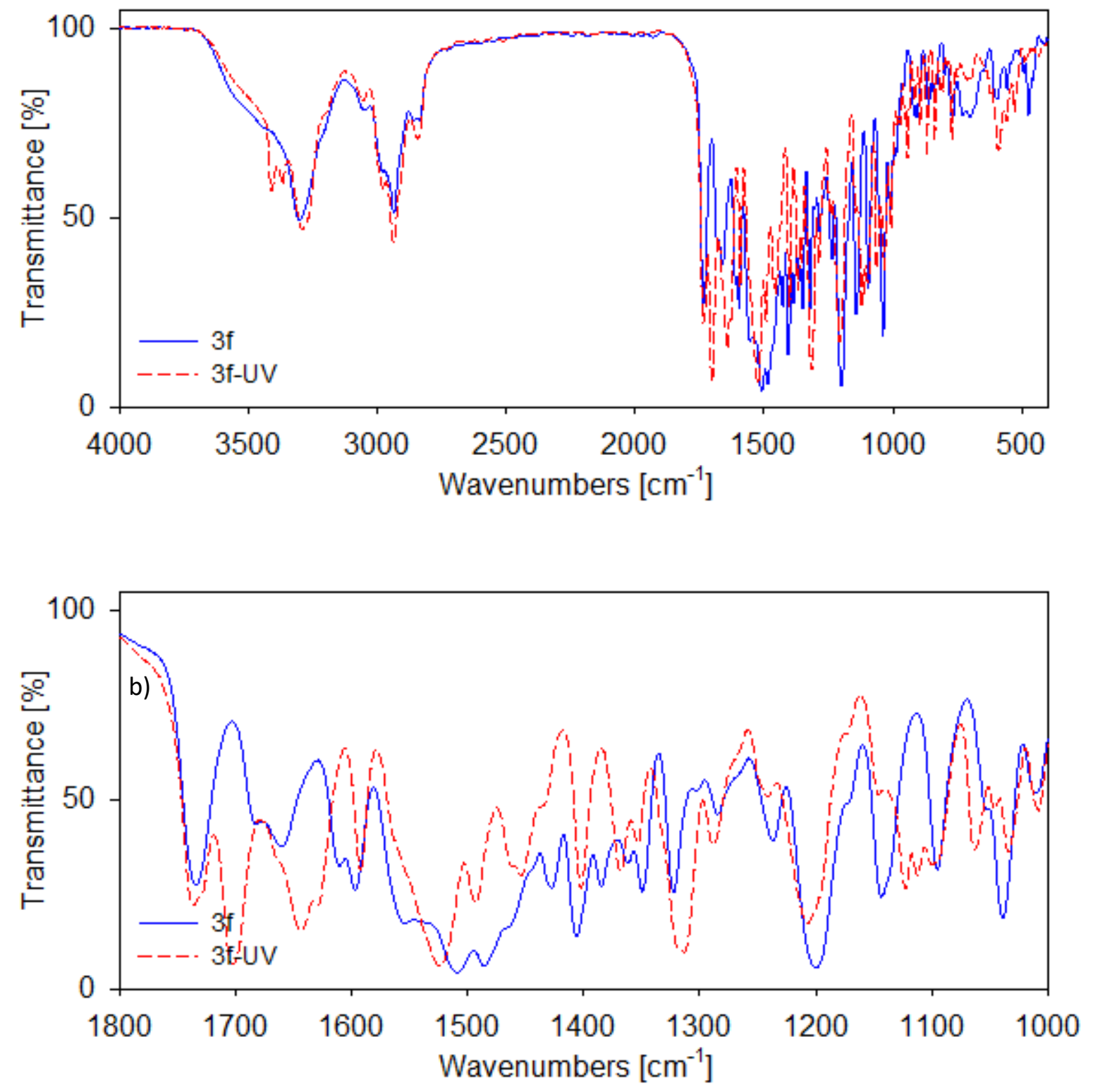

Figure S52. The stacked FT-IR spectra of $3 \mathrm{f}$ (blue solid line) and 3f-UV (red dashed line) in KBr: (a) $4000-500 \mathrm{~cm}^{-1}$, (b) $1800-1000 \mathrm{~cm}^{-1}$. 

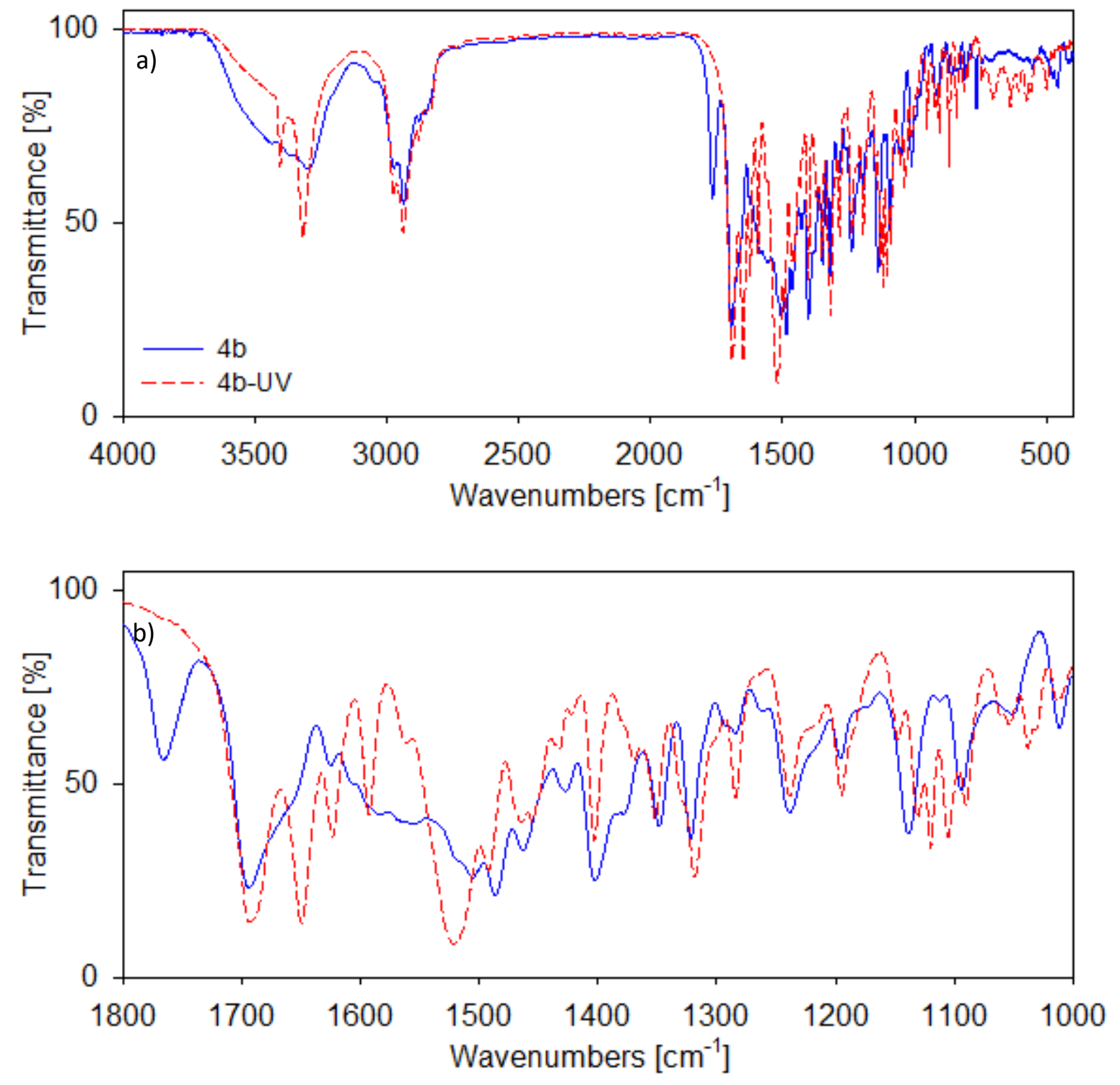

Figure S53. The stacked FT-IR spectra of $4 \mathrm{~b}$ (blue solid line) and $4 \mathrm{~b}-\mathbf{U V}$ (red dashed line) in KBr: (a) 4000-500 $\mathrm{cm}^{-1}$, (b) 1800-1000 $\mathrm{cm}^{-1}$. 

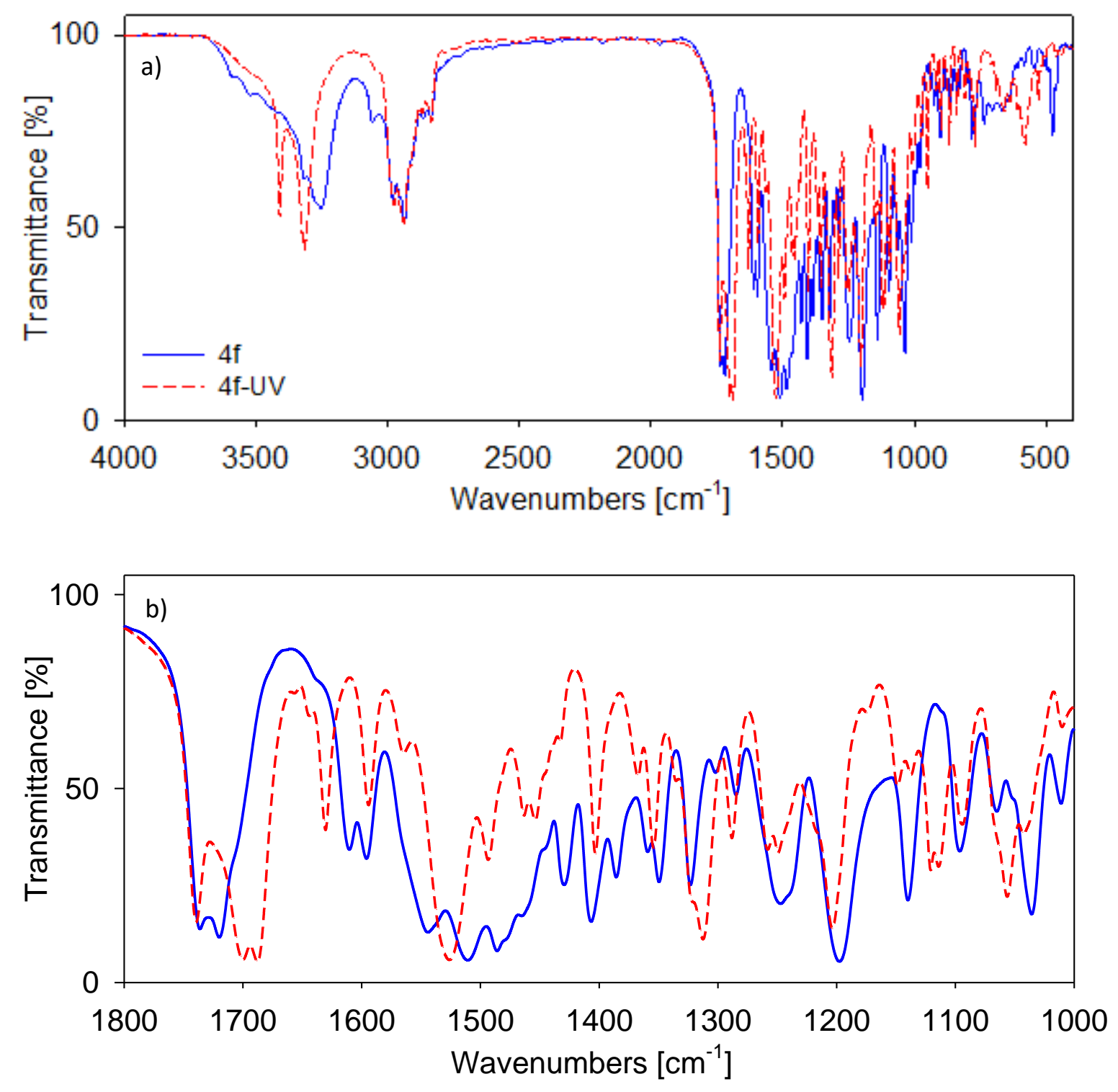

Figure S54. The stacked FT-IR spectra of $4 \mathrm{f}$ (blue solid line) and $4 \mathrm{f}-\mathrm{UV}$ (red dashed line) in KBr: (a) $4000-500 \mathrm{~cm}^{-1}$, (b) $1800-1000 \mathrm{~cm}^{-1}$. 


\section{UV-VIS spectra}

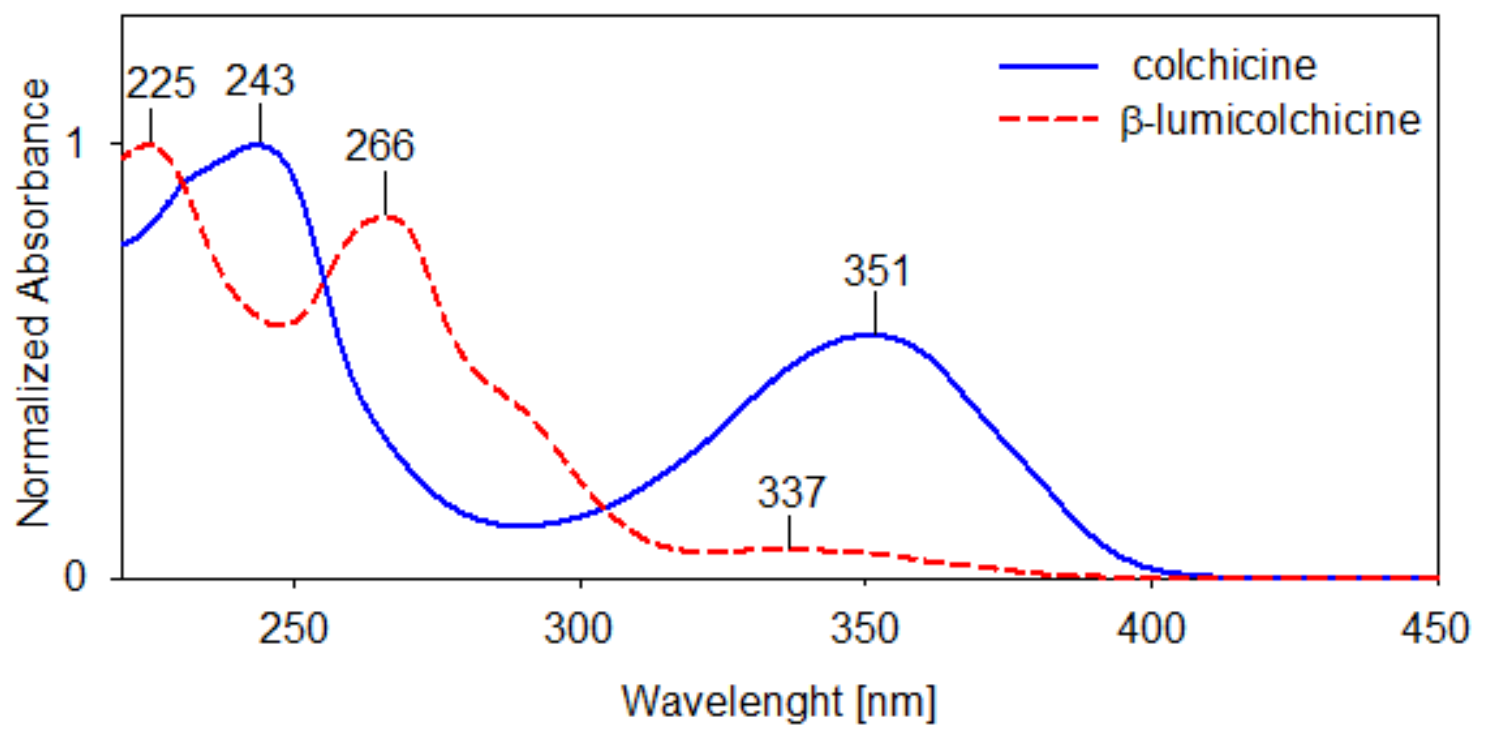

Figure S55. The stacked UV-VIS spectra of colchicine (blue solid line) and $\beta$-lumicolchicine (red dashed line) in methanol.

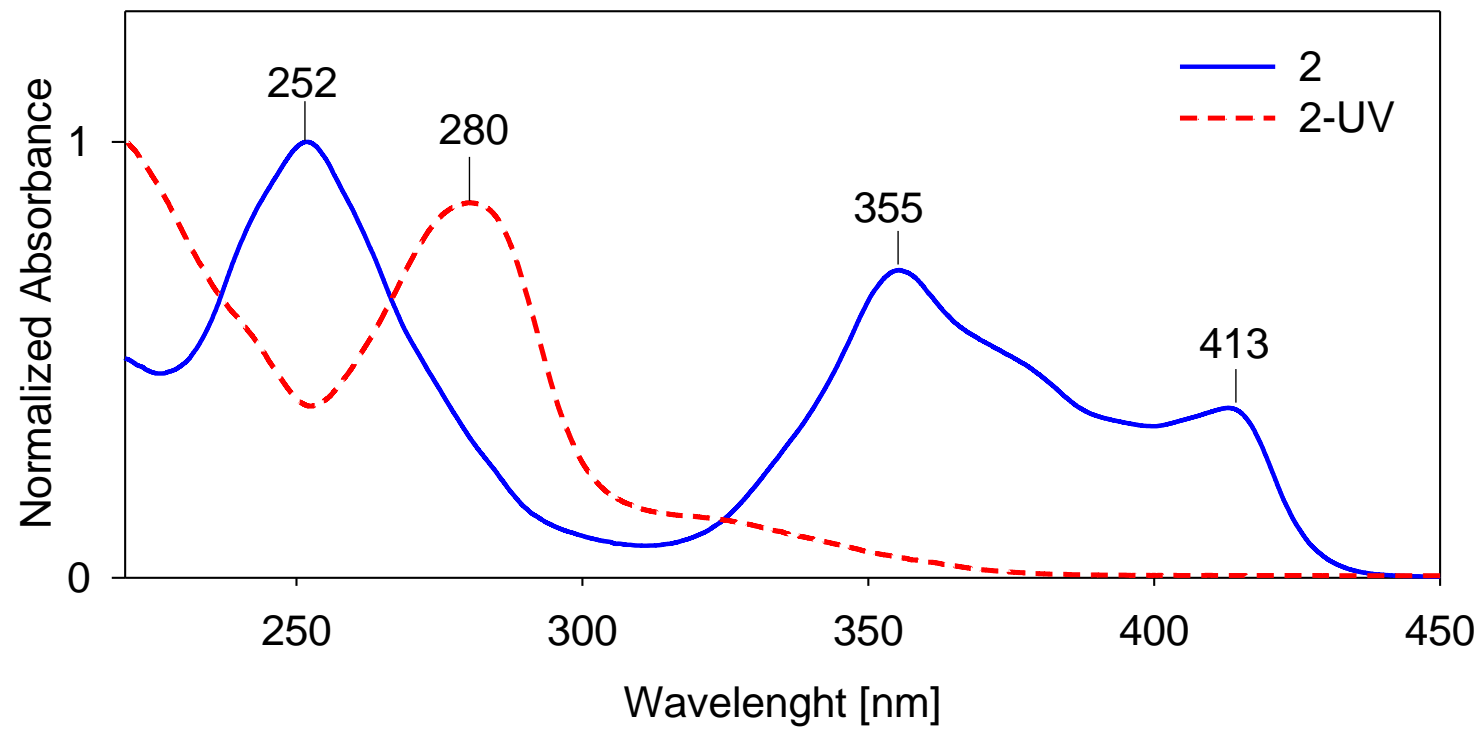

Figure S56. The stacked UV-VIS spectra of 2 (blue solid line) and 2-UV (red dashed line) in methanol. 


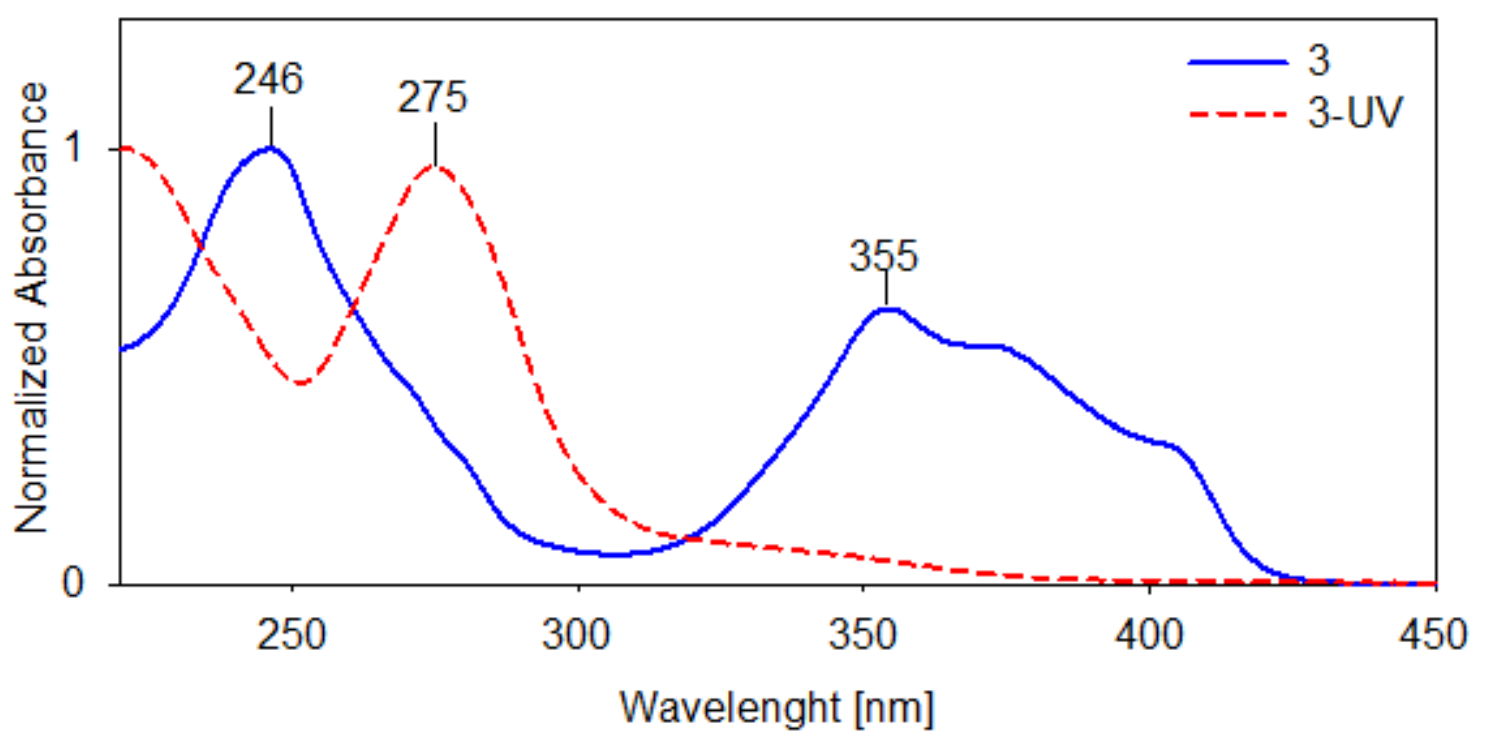

Figure S57. The stacked UV-VIS spectra of 3 (blue solid line) and 3-UV (red dashed line) in methanol.

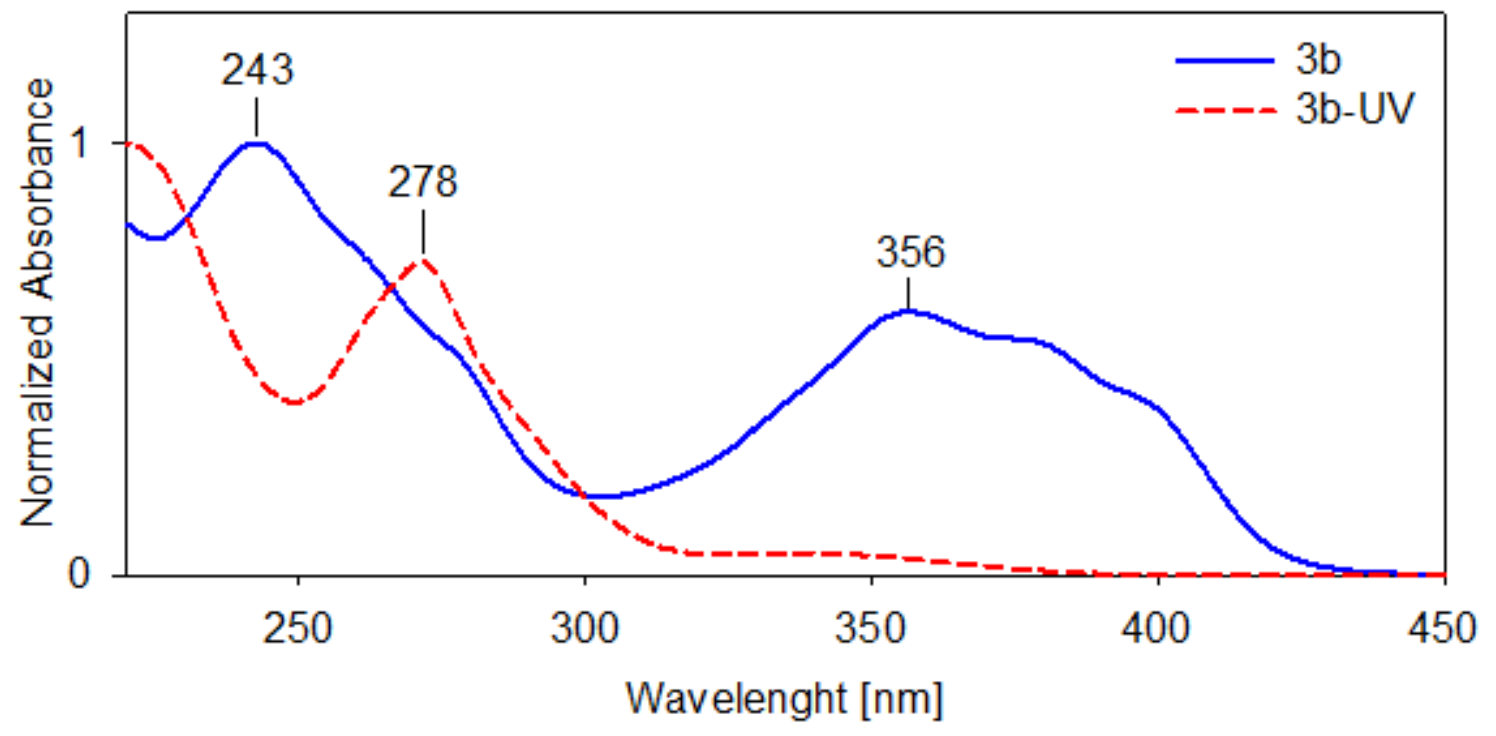

Figure S58. The stacked UV-VIS spectra of $3 b$ (blue solid line) and 3b-UV (red dashed line) in methanol. 


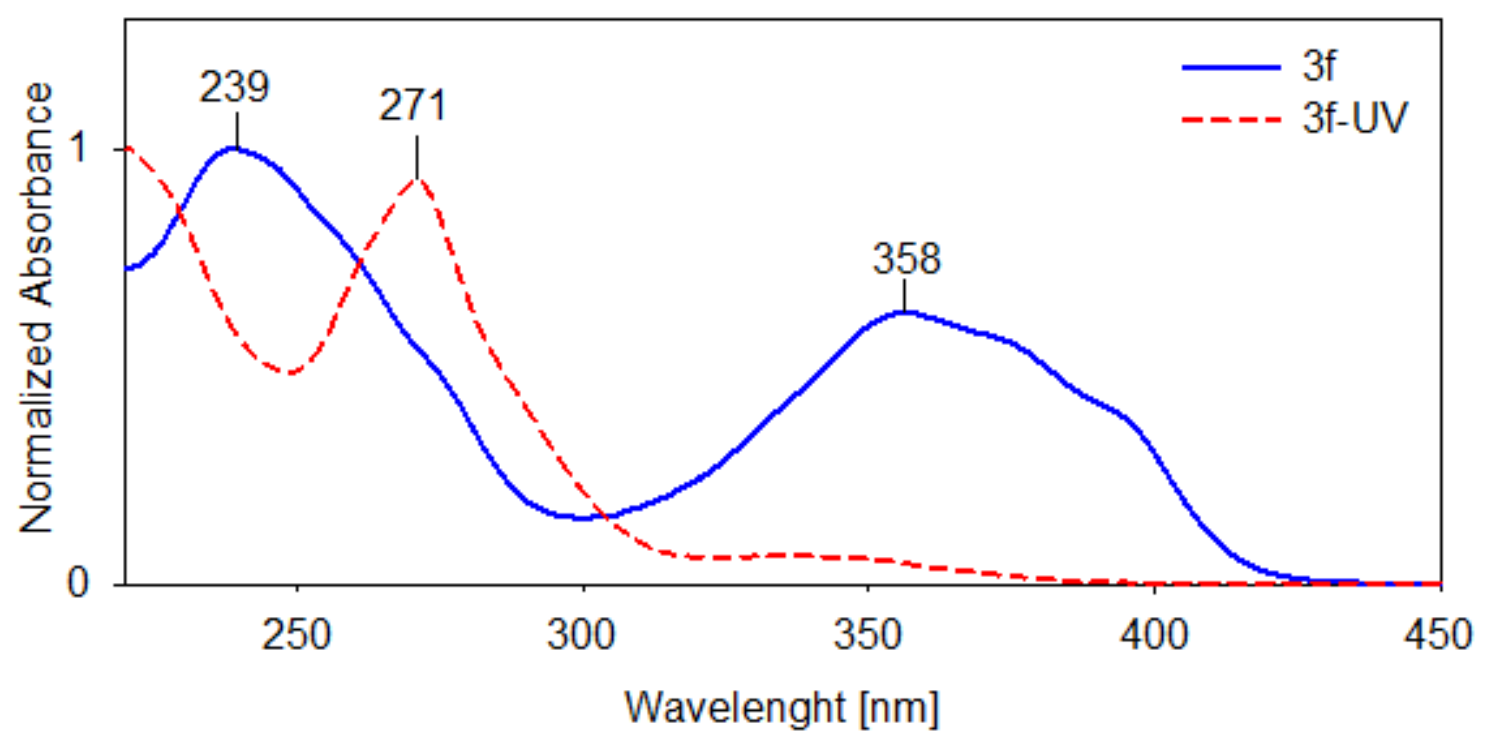

Figure S59. The stacked UV-VIS spectra of $3 f$ (blue solid line) and 3f-UV (red dashed line) in methanol.

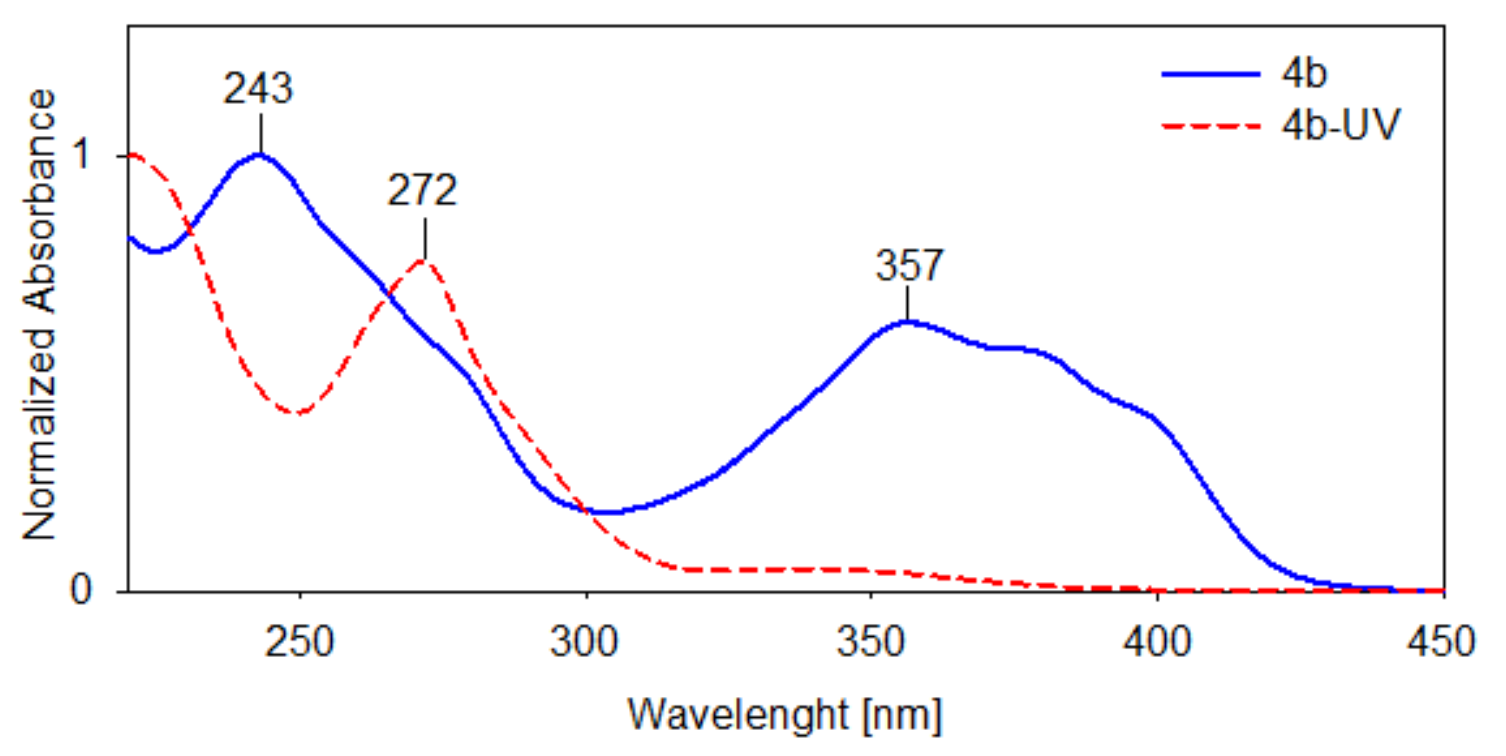

Figure S60. The stacked UV-VIS spectra of $4 \mathrm{~b}$ (blue solid line) and 4b-UV (red dashed line) in methanol. 


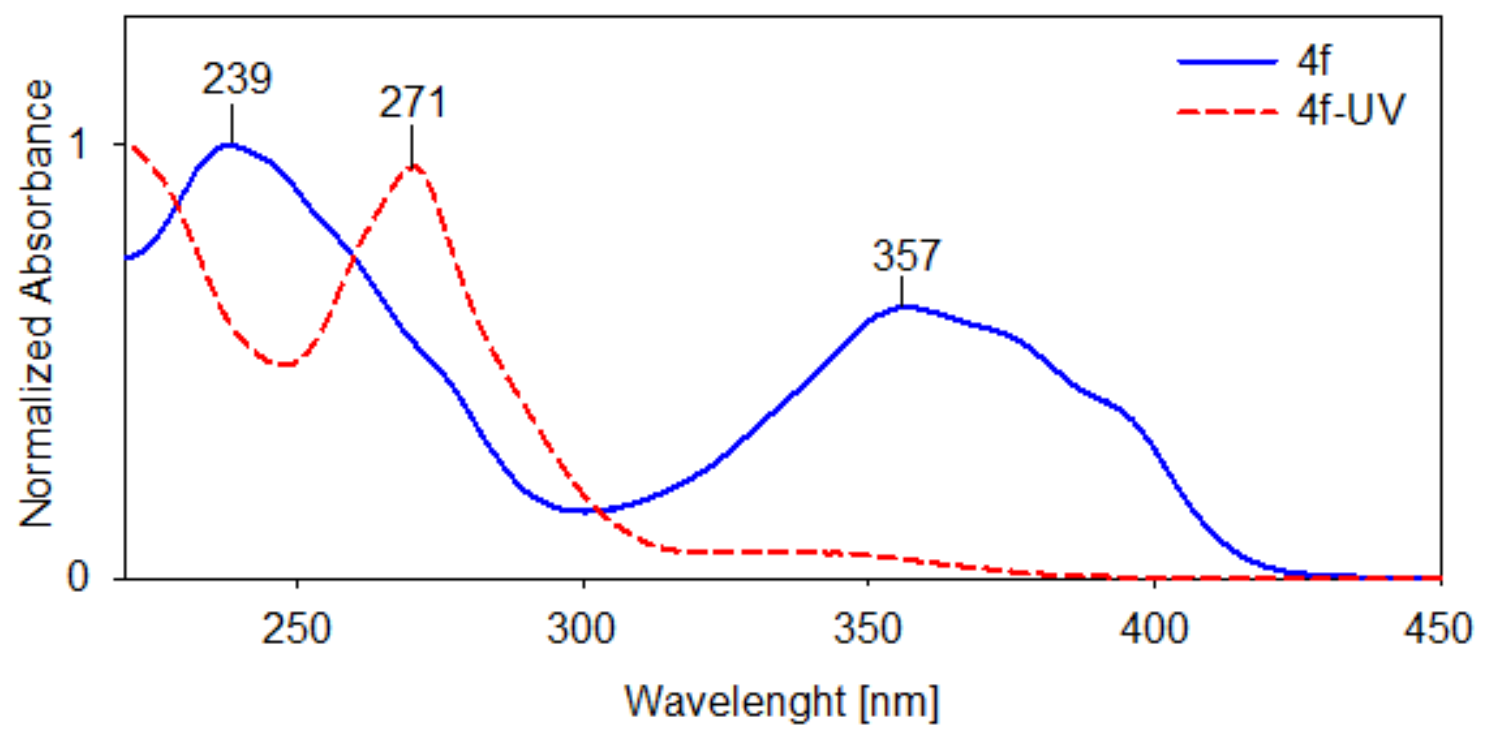

Figure S61. The stacked UV-VIS spectra of $4 \mathrm{f}$ (blue solid line) and 4f-UV (red dashed line) in methanol. 


\section{Photoreaction Setup}

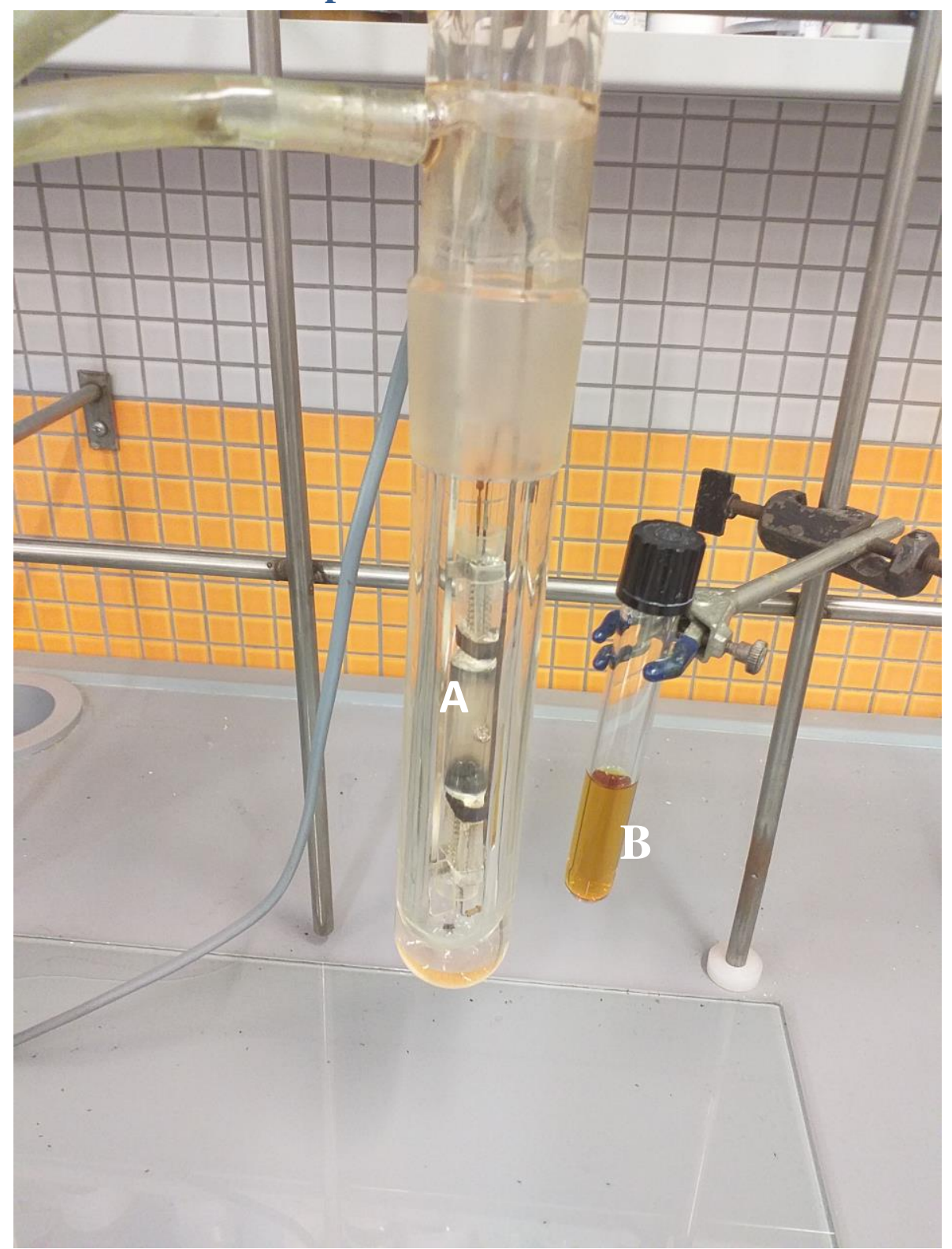

Figure S62. Photograph of a photoreaction setup. Reaction was carried out using a cylindrical photoreactor with an internal radiation source, equipped with a medium-pressure mercury lamp TQ 150W (Heraeus, Hanau, Germany), placed inside a cylindrical filter made of pyrex glass with a wall thickness of $1.5 \mathrm{~mm}$ (A). The lamp with the filter was inside a quartz glass cooler and was cooled with water. A solution of starting material was irradiated in Pyrex glass tube (B). During irradiation the whole setup was wrapped with aluminum foil and the irradiated solution was stirred. 


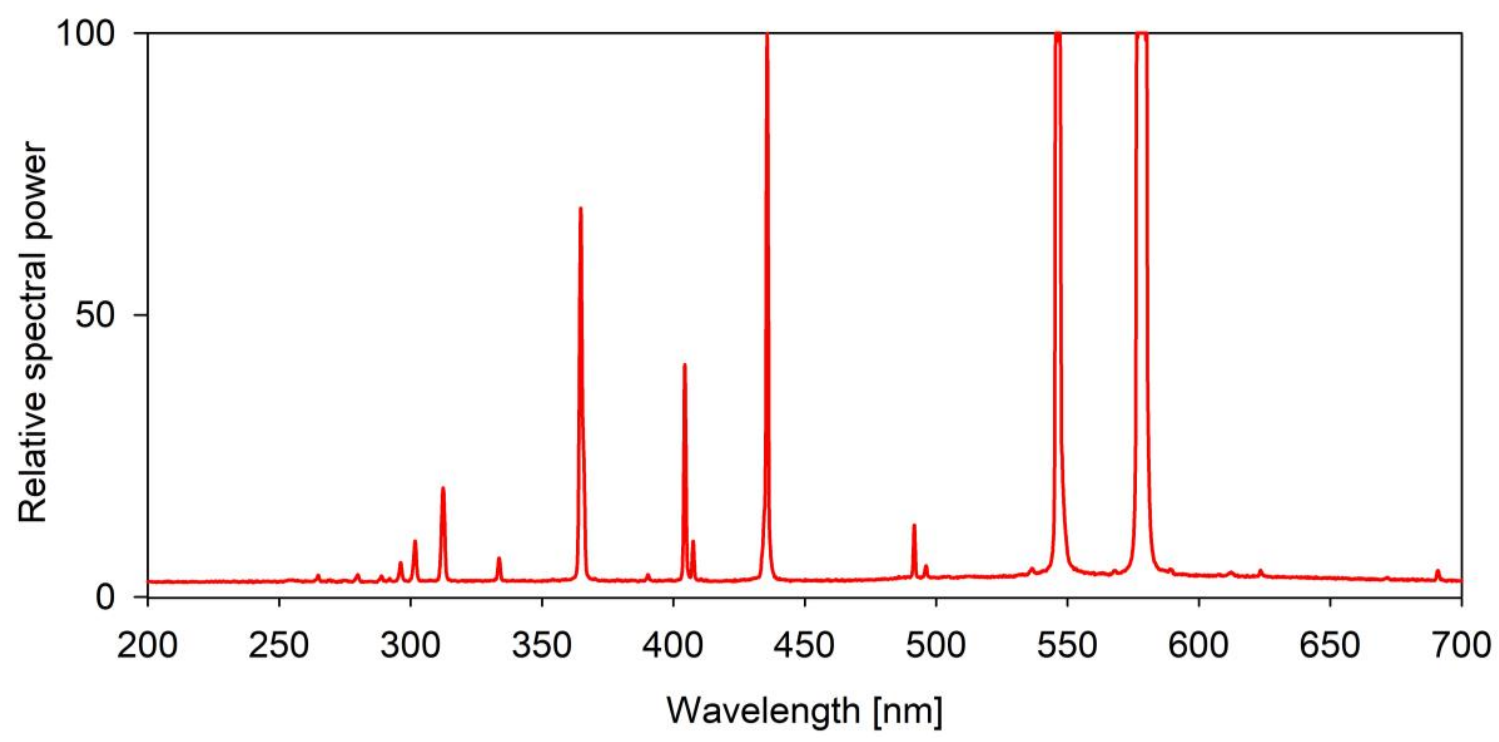

Figure S63. Emission spectrum of the Hanau TQ $150 \mathrm{~W}$ lamp after passing through the standard Pyrex filter.

The spectrum was acquired by the hand-held, fiber-coupled CCD spectrometer (Edmund Optics) 